Portland State University

PDXScholar

$5-1972$

\title{
Leben heisst Töten; die Kriegsdeutung Ernst Jüngers dargestellt an In Stahlgewittern und Der Kampf als inneres Erlebnis
}

Sabine Schroeder-Sherwin

Portland State University

Follow this and additional works at: https://pdxscholar.library.pdx.edu/open_access_etds

Part of the German Literature Commons, and the Other German Language and Literature Commons Let us know how access to this document benefits you.

\section{Recommended Citation}

Schroeder-Sherwin, Sabine, "Leben heisst Töten; die Kriegsdeutung Ernst Jüngers dargestellt an In Stahlgewittern und Der Kampf als inneres Erlebnis" (1972). Dissertations and Theses. Paper 951. https://doi.org/10.15760/etd.951

This Thesis is brought to you for free and open access. It has been accepted for inclusion in Dissertations and Theses by an authorized administrator of PDXScholar. Please contact us if we can make this document more accessible: pdxscholar@pdx.edu. 
AN ABSTRACT OF THE THESIS OF SaDine Schroeder-Sherwin

for the Master of Arts in German presented May 10, 1972.

Title: Leben heiBt toten:

Die Kriegsdeutung Ernst Jungers.

APPRO VED BY MEMBERS OF THE THESIS COMMITTEE:

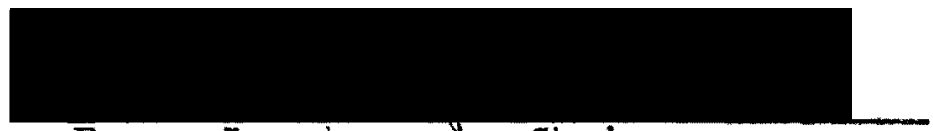

Franz Langhamme Chairman

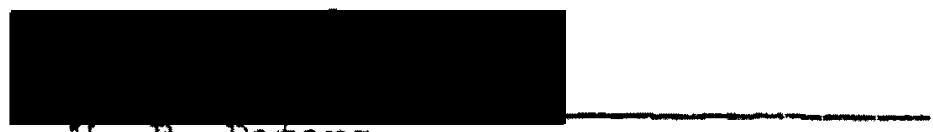

H. H. Peters



Frank F. Eaton?

In this thesis an attempt is made to show the impression World War I made on the mind of a young German author. I have tried to interpret his outlook on war and to show how he could arrive at such a seemingly sordid statement as "living is kỉlling".

In 1920 a relatively unknown member of the Reichswehr published an account of World War I that soon became a bestseller. The book was In Stahlgewittern, its author Ernst Junger. It was followed two years later by Der Kampt als inneres Erlebnis. Their common subject was war. The success of the two novels served to catapult Ernst Junger from being a highly decorated officer of the war, but otherwise widely unknown, into the limeiight of fame. It opened the doors for 
him to the intellectual and literary circles of Germany and later on of Europe.

Although the subject of both works specifically pertains to World War I, almost the whole length of which the author had seen on the western front, their scope is much much wider. Junger attempts to show how he sees war in general. To make this clear he deals lengthily with the word of Heraklit of war as the father of all things.

At the time that Junger published these books which show war as a positive experience, the general literary feeling in Europe was still strongly anti-war. Nevertheless he managed not only to voice his opinion, but also to use these works especially as the starting point of an immensely successful and prolific literary career.

Even though Ernst Junger does not deny the horrors and atrocities of war, his books are an apotheosis of the subject. Paradoxically, war to him is the one thing that will serve to perpetuate the human race. This is achieved in a way that is vaguely reminiscent of Darwin's theory of the survival of the fittest. In war a new elite or new "race" is born. Just as war has fathered it, it in turn will be responsible for the following generations. Race, in Junger's sense, is not a biological term, rather a philosophical experience. To survive, and to create the new man, the soldier has again to be made aware of his past. Only by linking his prehistoric existence with modern man and modern man's accomplishments, 
will he be able to form this new race.

Blood, i.e. instinct rather than reasoning, originality rather than the stifling process of learning, is modern man's only means for survival. Especially with this theory Junger came dangerously close to the world of ideas of NationalSocialism. Even though Junger was opposed to the crude ideology of the Nazis, he did little to defend his works against their use and exploitation. This, as well as his own ideas about war, have made him one of the most controversial German writers of the twentieth century. 


\title{
LEBEN HEISST TOTEN \\ DIE KRIEGSDEUTUNG ERNST JUNGERS \\ Dargestellt an In Stahlgewittern \\ und Der Kampf als inneres Erlebnis
}

$$
\text { by }
$$

SABINE SCHROEDER-SHERWIN

A thesis submitted in partial fulfillment

of the requirements for the degree of

\author{
MASTER OF ARTS \\ in \\ GERMAN
}

Portland State University

1972 
TO THE OFFICE OF GRADUATE STUDIES :

The members of the Committee approve the thesis of Sabine Schroeder-Sherwin presented May 10, 1972.

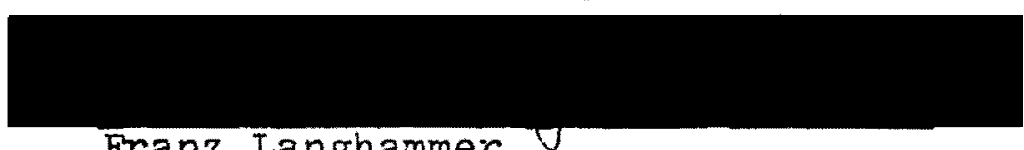

Franz Langhammer

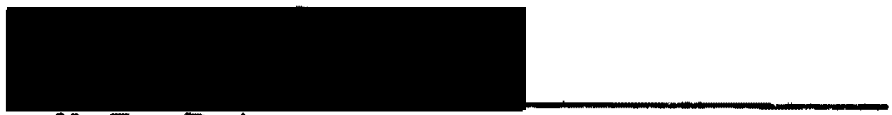

$\mathrm{H} \cdot \mathrm{F} \cdot$ Peters

\section{APPROVED :}



May 10,1972 
VORWORT

Es ist mir unmoglich, namentlich all denen zu danken, die mir bei der Entstehung dieser Arbeit geholfen haben.

Besonders danken mochte ich jedoch Kay Jones und Myra Wilson vom Interlibrary Loan Service der Portland State University. Die Beschaffung des Materials war unerhort schwierig und hatte ohne ihre Hilfe nie erreicht werden konnen.

Zu Dank verpflichtet bin ich auch Professor Dr. Franz Langhammer. Er hat mich whthrend meiner Jahre an Portland State stets anregend betreut und mir bei der Entstehung und Durchsicht meiner Arbeit hilfreich zur seite gestanden.

SchlieBlich gilt mein Dank noch Caroline sullivan fur ihre Hilfe beim Maschinenschreiben dieser Arbeit und Robert fur seine Geduld und sein Verstandnis, "for letting me do my thing".

Portland, im Mai 1972

Sabine Schroeder-Sherwin 
INHALT

KAPITEL I

ERNST JUNGERS FRUHE SUCHE NACH DER

AUSSERORDENTLICHKEIT . . . . • . . . . •

KRIEGSAUSBRUCH • . . . . . . . . . .

ERSTE NACHKRTEGSLITERATUR • . . • . . • .

DIE TAGEBUCHFORM VON In Stahlgewittern UND Der

Kampf als inneres Erlebnis . . . . . . . . . •

JUNGER-KRITIK . . . . . . . . . . . .

KAPITEL II

KRIEG • . . . . . . . . . . . . . .

DER KRIEGER . . . . . . . . . . . . . .

DIE NEUE RASSE . . . . . . . . . . . . .

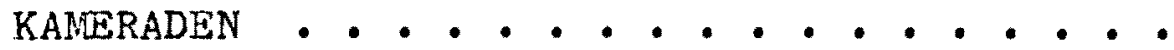

FEI ND . . . . . . . . . . . . . . . . .

ETAPPE . . . . . . . . . . . . . . .

DER KANPF . . . . . . . . . . . . . .

DAS TIER IM MENSCHEN . . . . . . . . . .

BLUT . . . . . . . . . . . . . . . . .

KAPITEI III

DER DICHTER ALS BAROMETER . . . . . . . 


\section{KAPITEL I}

\section{ERNST JUNGERS FRUHE SUCHE NACH DER AUBERORDENTLICHKEIT}

Bei Ausbruch des ersten Weltkrieges war Ernst Junger gerade neunzehn Jahre alt. Wie viele seiner Altersgenossen meldete er sich mit jugendlicher Begeisterung zum Fronteinsatz, um als Freiwilliger am Krieg teilzunehmen. Knappe sechs Jahre spater war aus dem unbekannten jungen Freiwilligen ein Erfolgsautor geworden, dessen Ruhm weit uber die Grenzen Deutschlands drang. Sein Buch In Stahlgewittern machte ihn in kurzester zeit weithin bekannt. Seit dem Erscheinen dieses Buches ist der "Kampf der Zitate" ${ }^{1}$ um den Autor nicht mehr zur Ruhe gekommen. "Der Ausgang ist zweifelhaft und wird es bleiben."2 Auch heute noch zuhlt Ernst Junger zu den umstrittendsten Personen jener Kriegsgeneration.

Ernst Junger wurde in ein gut-burgerliches Elternhaus hineingeboren. Die Mutter entstammte einer alten frankischen Bauernfamilie. Der Vater, der zunachst Apotheker in Heidelberg war, verselbststundigte sich spater und nach verschiedenen Umzugen lieB sich die Familie endgultig am Steinhuder Meer nieder. Wirtschaftlich und finanziell gesichert, konnte der Vater Ernst Junger eine gute Erziehung und Ausbildung zukommen lassen. Aber es gelang ihm im Grunde nie, naher auf den Jungen einzugehen oder gar eine warme, personliche Verbindung 
zu

schaffen.

In der Schule zeichnete sich Ernst Junger schon fruh durch seinen ungeheueren Lesehunger aus.

Die Abneigung gegen alles Nutzliche verdichtete sich von Tag zu Tag. Lesen und Trlumen waren die Gegengifte - doch die Gebiete in denen Taten møglich waren schienen unerreichbar fern. 3

In der Phantasie des Jungen hatte bald das Romantische, das Ungew Junger der Wunsch nach dem Abenteuer und nach der AuBerordentlichkeit. Die kindliche Vorstellungskraft verband damit das, wofur im Burgertum des wilhelminischen Zeitalters kein rechter Platz war.

Eher hatten mich noch die ganz einfachen THtigkeiten gelockt, wie diè des Fischers, des Jugers oder des Holzfullers, allein seitdem ich gehort hatte, daB die Forster heute eine Art von Rechnungsbeamten geworden sind, die mehr mit der Feder als mit der flinte arbeiten und daB man die Figche mit Motorbooten fungt, war mir auch das zur Last. 4

Das Unbehagen an der Zivilisation reicht somit weit in Ernst Jungers Kindheit zuruck und um inm zu entfliehen begibt er sich auf die suche nach dem urgrandigen sein. Immer deutlicher trat dabei Afrika als ein Fixpunkt hervor.

Dieser Kontinent bedeutete inm den

Inbegriff der wilden, urgebahnten und unwegsamen Natur und damit ein Gebiet in dem die Begegnung mit dem AuBerordentlichen und Unerwarteten noch am ersten wahrscheinlich war. 5

Junger verlebte seine schulferien huufig auf dem elterlichen 
Anwesen. Oft war er dann im Treibhaus anzutreffen. Mit Begeisterung und Hingabe verbrachte er dort oft Stunden, denn seine Phantasie konnte sich dort so recht der Vorstellung afrikanischer Hitze hingeben. Der Wunsch, selbst einmal tatsachlich nach Afrika zu gehen, nimmt den Jungen immer mehr gefangen, und es ist wenig uberraschend, daB er als Sechzehnjahriger die Schule verlaBt, allerdings ohne wissen der Eltern, und der franzosischen Fremdenlegion beitritt, um auf diese Weise sein ziel zu erreichen. Noch ehe er jedoch nach Afrika gelangt, wird dem jungen Legionar eine fremde, bunte Welt aufgetan. Die anderen Legionare teilten gleich inm die Iust nach der Abenteuerlichkeit und die Suche nach dem ungewohnlichen Leben. Aber die meisten befanden sich durch inre Erziehung und ihr Elternhaus in krassem Gegensatz zu ihm. Ihn hatte die

Sicherheit einer gutburgerlichen Umgebung in die Ungebundenheit getrieben, wo er sich sein eigenes Leben gestalten kunne. 6

Was er hier vorfand, waren viele

deren Namen die tagliche Chronik einmal im Leben in drei Zeilen erwahnt, wenn innen ein ZusammenstoB mit der Liebe, der Pflicht oder den Gesetzen fur einen Augenblick das Steuer aus den Handen reiBt.?

Es schien eine wildzusammengewtrfelte Schar, deren gemeinsamer Nenner ihr Gegensatz zur burgerlichen Welt war.

Alle hatten sie etwas Vages gesucht - vielleicht einen Ort, an dem die Gesetze aufgehoben sind, vielleicht eire marchenhafte Welt oder auch die Insel der Vergessenheit. 8 
- Von Idealvorstellungen besessen, war der junge Primaner ausgezogen, um die blaue Blume der Romantik in Afrika zu finden. Aber seine Hoffnungen erfullen sich nicht. Die Romantik Afrikas zerplatzt bei genauerer Betrachtung wie eine Seifenblase und

sogleich erfullte sich an ihm der Satz, daB einem Romantiker nichts Schlimmeres geschehen kann, als die Erfullung seiner Sehnsucht.9

Nur allzu bereit nimmt er des Vaters Hilfe an und kehrt nach Hause und zur Schule zurtlck.

Aber noch immer wird er von dem Wunsch getrieben das Ungew $h n$ liche $\mathrm{zu}$ finden. Es werden bereits Vorbereitungen fur eine Expedition zum Kilimandscharo getroffen, Plane werden geschmiedet, Afrika ein zweites Mal in Angriff zu nehmen, als der erste Weltkrieg ausbricht und allen Unternehmungen dieser Art ein juhes Ende bereitet. Fur Junger gibt es keine Wahl. Wie selbstverstandlich gesellt er sich zu der langen Reihe derer, die sich in den ersten Wochen und Monaten als Freiwillige zum Heeresdienst melden. Als er nach fast vier ununterbrochenen Kriegsjahren aus Frankreich zuruckkehrt, findet er eine veranderte Welt vor. Das burgerliche Zeitalter ist tot, die schein-Sekurityt der wilhelminischen Ara fur immer begraben. In dem Vorwort zur neunten Auflage seines Erfolgsromans Der Kampf als inneres Erlebnis von 1943 schreibt Junger selbst uber diese Jahre: "Es war eine eigenartige Zeit, eine zeit, in der nichts bejaht und alles in Frage gestellt wurde." 10 


\section{KRIEGSAUSBRUCH}

Das neunzehnte Jahrhundert geht im Sommer und Herbst des Jahres 191.4 seinem Ende entgegen. Der Wilhelmisismus mit seinem Kult des Scheins und der rhetorischen Fassade murde in diesen wenigen Monaten endgultig zu Grabe getragen.11 Fur die jungen Freiwilligen schien die Vorkriegsexistenz fragwurdig geworden. Neue Werte und Vorstellungen muBten geschaffen werden, damit sie nicht am Verlust der alten zu Grunde gingen.

Mit unuberwindlicher Eigenmacht bricht das Leben ein in den gesicherten Bezirk des burgerlichen Daseins, Kumpfe in ihn hilneintrasard durch die seine Wirklichkeit anders wird wie nur eine Grabenlandschaft in der Champagne whrend des Krieges. Die Sicherungen, auch die geglaubtesten: Geld und Besitz, sind zertrummert, Werte zeigen sich nichtig. 12

Diejenigen, die diese Umanderungen am tiefsten und nachdrucklichsten erfuhren, gehorten zum groBen Teil zur "jungen Frontgeneration". Es war die Generation derer, die zwischen 1891 und 1900 geboren wurden. Goring, Himmler, Hess, Bormann, Rosenberg, die Gebruder Junger und Gunther, Franz Schauwecker, Ernst Niekisch, Hartmut Plaas, Schlageter, sie alle waren ein Teil davon. Wie Ernst Junger waren die meisten von innen 1914, den Schulbanken kaum entwachsen, in ihrer Entwicklung vorgebildet, aber noch nicht gefestigt, uber ihre engere Heimat hinaus weithin unbekannt. Kaum zwei Jahrzehnte spater hatte sich die Lage genau umgekehrt. Ihre Namen wurden zu Begriffen, die man mit der einen oder 
anderen Ideologie oder politischen stromung in Deutschland verband. Noch ungefestigt wie sie waren, bedeutete innen die Kriegs- und die unmittelbare Nachkriegszeit das entscheidende Erlebnis. Die fur ihr Leben bestimmenden Erfahrungen sammelten diese Munner nicht in den Horsalen und Seminaren, den Literatencafés und Redaktionsstuben, sondern in den Schltzengraben und Materialschlachten des ersten Weltkrieges.

Die alteren Kriegsteilnehmer hatten sich bereits eine burgerliche Existenz geschaffen, "ihr Berufsleben verlief in Uberschaubaren Bahnen, ihre Weltanschauung war auch durch den Krieg kaum zu erschtttern."13 Fur sie waren Lehrzeit und Studienjahre lange verflossen. Der Krieg konnte sie zwar beruhren, ja erschuttern, aber er konnte sie nicht mehr grundlegend verandern oder formen. Die Kriegsjahre bedeuteten fur sie in erster Linie eine Unterbrechung inres friedlichen Daseinsrhythmus, den sie wieder aufnehmen konnten, sobald sich dazu die Moglichkeit ergab. Sie konnten wirklich "zurtlckkehren" und nach Hause kommen, sie konnten den Faden fast genau da wieder aufnehmen, wo sie ihn verlassen hatten, denn ihr Vorkriegsleben war wirkliche Existenz, whrend sich die Jungeren noch auf der suche nach der Existen: befanden.

Fur die junge Kriegsgeneration war die Front das progende Bildungserlebnis tberhaupt. Soldatische Tugenden bildeten die hochsten Werte. 
Der Krieg - ein Normalzustand; Kumpfen, TUten, Siegen und Besiegtwerden - die ewige, unausweichliche Bestimmung des Menschen; die totale Mobilmachung das Geschichtsgesetz der Weltstunde: die Erde eine legitime Beute der tapfersten Krieger. 14

\section{ERSTE NACHKRIEGSLITERATUR}

Dieses Erlebnis muBte seinen Niederschlag finden. Von den Auswirkungen auf die meisten dieser Generation, was es psychologisch, emotionell fur sie bedeutete, werden wir nie etwas erfahren. Einigen jedoch gelang es, ihre Reaktion kunstlerisch zu verarbeiten. Wie bedeutsam dieser Einschnitt war, und wie schwer er sich fassen lieB, mag man daran erkennen, daB der groBe Kriegsbuchboom fast erst ein Jahrzehnt nach Beendigung des Krieges einsetzte. Hans zoberlein, Werner Beumelburg, Franz Schauwecker, aber auch Ludwig Renn oder Erich Maria Remarque errangen ihre durchschlagenden Erfolge erst Ende der zwanziger Jahre. Der Kunstler muBte ebenso wie seine Leserschaft geistigen Abstand von den Ereignissen gewinnen, um fur die Auseinandersetzung damit aufnahmefunig zu sein. Umso erstaunlicher ist es, daB Ernst Junger schon so fruh mit seinen Kriegsromanen an die Offentlichkeit treten konnte. zu einer zeit, zu der sich die öffentlichkeit noch lange nicht soweit von den Schrecken dieses Krieges erholt hatte, um inn als positives Erlebnis zu betrachten, konnte Junger schon enorm hohe Auflagenzahlen fur sich verbuchen. Dies gelang inm dadurch, daB er genau den Typ in seiner Leserschaft anzusprechen vermochte, den er 
selbst verkorperte und den er literarisch in seinen Kriegsbuchern auferstehen lieB. Er wurde Sprachrohr fur diejenigen, die annlich wie er empfanden, oder zu empfinden glaubten, aber selbst unfuhig waren, diesen Gefunlen einen bewuBten Ausdruck zu geben.

Man muB zugestehen, $d a B$ die tberlebenden nicht alle durch den Krieg enttauscht und zerbrochen wurden, und zu der kleinen Ritterschaft, die einen Gewinn eingebracht zu haben meinte, zuhlte neben Lawrence, Quinton und Monthérlant Ernst Junger.15

Aber noch war die zeit nicht reif fur die groBe Auseinandersetzung mit dem Krieg, und so bleibt Junger einige Jahre alleine als hervorstechender Kriegsliterat.

In Stahlgewittern, which is a near fanatical glorification of the experience of war, appeared in 1920, when the whole of Europe was nauseated with the subject, and the trend of literary feeling was bitterly anti-war to the point of pacifism. 16

Junger scheint sich der allgemeinen stimmung durchaus bewuBt gewesen zu sein, denn sein erstes Werk Uber den Krieg erscheint zunachst im Selbstverlag. Dies war wohl zu verstehen, da Junger mit seiner Behandlung des Krieges "gegen den Strom der expressionistischen Anklage und Verdammung"17 schwamm. Die erste Ausgabe von In Stahlgewittern trug den Vermerk

aus dem Tagebuch eines StoBtruppfuhrers von Ernst Junger, Kriegsfreiwilliger, dann Leutnant und Kompaniefthrer im Fuselier-Regiment Prinz Albrecht von PreuBen (Hannoy. Nr. 73). Mit $5 \mathrm{Abb}$. und dem Bilde des Verfassers. ${ }^{18^{\circ}}$. 
Beim Erscheinen seines zweiten Buches konnte Junger bereits darauf verzichten, dem Werk seine "biographische Visitenkarte"19 beizufugen. AuBerdem hatte er inzwischen in $\mathrm{E}$. $\mathrm{S}$. Mittler und Sohn seinen langjuhrigen Verleger gefunden. Gleich mit dem Erscheinen seines ersten Buches hatte Junger sich als Schriftsteller etabliert. Er war aus der relativen Anonymitat des Soldaten ausgebrochen und ins Rampenlicht des Ruhmes gertlckt. Von da an erschienen seine Kriegsbucher, mehrmals uberarbeitet, in immer neuen Auflagen. In Stahlgewittern erreichte 1942 bereits die vierundzwanzigste Auflage, Der Kampf als inneres Erlebnis immerhin die neunte. 20 zu Hilfe kam Junger immer wieder, daB es ihm in fast allen seinen Erstveroffentlichungen gelang, Geistesstromungen innerhalb der deutschen Kultur gleichermaBen vorauszufuhlen und vorauszuspuren.

DIE TAGEBUCHFORM VON IN STAHLGEWITTERN UND DER KAMPF ALS INNERES ERIEBNIS

Ernst Junger hat Zeit seines Lebens geschrieben. Die ersten Buchveroffentlichungen erschienen Anfang der zwanziger Jahre, die vorluufig letzten 1970 und 1971. Sein Verk umfaBt hauptsachlich Romane, nur ganz wenig Lyrik. Bezeichnend ist, daB Junger immer zu weltgeschichtlich oder personlich unruhigen zeiten Tagebuch gefuhrt hat und nicht selten hat er diese Aufzeichnungen spater in uberarbeiteter Form in einen Roman integriert, haufig sogar einen Ro- 
man im Tagebuchstil geschrieben. Die bekanntesten dieser so entstandenen Werke sind die Romane und Erzahlungen der beiden Weltkriege und der Bericht seiner Reise nach Stdamerika. Ein weiteres Tagebuch, das er in Berlin wahrend der zeit um den 30. Januar 1933 fuhrte, hat er spater im AnschluB an eine Haussuchung vernichtet. 21

In Stahlgewittern tragt den Untertitel Aus dem Tagebuch eines StoBtruppfuhrers. Es wird also ausdrucklich auf diese Form der epischen Gestaltung hingewiesen. Auch sein Werk Der Kampf als inneres Erlebnis hat Tagebuchcharakter. Onne Zweifel konnte Ernst Junger mit dieser Art des Schreibens seinen eigenen Anspruchen gerecht werden. Es gelingt ihm, eine vollig subjektive Darstellung des Krieges zu geben, ohne dies in irgendeiner Weise begrunden $\mathrm{zu}$ mussen. Da er vorgibt, den Krieg als Einzelner zu sehen und auszuwerten, kann er auf die Gestaltung der anderen Charaktere verzichten, ohne daB dies dem kunstlerischen Werk selbst Abbruch tut. Er selbst ist der Held des Romans und die Handlung ist sein eigenes Kriegserlebnis.

Zwei Dinge sind bei dieser Darstellungsweise gefuhrlich. Zum einen entspricht der weltanschauliche Horizont des Helden dem weltanschaulichen Horizont des Autors. Er kann daruber hinaus erweitert werden, aber er muB es nicht, besonders da in dieser Erweiterung leicht eine Sprengung des kunstlerischen Rahmens liegen konnte. Zum anderen sehe ich eine Gefahr darin, $\mathrm{d} a \mathrm{~B}$ Junger sich der Verallgemeinerung des krieges fur den Einzelnen, namlich den Frontkampfer, zu sehr hingibt. 
Die epische Struktur des Tagebuches legt auf der einen Seite nur die Darstellung eines Einzelschicksals nahe, erlaubt andererseits dem Autor aber die Meditation, die Ausbreitung allgemeiner philosophischer tberlegungen. 22

Sobald nun der Autor versuchen sollte, seine tberlegungen zu der totalen Wirklichkeit in Bezug zu setzen, fehlen ihm dazu die Mittel; er muBte auf eine andere Ausdrucksform als die des Tagebuches ausweichen, um wirklich zu Uberzeugen.

Jungers Kriegsdarstellung ist auf das Fronterlebnis beschrankt. Zivilisten, Frauen und Kinder werden, wenn Uberhaupt, nur beilaufig und als im Wesentlichen unwichtig dargestellt. Ebenso ergeht es der Etappe und dem Stab. Kriegswirklichkeit heiBt bei Junger nur das Leben und Erleben des Kriegers in der vordersten Reihe, des Frontkumpers. Alles andere nimmt dem Krieger gegenuber eine untergeordnete Stellung ein. Es wird aus der Wirklichkeit des GrabenKumpfers ausgeklammert und somit der Realitat entzogen. Auffallend ist, wie wenig Junger dem Leben in der Heimat Beachtung schenkt. Nur ganz selten wird ein Urlaub, ein Brief oder die Politik erwahnt. Es hat den Anschein, als ob das Leben an der Front das Leben schlechthin darstellt und nicht einen Ausschnitt davon. Der Soldat lebt nur sich selbst und seinem Handwerk, dem Krieg. Darin liegt die Gefuhrlichkeit des Jungerschen Kriegswerkes, aber auch sein Erfolg. Der Leser kann sich mit dem Helden/Autor identifizieren. Vielleicht hat er ahnliche Erlebnisse gehabt und sieht seine eigenen Erfahrungen hier glorreich beschrieben. Der Unterschied 
zwischen eigenem und fremdem Leben wird in der Erinnerung verwischt, ebenso wie der Unterschied zwischen der Wirklichkeit des Frontkumpfers und der Wirklichkeit des Krieges insgesamt. Die Jungersche Kriegswelt ist nur eine Teilwelt, die aber durch das AusschlieBen anderer Realitaten als totale Welt erscheint. Fur den Leser jedoch, der sich geistig nicht engagiert, wird diese Teilwirklichkeit wiederum Wirklichkeit schlechthin. Sie scheint es nicht mehr, sie ist es, und somit wird alles andere unwahr und unwirklich.

In der Handhabung der Darstellung und der Mittel zur Darstellung liegt das Fragwurdige an Ernst Junger. Es ist nicht die brutale Verherrlichung des Krieges und der Gewalt, nicht die immer wiederkehrende Formel, daB auf Grund seines Verdienstes nur der Frontkampfer einen legitimen Anspruch auf therleben hat, die seine Bucher zumindest zweifelhaft erscheinen lassen. Sondern es ist der viel subtilere AusschlieBlichkeitsanspruch seines Kriegserlebnisses, der Jungers Schreibart so gefthrlich macht. Es ist nicht das Werk selbst, oder die Darstellung des Erlebnisses, sondern das Wie des Stiles, das mir bei den Kriegsbuchern als entscheidend arscheint. Um Junger auch nur etwas Gerechtigkeit widerfahren zu lassen, muB man sich stundig vor Augen halten, daB sein Werk nur der personlichen Erfahrung entspringt und nur individuell verstanden werden kann, selbst wenn der Autor sich in standigen Allgemeinheiten zu verausgaben scheint. 


\section{JUNGER-KRI TIK}

Aus dem Vorhergesagten mag deutlich werden, warum ein Autor innerhalb eines halben Jahrhunderts in fast vollige Vergessenheit geraten kann. Noch erscheinen Werke von Junger und uber Junger, aber der Nachkriegsgeneration des letzten Weltkrieges ist er ein weithin Unbekannter geblieben. Noch mag es zu fruh sein, uber seinen Nachruhm zu urteilen, aber man kann sich des Eindrucks nicht erwehren, daB zumindest Jungers Kriegsbucher nicht sehr weit uber die Schar der Kriegsteilnehmer hinausreichen, und daB seine Beliebtheit mit dem Aussterben jener Generation zuruckgeht.

Viele der Bewunderer Jungers sind, gleich ihm, nicht nur Kriegsteilnehmer gewesen, sondern sie sind ebenso wie er von der Schulbank an die Front geeilt und sie konnen sich umso leichter mit dem Autor identifizieren und auf die Suche nach neuen Werten begeben.

Jungers Gedanken waren durch die einhammernde Monotonie und das pausenlose Fortissimo ihres Vortrages mehr ertotend als weckend, wenn der Soldat nicht zugleich ein Literat ware, der uber eine Bildung verfugt, die er der burgerlichen Kultur des letzten Jahrhunderts verdankt. Ihr schuldet er auch jene Reste von $\mathrm{Zweifel}$ und von philosophischen Einfullen, wodurch seine Schriften die Masse ${ }_{3}$ der andern, die Ahnliches mochten, so weit uberragen. 23

Dieses Erlebnis war nicht auf Deutschland beschrunkt, obwohl es hier besonders deutlich hervortreten mag. So ist es verstundlich, daB die Kritik an Ernst Junger ebenfalls 
nicht auf den deutschen Sprachraum oder gar auf das deutsche Reich begranzt bleibt, sondern sich auch auf die ehemaligen Peindlander erstreckt. Zwar wurden im Krieg die Fronten durch Nationalitaten geschieden, aber das Kriegserlebnis, wie es Junger sieht, war ubernational. Man bewunderte nicht den deutschen Soldaten in dem Autoren Junger, sondern die soldatischen Tugenden, die er als Krieger schlechthin verkorpert. Ein englischer Kritiker schrèibt uber Junger und sein Buch In Stahlgewittern: "His mind is limited, his imagination small, his heart narrow and hard. But he is saved by his absolute honesty, and his picture of war is direct and vivid." 24

Aber auch in der auslandischen. Kritik lassen sich jene finden, die sich von Jungers Heldentum nicht blenden lieBen, sondern den Autor und sein Werk klar ejnzuschatzen vermogen. Es sind dies diejenigen, die erkennen, daB "honesty" nicht auf den soldatischen Kreis der Tugenden beschrankt bleiben muB, und die Autor und Werk auf das reduzieren, was sie wirklich darstellen.

This rehandled diary is too valuable a document and much too self-revealing a confession to need any sort of ingratiating apology. It is the narrative of a boy who lived to become a Prussian officer; the selfvindication of a type of mind that thinks "My country right or wrong", and is courageous enough and thickheaded enough to hold that doctrine after millions of men lie dead on the battlefields of Europe as a direct result of its propagation and practice. 25

Wie klar wird hier schon 1929, zur Zeit des Erscheinens der englischen Ausgabe von In Stahlgewittern, der Charakter 
Jungers gezeichnet. Es scheint, als ob der ausschlieBliche Lebensinhalt Jungers darin liegt, zu leben, um Offizier zu werden, oder doch zumindest zu leben, um am Krieg teilzunehmen. Es ist dies etwas, was Uber den Selbsterhaltungstrieb des Grabenkämpfers hinausgeht. Man ist versucht einen willen zur Kraft, der Kraft zu Uberleben, darin zu sehen. Derselbe Kritiker versucht gleich darauf jedoch Junger wenigstens etwas Gerechtigkeit wiederfahren zu lassen.

Ernst Jungers was not the blond beast of fiction or anything resembling that monstrosity. When he volunteered for service in the ranks of the 73rd Hanoverian Regiment at the age of nineteen, he was just a plucky lad to whose head the war had gone as perfectly and as completely as any recruiter of 1914 could have wished.26

Auch hier wird deutlich herausgestellt, das Junger eben nicht zur Generation derer gehort, die bereits ihre Existenz aufgebaut haben, soncien er wird einfach als "junger Bursch" bezeichnet. Das beleuchtet nochmals die abenteuerliche Seite des Autors, der sich beim ersten TrompetenstoB begeistert zu den Waffen meldete.

Dièse Kritik kommt zu dem SchluB, daB sich bei Junger das Verhaltnis des Einzelnen zur Masse, des Individuums zur Allgemeinheit verwischt, und $d a B$ damit jegliche realen Proportionen verloren gehen.

What takes place in the minds of all those who abandoned their human, moral and rational sense of values at the bidding of others is made obvious by the extreme case of Herr Junger. The natural egotism of an ambitious young man is fastened on by the State and unified with the egotism of the nation. When this 
happens individuality is destroyed, the sense of human proportion is lost, and littleness sees itself in terms of immensity - to the great gratification of its vanity. 27

Hier wird die Schuld fur das Fehlen dieser Grenzen schon nicht mehr beim Autoren Junger gesucht, sondern beim Soldaten. Was er in seinen Buchern darlegt und $\mathrm{zu}$ verteidigen sucht ist das gleiche, das er im Krieg zu verteidigen gesucht hat. So wie der Held des Romans stellvertretend fur die vielen steht, so ist auch dem Kriegsteilnehmer nicht der einzelne Grabenkampfer wichtig, sondern der Krieger an sich, der das Ideal darstellt.

Daher wirken die Kriegsbucher zwangslaufig entmenschlicht und mechanisch. Denn nicht der Mensch ist darin wichtig, der tagaus tagein der zermurbenden Kraft des Stellungskampfes ausgesetzt ist oder der Spthtruppfuhrer, dem jede unbedachte Bewegung, jeder unuberlegte Schritt das Leben kosten kann, sondern es ist der Prototyp des Kriegers schlechthin, den Junger hier beschreibt und den er in seinen Buchern darstellt. Ihm gilt nicht das Überleben Einzelner, sondern das tberleben des Typus.

Solche Auffassung laBt schwerlich menschliche Bindungen, Emotionen, Wunsche oder Gedanken aufkommen. Und wenn Gefuhle entstehen, so sind sie immer wieder nur auf den kleinen Kreis der Eingeweinten bezogen. Alles was sich auBerhalb dieses Kreises befindet, verdient und erlangt keine Beachtung. Es wird aus der Realitat des Grabenkumpfers 
verbannt. Wo sich menschliche Werte finden lassen, beschranken sie sich auf einen Teil Gleichgesinnter und werden von ihnen bestimmt. Nur diejenigen Werte erlangen uberhaupt Aufmerksamkeit, die das tberleben der Kaste garantieren. Munnlichkeit, Treue eines Kriegers zum anderen, Gefolgschaft, Gehorsam, das sind einige der Ideale, nach denen der Krieger streben sollte. Anderen Empfindungen steht er, sofern sie ihn nicht selbst betreffen und zur Hartung seines Daseins fuhren, verstandnislos gegenuber. Er kann damit nichts anfangen, denn in seiner wirklichkeit haben sie keinen Platz.

Sein Krieger gehort einer Elite an, die sich uberall finden laBt. Verbunden sind die Kumpfer durch die Abwesenheit jeglicher menschlicher Regung, die etwas auBerhalb ihres elituren Zirkels liegt. Fast mechanisch rollt der Krieg vor ihren Augen ab. Sie stehen mitten darin und scheinen doch andererseits vollkommen herausgelust. Wie Roboter vollfuhren sie die ihnen aufgetragenen Arbeiten. Ihr Blick geht nur in eine Richtung. Alles, was daneben liegt, entzieht sich entweder ihrer Aufmerksamkeit oder wird von ihnen geflissentlich Ubersehen. Sie leben nur dem Hier und Heute, nur dem Augenblick. Junger preist wiederholt die Vorzuge und Wunder des technisierten Krieges. Aber man braucht nicht an die gewaltigen Fortschritte in der Kriegsmaschinerie zu Anfang des Jahrhunderts zu denken, um Jungers Idee des Material zu verstehen. Auch sein Krieger ist 
Material insofern als er bar jeglicher Empfindungen sein Handwerk verrichtet. Wie eine Maschine lauft der ihm eingedrillte Vorgang des Oberlebens ab.

In war, he himself becomes the instrument of machinery, and machinery becomes the instrument of his will. This is the "mystique" which justifies war for Ernst Junger; and war is justified as an end in itself; he has no feelings of pity for war's victims, almost no feelings about the righteousness of war. 28

Nur wenn die Technik Mangel oder Fehler aufweist, zeigt er, daB er dartuber hinaus noch Mensch ist und menschlich empfinden kann.

Allerdings bedeutet dies meist, daB das elitare system der Kriegerkaste zusammenbricht. So kommt es, daB der einfache Soldat bei Junger, d. h. derjenige, der nur meint im Krieg seine Pflicht erfullen zu mussen, der zwar auch sein Kriegshandwerk ausubt, bei dem aber die Verbindungen zur wirklichen Welt noch viel offensichtlicher sind, wenn er in Jungers Werk uberhaupt Eingang findet, viel menschlicher gezeichnet ist. sicher mag er auch seine menschlichen Schwachen haben, aber man spurt, daB dieser zumindest lebt und daB bei inm kein vorprogrammiertes Geschehen abluuft, das er nur mechanisch erfullt.

Der entmenschlichte Held entspricht genau dem Stil Jungers. Helmut Kaiser spricht von dem "unertraglichen Gefuhl der Sterilitat der Jungerschen Schriften." 29 Der Held der Romane ist genauso steril, unfahig irgendetwas zu 
produzieren, was inn menschlicher, aber eben auch verwundbarer machen kunnte. Junger verzichtet sowohl darauf, uns eine Alternative zu seinem Helden vorzustellen, noch diesen selbst objektiver $z u$ sehen. Sein Held ist total eindimensional ausgerichtet und Junger laBt keinerlei Zweifel daruber aufkommen, daB er sich mit seinem Verhalten bis ins kleinste identifiziert.

Nur zweierlei ist muglich bei solchem Verhalten des Autors, Zustimmung oder Ablehnung, auf gemeinsame Wahrheitsfindung verzichtet Junger von vorneherein. Der Leser gehort bei Zustimmung zur erlesenen Gemeinde, bei Ablehnung, bei Einwanden, disqualifiziert er sich selbst. 30

Die Ziele des Kampfes sind fur Junger von untergeordneter Bedeutung, denn sein Kumpfer bejaht den Krieg um seiner selbst willen.

Der Grundgedanke ist einfach. Wer sein Leben freiwillig hingibt, legt Zeugnis ab fur die Gultigkeit einer die individuelle Person uberwulbenden Idee. Er befreit sich vom lahmenden $\mathrm{Z}$ weckdenken und bestatigt seine eigene absolute Freiheit gegenuber der Materie.... In der Hingabe des Lebens erfolgte der Austritt aus dem Gefangnis der Individuation. ... Es ist das Gluck der Vereinigung mit dem Absoluten, auf das hin, so glaubt er, jede Existenz angelegt ist.31

Zwar ist das Überleben wichtig, aber selust wenn der Kumpfer zu Grunde geht, so wird doch der Typus des wahren Kriegers fortleben. Und dieser braucht nicht den Tod, um die Vereinigung mit dem Absoluten zu erlangen, denn er selbst wird als absolut dargestellt. Im Grunde scheint keine andere 
Daseinsform ihre Berechtigung zu haben. Der Typ wird zugunsten der Individualitat zum Ideal erhoben.

Genauso wie Jungers Elite Ubernational ist, ist sie auch an keine soziale schicht gebunden. Der Typ des kriegers labt sich Uberall finden, denn seine Fuhigkeiten werden nicht durch Geld oder stand hervorgebracht, sondern sie sind angeboren. "Das was seine Elite auszeichnet, ist nicht die Zugehorigkeit zur Klasse der GroBgrundbesitzer; die Elite, die Junger fordert, hat Rasse." 32 Damit wird Jungers Begriff der Elite aus der soziologischen Sphare herausgenommen und auf scheinbar unangreibare biologische Fundamente gestellt. Rasse bedeutet fur inn etwas das nicht erworben werden kann, sondern nur gereckt und ausgebildet. Sie laBt sich auch nicht andern, da sie sich menschlichen Eingriffen entzieht.

So ist die Elite, wenn sie einmal da ist, so notwendig wie das Leben selost. Daher sind ihre riandiungen auch nicht den Normen der Moral unterworfen; was sie tut, sei rein phanomenal, jenseits von Gut und Bose, so unschuldig wie das Leben selbst. 33

Gerade die Tatsache, daB sich ein Mann wie Junger in dieser Weise zum Krieg auBert, sollte nicht unterschatzt werden. "Junger konnte darauf hinweisen, daB er vom ersten Tage an am Krieg teilnahm." 34 Schon daran mag seine vollige subjektivitat erkenntlich sein. Dennoch Ubte er mit einer solchen Legitimation eine ungeheuere Wirkung auf groBe Teile seiner Leserschaft aus.

So sehr Junger hier seine eigenen Ideen propagiert, so wenig labt sich verkennen, daB ein Teil dieser Ideen Gedan- 
kengut des Selbstverstundnisses jeder Armee sein mussen. Eine Armee kann nur dann voll einsatzbereit sein, wenn sie sich Uber die gewUhnlichen MaBstube der Moral hinwegsetzt. Um die soldatischen Tugenden erfullen zu kunnen, darf der Soldat nicht nach der Zielsetzung fragen, denn das wurde unter Umstanden bedeuten, daB $Z$ weifel an seiner Berechtigungsexistenz aufkommen kunnten. Krieg wird um seiner selbst gefuhrt, es ist gewissermaBen eine pervertierte Auffassung von l'art pour l'art.

Er urteilt vom Standpunkt des preuBischen offiziers, dem der Krieg unabhangig von Zielsetzung und Form seines Verlaufs Beruf ist. Verantwortung, Denken, Vernunft erhalten nur Spielraum in den Grenzen, die nach des Autors Auffaşsung Beruf und verpflichtung des offiziers setzen. 35

Beruf oder Berufung ist hier gleichzusetzen mit dem Wecken und Ausbilden des elituren BewuBtseins. Dies wird beim Helden der Aufzeichnungen bis zur Perfektion gesteigert, soweit bis sich die Elite durch ihr Anders-Sein vollkommen von der Allgemeinheit getrennt hat und ihre eigenen werte und MaBstube setzt. J.F. Stern vergleicht diese Haltung der eines Patienten in einer Teilnarkose wathrend einer Operation, dessen BewuBtsein zwar klar ist, aber der. den ganzen Vorgang im Grunde unbeteiligt und ohne Gefuhl betrachtet.

Every incision in the gaping flesh suffused with blood; every resection of bone and sinew; every stopping of a vein; every stitch of the surgeon's needle he intently sees and registers. Nor is he wholly without sensation; but what he feels and registers is a toned-down, numb sensation, a mere 
tracing-out by a few nerves of what his eyes follow in the mirrors above him. He lies in a cave of unfeeling. He feels mere shadows; no more than an abstraction from that which to his ordinary unshocked consciousness would be an agony of sheer and unbearable pain. His ordinary self is in abeyance, it has been left outside, where the shock of the anaesthetic was first administered. 36

Genau wie der Patient kann der Krieger die Wunden zwar sehen, aber sie entziehen sich seinem Gefuhl und so entzieht der Schmerz sich seinem Verstundnis. Der Patient braucht die Betuubung, damit die Operation erfolgreich durchgefuhrt werden kann. Hatte er sie nicht, bestunde die Gefahr, daB das Gefuhl des Schmerzes den Geist uberwaltigte. Gefuhl dominierte dann uber den Geist. Dem Kumpfer geht es genauso. Um nicht in Kampf aufgerieben zu werden, muB er versuchen, das Gefunl so weit wie moglich aus seinem BewuBtsein auszuschalten. Gelingt ihm das nicht, begibt er sich in eine viel grobere Gefahr als die Gefahr der Schlacht. Er setzt sich der Gefahr aus, daB sein Geist die Gefuhle und Eindrucke nicht verkraften kann, und daB er geistig zerstort zuruckkehrt, obwohl er physisch vielleicht vollkommen gesund ist. Stern fahrt fort:

Who therefore will blame him for taking this brilliant cave of an operating theater to be a world, to be the whole world? The daylight that has been shut out is no longer real to him. There is no world beyond this, his world of pain which is to him no pain; no world, for him, beyond this world of bared layers of flesh, of fast and precise actions, feverish yet coldly exact movements, of brief command mechanically obeyed, beyond this world of seemingly endless activity. 


\begin{abstract}
Drugged he is, but what he registers is true enough, true not only of his sensations but also of the operation that is taking place here, somewhere, within the sharp shadows cast by the glaring lamp. But can he convince us that what he registers is true of the whole world which knows day and night? And is not this brilliantly lit scene in the operating theater, too, ensconced in the world of daylight, which is a light at once harder and more merciful than that he knows? The description, giving a full account of this part of our world, is precise and true; the claim, which goes beyond the account, is a false claim.37
\end{abstract}

Da der Patient und der Krieger ihre Welt als absolute Welt betrachten, erscheint sie ihnen zwangsluufig als naturliche Welt, und sie betrachten ihre Normen als allgemeingultig, ihre Ordnungen als selbstverstandich. "...there is no thought of war as an unfortunate disease or ghostly crime which man in a more advanced and more perfect world will discipline himself to avoid." 38

Der psychologisch Kranke ist unfuhig seine eigene Krankheit zu erkennen. Er sieht seine eigene Welt als die einzig-mugliche Lebensform und setzt seine MaBstube als absolut. Nicht er vermeint er sei abnorm, sondern die anderen, fur die in seiner Welt kein Platz ist und die andere MaBstabe anlegen als er selbst. So betrachtet Jungers Krieger auch nicht sich selbst, sondern die anderen als abnorm. Er hat sich seine eigene Welt aufgebaut, wer sich darin nicht zurechtfinden kann oder will, wird sie auch nicht uberleben. Nur der, der seine Regeln und Ordnungen anerkennt, wird darin auch bestehen konnen. Tragisch ist, daB dabei Junger der gleiche 
Denkfehler unterlauft, wie dem Kranken. Auch er nimmt ein viel zu kleines Segment aus der Totalen und stellt es als das Alleingultige dar. Dies mag gut gehen, solange ar sich in seiner eigenen welt befindet. MuB er aber zur anderen Welt zuruckkehren, so bedeutet dies, daB er sich nun an dieser Welt orientieren und an die anpassen muB oder er wird darin untergehen, falls es ihm nicht gelingt, die Realitaten beider Welten zu vereinen. Kommt es zu einer vorrubergehenden Beruhrung der beiden Welten, so ist das Resultat ein Schock, der an Starke des Gefuhls bei weitem das Ubertrifft, was auch immer sich in einer der beiden Welten allein erleben lieBe.

Ein Schaufenster hatte sich merkwurdig klar erhalten inmitten der beginnenden Zersturung. Es barg eine ganze Reihe von Damenhuten. Wenige Tage zuvor hatte ich, am Spatabend einer Schlacht, einen gefallenen Freund suchend, die Kurper einer Leichengruppe auseinandergezerrt. plotzlich war mir aus dem zerrissenen Rock des einen eine gemastete Ratte entgegengesprungen. Trotzdem hat mich dieses Erlebnis nicht so gepackt wie der geisterhafte Kontrast zwischen der verodeten StraBe und dem glanzenden Flitter aus lackiertem Stroh, Seide und bunten Federn, der so an Frauenhande und an die tausend Uberflussigkęiten erinnerte, die unser Leben erst farbig machen. 39

Es ist bezeichnerd, daB es nicht irgendetwas Menschliches ist, das Junger hier anruhrt, sondern etwas ganz Banales, "Flitter" wie er selber sagt. Nicht die Menschenleben, die hinter diesem Laden stehen, ergreifen ihn. Er weiB nicht einmal, ob die Frauen, die hier diese Hute verkauft haben, noch am Leben sind, oder diejenigen, die diese Hute getragen haben. Es interessiert ihn nicht, er fragt nicht einmal danach. Es sind die 
"Überflussigkeiten", die seine Aufmerksamkeit erregen. Frauenhande, Menschlichkeit, Warme, all dessen kann er ohne schweren Herzens entbehren. $Z$ war muB er zugeben, daB diese Dinge recht angenehm sind und das eigentliche Leben erst ausmachen. Aber es ist nicht sein Leben dem sie entstammen, nicht seine Welt, und so kann er sich leicht daruber hinwegsetzen. Nur der Schock der Erkenntnis, daB Uberhaupt eine andere Welt existiert kann inn momentan aufrutteln, besonders wenn die beiden Welten so aufeinanderstoBen, und er nicht umhin kann, diese zu erkenner. wahrend eines Heimaturlaubs hatte er diesen Laden wahrscheinlich Ubersehen, aber wenn er dort auftaucht, wo er eigentlich nicht hingehort, in Jungers Welt numlich, lust dies bei ihm eine unverstandiche Ergriffenheit aus.

vielleicht jedoch reagiert er deswegen so stark auf diesen Anblick, weil er in ihm Gefuhle auslost, und das ist etwas, dem er sich in seiner Welt auf keinen Fall hingeben darf, um seine Aufgabe erfullen zu kunnen. Im Kampf mussen alle Gefuhle unterdruckt werden.

Wo alles Denken und alle Tat sich auf eine Formel zuruckfuhrt, mussen auch die Gefuhle zuruckschmelzen und sich anpassen der furchterlichen Einfachheit des zieles, der Vernichtung des Gegners.40

Da Junger keine Welt auBer seiner Kriegswelt anerkennt, erubrigt sich auch die Frage nach Recht oder Unrecht. "Das Fehlen aller ethischen Wertungen auBert sich in Ernst Jungers Kriegsdarstellungen in Urteilen, die allem Humanen absagen. " 41 
Gut und BOse sind nicht mehr relevant, da sie auf die Erfullung des Zieles keinen EinfluB haben, ja diesem vielleicht nur hinderlich sein kunnten. Die Formel, auf die diese Existenz reduziert worden ist, heiBt nicht so sehr "Leben" als "Uberleben", wobei zunachst immer nur der Einzelne gemeint ist. Im therwinden der burgerlichen Existenz liegt das grobte Hindernis und somit ist der Einzelne sich sein argster Feind. 42 Nur wenn dieses bberwinden nicht gelingt, besteht fur den Krieger wirkliche Gefahr.

Jungers Stil entspricht dem Inhalt seiner Werke und dessen Darstellung. Genauso anteilnahmslos wie der Autor uns vom Auseinanderzerren einer Leichengruppe erzahlen kann, bleibt er wahrend des ganzen Romans. Er scheint uber dem Geschehen zu stehen, nichts kann ihn emotionell mehr anruhren, selbst in der Erinnerung nicht. Diese unpersunliche Art den Leser mit der Tragik des Krieges vertraut zu machen, die wohlgemerkt fur ihn keine Tragik ist, vermittelt leicht ein Gefuhl der therheblichkeit. Seine Verachtung des Abgebildeten als niedere Erscheinung, die Verschmahung der logischen Beweisfuhrung und seine Absicht, fur eine Elite zu schreiben, sind omniprasent. 43 Man ware versucht, Junger als sonderbaren Einzelganger abzutun, wenn sein Thema nicht so etwa Sustantielles darstellte. Gerade da das Geschehen von so auBerordentlicher Wichtigkeit ist, kann die Haltung Jungers dazu nicht mit einer Handbewegung beiseite geschoben werden.

Die Folge ist eine Darstellungsweise, der die lebendige wirkung der Dinge aufeinander fehlt. Sie werden betrachtet 
wie pruparierte Insekten, kalt und distanziert, nur unter dem Blickwinkel des moglichen Weges zum gesteigerten Zustand der magischen Perspektive. 44

Es versturkt sich das Gefuhl einer ungeheueren Arroganz eines Autors, dem es gelingt, den wirklich interessierten Leser wieder und wieder mit uberheblichen Plattituden vor den Kopf zu stoBen. Will man diese Arroganz entschuldigen, so besteht nur ein Ausweg, numlich der, daB der Autor an einer fast krankhaften Gefuhlsarmut, um nicht zu sagen Gefuhlsroheit, leidet.

Junger selbst scheint sich dessen an ganz wenigen Stellen bewuBt zu sein. Durchbrochen wird diese Art des Schreibens fast immer dann, wenn er von seinem drei Jahre jungeren Bruder Friedrich Georg spricht, der gleich ihm Kriegsteilnehmer war. Das Erstaunliche ist, daB der Bruder entweder nicht ofter oder auf der anderen seite nicht noch weniger erwahnt wird. Funde der Bruder mehr Erwahnung, so bedeutete dies, daB der Autor seinen sachlich-uberlegenen Standpunkt aufgeben muBte. Denn obwohl es ihm gelingt auch bei der Beschreibung der entsetzlichsten Szenen kuhl und unbeteiligt zu bleiben, wird er menschlich, sowie sein Bruder Erwahnung findet. Berichtete er jedoch mehr von seinem Bruder, hieBedies, daB er umso mehr seinen Emotionen Ausdruck verleihen muBte, und der $\mathrm{Zweck}$ des Buches, die unemotionelle Apotheose des Krieges, ware damit unerreichbar fern geruckt. So scheinen die wenigen Stellen, an denen Junger scheinbar mit allen seinen vorsatzen und mit 
seinem Stil bricht, uns nur daran erinnern $z u$ wollen, daB er trotz allem noch menschlich ist. Man spurt plotzlich, daB er sich doch noch einen Rest an Gefuhl bewahrt hat.

It is this defective sensibility which is fundamental to Junger's ideology of the existential moment. There is little doubt that Junger is conscious of the predicament. And there are two ways in which he tries to repair the flaw in his system. The first is simple enough, at a given point he abandons the system. Thus his description of the battle at Langemarck (July 1917) is briefly interrupted by an account of how, in the thick of it, he suddenly came upon his younger brother, who had been wounded, and how he ordered five of his remaining men to take the boy back to a field ambulance. Now nothing could be a more humane, a more natural thing to do than this brotherly service; yet in a world such as Junger extols, this act is nothing but a dereliction of duty. The It. Junger we know would challenge at pistol-point any subaltern who proposed to do what he is doing. 45

Wenn wir es trotzdem fur eine menschliche und naturliche Geste halten, so nur deswegen, weil Junger uns nicht von seinem System Uberzeugen konnte. Jungers System ist ein System der verachtung, sein stil ein stil unglaublicher Arroganz.

The overwhelming impression this style makes is not one of heroism, or of courage-and-fear, but of cold contempt. Contempt for those who do not "follow"; for those who do not accept, or who oppose, its "scale of values", for those who have not renounced "the old orders"; contempt, in brief, not for death, but for all life that is lived on any cther but the "existential level". 46

So sind Jungers Bucher in doppel tem Sinne herausfordernd. Zum einen ist es der Inhalt. Man kann dem Autoren 
zustimmen oder man kann ihn ablehnen, aber die Sache selbst ist so wichtig, daB man nicht gleichgtultig daran vorbeigehen kann. Genauso ist es mit Jungers Stil. Man kann ihn nicht einfach ignorieren. Man funlt sich gepackt, ob man will oder nicht, ob man ihm zustimmt oder nicht. Diese beiden Tatsachen mogen die Erklarung dafur sein, daB die Junger-Kritik von Anfang an so umfangreich war. Es mag zugleich erkluren, warum der "Kampf der Zitate" so heftig und ausdauernd gefochten wurde. Diejenigen, die Junger zustimmen, vermogen sich zumeist mit ihm oder seinen Helden zu identifizieren. Junger wtarde sie wahrscheinlich zu seiner Elite zahlen. Auf der anderen Seite stehen diejenigen, die sich durch Jungers Verachtung persunlich in ihrem Wesen angegriffen fuhlen mussen. So teilt sich die Junger-Kritik in zwei groBe, lautstark lamentierende Lager, mit nur einm ganz kleinen Streifen Niemandsland dazwischen. 
KAPITEL II

KRIEG

In der Gesamtausgabe seiner Werke widmet Ernst Junger sein Buch In Stahlgewittern "den Gefallenen"l und seinen Roman Der Kampf als inneres Erlebnis seinem "Bruder Fritz zur Erinnerung an die Begegnung auf dem Schlachtfeld von Langemarck" 2 . Noch Jahrzehnte nach dem Ende des Krieges nehmen also fur inn die Kriegsteilnehmer die wichtigste Stellung unter allen Betroffenen des Krieges ein. Das eine Buch ist denen gewidmet, die den Krieg nicht Uberlebt haben, das andere jemandem, der Ernst Junger persunlich sehr nahe steht und ebenso wie er im Krieg sein eigentliches Bildungserlebnis hatte. Wie sah nun der Krieg tatsachlch aus, wie sah konkret Ernst Jungers Krieg aus; denr man muB sich immer vor Augen halten, daB Junger den Krieg stets nur aus seiner eigenen Perspektive sieht und sein Bericht subjektiv ist.

Junger hatte sich frisch von der Schulbank als Freiwilliger an die Front gemeldet und wurde nach ein paar Monaten an der Westfront eingesetzt.

Mit ungluubiger Ehrfurcht lauschten wir den langsamen Takten des Walzwerks der Front, einer Melodie, die uns in langen Jahren Gewohnheit werden sollte. Ganz weit zerfloB der we:Be Ball eines Schrapnells im grauen Dezemberhimmel. Der Atem des Kamptes wehte heruber und lieb uns seltsam erschauern.3 
Das erste Gefuhl, das Junger erfahrt, ist nicht Furcht oder Angst, sondern Ehrfurcht, gemischt mit einem Schauer vor dem groBen Unbekannten. Weggeblasen sind alle Begeisterung, aller Jubel, den er noch bei der Nachricht der Mobilmachung an den Tag gelegt hatte. Allein die Ehrfurcht vor etwas so UnfaBbarem, bis dahin so Unerreichbarem, wird zum dominierenden Gefunl. Das Ziel seiner Traume und Abenteuer ist erreicht. Afrika, die Fremdenlegion, Reiseplane zum Kilimandscharo, das alles lag weit hinter ihm. Suchte er dort noch das physische Abenteuer, so ist es hier das Spirituelle, das NichtErfaBbare, was ihn erschuttert. Beim Anblick der ersten Kriegsschaden, fuhlt er seine "Augen wie durch einen Magneten an diesen Anblick geheftet". 4 . Kaum an der Front ist er schon vollkommen in den Bann des Geschehens geschlagen. Es ist, als ob jemand am Lebensende endlich einen lang gehegten wunsch in Erfullung gehen sieht. Von der ersten Minute an laBt er sich ganz von dem Erlebnis gefangen nehmen, und es ist ihm unmoglich, sich wieder daraus zu losen. So lange hat er auf diesen Augenblick gewartet, daB der Moment einfach groBartig und atemberaubend sein muB. Schon vorher wuBte er wie alles auszusehen hatte und umso leichter ist es fur ihn, sich nun total in das Erlebnis hineinzuversenken. Er weiB, daB er hier endlich seine mannliche Bewahrungsprobe wird ablegen kunnen. Abenteueriust und das Verlangen fremde Lander $\mathrm{zu}$ sehen, hatten ihn zu seinen fruheren Taten bewegt. Hier aber wird er mehr finden - sich selbst. 
Aber wir gehen wohl nicht fehl, wenn wir vermuten, daB die Geborgenheit eines gepflegten Haushalts, die Sicherheit einer gutburgerlichen Umgebung in ihm ein nicht genauer zu bestimmendes unangenehmes und unwilliges Gefuhl erzeugten, das ihn in die Ungebundenheit trieb, wo er aus sich ein eigenes Leben gestalten konne.5

War Junger selbst auf dem Kasernenhof in die burgerliche Ordnung gefugt gewesen und hatte nur die zucht der schule und des Elternhauses gegen die des Heeres eingetauscht, so ist er hier niemandem mehr verantwortlich als sich selbst.

Krieg, das war fur den Fahnenjunker die Umkehrung aller burgerlichen ordnungen, das Individuum wurde freigesetzt und konnte zu sich selbst finden.

For Junger, modern war is the supreme occasion in which man discovers the mystery of his own existence, not apart from, but in relation to and in conflict with modern inventions, modern technique, modern industry. 6

Endlich ist Junger an den Rand des AuBerordentlichen, des Ungewohnlichen vorgestoBen, das er so lange vergeblich gesucht hat. Alle konventionellen Werte und vorstellungen sind hier aufgehoben. "Im Kriege war bekanntlich alles erlaubt."? Bis dahin sah Junger sein Leben durch burgerliche Konventionen und Ideen eingeschrankt. Er hatte sich nicht frei gefuhlt, das zu tun, was er eigentlich wollte; er strebte nach dem AuBerordentlichen, dem Unerreichbaren, wollte fort von allen burgerlichen Bindungen und kehrte doch immer wieder genau dahin zurtack. Ja, was noch schlimmer war, gerade diese burgerlichen Bindungen waren es, die ihn wieder zu seinem Ausgangspunkt zu- 
rllckholten, wenn er bei der Verwirklichung seiner Traume nicht weiter kam. Im Krieg erkennt er seine Chance, das UngewUhnliche doch noch zu finden und dabei auch noch die Moglichkeit, sich endlich selbst zu gestalten, frei von allen herkormlichen Wertungen.

In der Welt, in der er aufwuchs, hatte das AuBerordentliche und Wunderbare keinen Raum gehabt. Die Erziehung hatte es ihm ausrotten wollen. Wenn es jetzt doch in Gestalt des Krieges in die burgerliche Welt einbrach, so schien es ihm, als muBte der Krieg von Kraften ausgelost sein, die auBerhalb des Wirklichen, Verstehbaren, durch die Ratio ErfaBbaren lagen. 8

Daher ruhrt seine Ehrfurcht beim Eintreffen auf dem Kriegsschauplatz. Zum einen glaubt er sich nun endlich am ziel seiner wunsche, zum anderen meint er in dem, war er nun erreicht hat, etwas im Grunde UnfaBbares gefunden $z u$ haben. Hierin liegt die Quelle seiner irrationalen Kriegsdeutung.

Da Junger den Krieg nicht rational erklaren kann, sucht er die Erklarung im Irrationalen, im Transzendenten, im Ubernaturlichen und folgerichtig setzt eine heroische verbrumung des Erlebnisses ein.

Der Krieg ist die machtigste Begegnung der volker ... Welche Fragen und Ideen auch immer die Welt bewegten, stets war es der blutige Austrag, der uber sie entschied. Wohl wurden alle Freineit, alle GroBe und alle Kultur in der Idee, im Stillen geboren, doch nur durch Krieg erhalten, verbreitet oder verloren. Durch Krieg erst wurden groBe Religionen Gut der ganzen Erde, schossen die tuchtigsten Rassen aus dunklen Wurzeln ans Licht, wurden unzahlige Sklaven freie Manner. Der Krieg ist ebensowenig eine menschliche Einrichtung wie der Geschlechtstrieb; er ist ein Naturgesetz, deshalb werden wir uns niemals seinem Banne entwinden. Wir durfen ihn nicht leugnen, sonst wird er uns verschlingen. 9 
Wenn Junger den Krieg und seine Macht den Trieben paralellisiert, so entgeht $\mathrm{ihm}$, daB gerade der Mensch in Vollbesitz seiner korperlichen und geistigen Krafte in der Lage ist, seine Triebe zu kontrollieren. Unwidersprechlich ist Aggression Teil der Kreatur, aber nur wo diese Kreatur pervertiert ist, wird sie die Aggression bis zum Krieg steigern. Wenn Junger hier schon das Tier oder die unbezuhmte Natur im Menschen anspricht, so sollte er versuchen konsequent zu bleiben. Noch ehe die moderne Psychologie und Verhaltensforschung wissenschaftlich das Phanomen der Aggressicn untersuchten, belegte der Volksmund schon, daB ein Lebewesen einer bestimmten Art ein anderes der gleichen Art nur in ganz wenigen Fullen angreift oder gar schadigt. Wenn es vorkommt, so handelt es sich fast ausschlieBlich um Ausnahmezustande.

Es stimmt zwar, daB groBe Entscheidungen durch Kriege erzwungen wurden, doch nicht weil es folgerichtig so sein muB, sondern weil es fur den starkeren die einfachste Iosung des Problems darstellt. Es stimmt auch, daB viele Religionen, und man muchte dies auf Ideologien erweitern, inre verbreitung durch Kriege fanden, aber es ist nicht nachzuweisen, ob sie ohne Kriege schlieBlich nicht ebenso verbreitet worden waren. $\mathrm{DaB}$ etwas auf eine bestimmte Weise herbeigefuhrt wurde, heiBt doch nicht, daB es auf andere Weise nicht ebenfalls erreicht worden ware.

Was Jungers Beispiel des Sklaven, der durch Krieg zum freien Mann wird, angeht, so ist man versucht, dies nur zu be- 
Iacheln. Denn wie viele Freie wurden durch Kriege Uberhaupt erst zu Sklaven? Es ist weit mehr als ein logischer Denkfehler, wenn Junger versucht, Krieg als Folge eines Naturgesetzes oder als Naturgesetz schlechthin darzustellen. Seine Erklarung dafur ist durftig und seine Beweise weder zutreffend noch uberzeugend.

"Der Krieg ist es, der die Menschen und ihre Zeiten zu dem machte, was sie sind."10 so heiBt es gleich zu Beginn seines zweiten Buches Uber den Krieg. Ob er diese Einsicht im Krieg gewonnen hat, oder ob er schon mit dieser Uberzeugung an die Front gezogen ist, bleibt ungewiB. Hier unternimmt er noch nicht einmal den Versuch, eine so tiefgreifende Behauptung weiter auszufuhren, sondern laBt den Satz gleichsam fur sich selbst sprechen, um sogleich seine Ausfuhrungen uber das neue Geschlecht zu erlautern.

Ein Geschlecht wie das unsere ist noch nie in die Arena der Erde geschritten, um unter sich die Macht uber sein Zeitalter auszuringen. Denn noch nie trat eine Generation aus einem Tore so dunkel und gewaltig wie aus dem dieses Krieges in das lichte Leben zuruck. II

Zunachst einmal fallt es schwer, die Verbindung zwischen der allumfassenden Behauptung des ersten zitats und dessen unmittelbar darauffolgenden Erlauterung zu sehen. Sicher hat Ernst Junger Recht mit seiner Hberzeugung, daB der Krieg oft die Menschen und ihre zeit zu dem gemacht hat, was sie sind, aber so vollkommen unmodifiziert kann er diese Behauptung gewiB nicht bestehen lassen. Denn auch andere Faktoren haben 
auf die Menschen und ihre Zeit ganz wesentlichen EinfluB genommen. Man bedenke etwa nur das Klima, die geographische Lage eines Volkes, spater den EinfluB der Technik, in der Neuzeit die industrielle Revolution. Wissenschaft und Lehre, Musik, Geist, all dies hatte seinem Wort zu Folge nicht den geringsten EinfluB auf den Menschen gehabt. Er laBt nur den Krieg bestehen als das, was den Menschen $z u$ dem gemacht hat, was er ist. Das Ungeheuerliche dieser Behauptung ist ganz offensichtlich. Oder ist dieser Satz wiederum nur ein Beispiel fur Jungers uberlegenen Stil? Der aufmerksame Leser wird auf alle Fulle wissen, was Junger meint. Ihm braucht eine solche Behauptung nicht weiter erlautert zu werden, denn der Autor und er verstehen einander schon. Da braucht es nicht der groBangelegten Erklarungen und Deutungen. Der Autor und der rechte Leser wissen, auf was es ankommt, und der, der eine solche Behauptung nicht versteht, gehort eben nicht zu ihrer elituren Gruppe, und es ware muBig, inm etwas so Elementares erkluren zu wollen.

Es charakterisiert inn, daB er immer dann, wenn er die Schwache der eigenen Position besonders deutlich fuhlt, mit der tberheblichkeit des aristokratischen Anspruchs auftritt. 12

Junger hat keineswegs so sehr recht, wie die Behauptung erwarten labt, aber gerade hier wird seine tendenziuse Schreibart besonders deutlich. Er schreibt nur fur ein Mitglied der Elite, wie er es selber ist, und wird dort auch ohne weitschweifige Erlduterungen Zustimmung finden. 
Es stimmt wahrscheinlich, daB noch nie ein Volk einen Krieg von solchen AusmaBen gefochten und von solcher Grausamkeit erlebt und uberlebt hat. Junger versucht hier jedoch, etwas ganz Banales heroisch auszudeuten und $\mathrm{zu}$ veredeln. Leider scheint es ein Merkmal des Phanomens Krieg zu sein, daB jeder folgende noch verwastender, noch blutiger ist als der vorhergegangene. So ist seine Behauptung umso widersinniger, daB eben diese Generation in das lichte Leben zurtuckkehrte. Gerade im ersten Weltkrieg war auch die Zivilbevolkerung vom Kriegsgeschehen betroffen. Wenige nur werden es gewesen sein, die in das "lichte Leben" zuruckkehrten. Deutschland lag, wo nicht Uberall physisch, so doch auf kunstlerischem und geistigen Gebiet in Schutt und Asche. Es erlebte den Zusammenbruch seiner Staatsform, Anarchie und Terror breitetensich auf den StraBen aus, es gab Not und Hunger, Verzweiflung. Anderen kriegsteilnehmenden Nationen mag es besser gegangen sein, doch nirgendwo herrschte Grund zu edler Freude, wie sie Junger hier zu finden vermeint. Trotzdem Junger seine Kriegsromane mehrmals Uberarbeitet hat, sah er offensichtlich keinen AnlaB, den Versuch zu unternehmen, so einwandfrei falsche Behauptungen zu korrigieren oder doch wenigstens zu modifizieren.

SchlieBlich borgt sich Junger noch ein Wort Heraklits, um uns das Wesen des Krieges und seine Bedeutung verstandlicher zu machen.

Der Krieg, aller Dinge vater, ist auch der unsere; er hat uns gehammert, gemeiBelt und gehartet zu dem, was wir sind. Und immer, solange des Lebens schwin- 
gendes Rad noch in uns kreist, wird dieser Krieg die Achse sein, um die es schwirrt. Er hat uns erzogen zum Kampf, und Kumpfer werden wir bleiben solange wir sind. Wohl ist er gesterben, sind seine Schlachtfelder verlassen und verrufen wie Folterkammer und Galgenberg, doch sein Geist ist in seine Fronknechte gezogen und last sie nie aus seinem Dienst. Und ist er in uns, so ist er uberall, denn wir formen die Welt, nicht anders, Anschauende im schopferischsten Sinne.1.3

Hier verliert Junger nun vollends jeden MaBstab. Mit gleichsam religioser Inbrunst ruft er die Krieger der Welt auf, das Werk des Vaters Krieg zu vollenden. So sie wahre Kumpfer sind, werden sie gar nicht anders konnen, da der Geist des Vaters viel zu sehr in ihnen lebt. Der Vater, der hier symbolisch verwendet wird, ist weder gutig noch liebend. Er hat seine Kinder zwar "gehmummert und gemeiBelt", aber damit scheint sich seine Fursorge erschypft zu haben.

Obwohl Junger es nicht deutlich ausspricht, wird klar, daB auch hier schon, wie in Jungers gesamtem Kriegswerk, fur die Frau kein Platz ist oder sie zumindest nur als unwichtige Erscheinung auftreten kann. An dem Krieg, den Junger hier beschreibt, haben Frauen nicht aktiv teilgenommen. Folglich fehlt ihnen auch die Berechtigung dazu, den weiteren Verlauf der Dinge zu bestimmen, denn nur die Kinder, also die suhne des Krieges formen die Welt. Auch hier tritt uns Jungers Gemeinschaftsbild vor Auger. Seine Welt ist eine ausschlieBliche Mannerwelt, in der dazu noch der Sturkste die Vorherrschaft haben wird. Der Krieg verschlingt seine Kinder. Das sind diejenigen, die sich der brutalen Gewalt nicht anpassen 
kunnen oder wollen. Das Zitat, $z u$ was es Junger auch immer gedient haben mag, ist im Grunde nichts weiter, als eine Apotheose der Starke, die er ein biBchen religiusklirgend verziert.

Doch Junger fuhrt seine Erklarung uber den Krieg noch weiter aus.

Indes: Nicht nur unser Vater ist der Krieg, auch unser Sohn. Wir haben ihn gezeugt und er uns. Gehummerte und GemeiBelte sind wir, aber auch solche, die den Hammer schwingen, den MeiBel fuhren, Schmiede und spruhender Stahl zugleich, Martyrer eigener Tat, von Trieben Getriebene. Das zeigte sich, als der Krieg die Gemeinschaft Europas zerriB, als wir hinter Fahnen und Symbolen, uber die mancher langst unglaubig gelachelt, uns ge gentberstellten zu uralter Entscheidung. Da entschadigte sich der Mensch in rauschender orgie fur alles versaumte. $\mathrm{Da}$ murden seine Triebe, zu lange schon durch die Gesellschaft und ihre Gesetze gedummt wieder die einzige und heilige und letzte vernunft. Und alles, was das Hirn im Laufe der Jahrhunderte in immer schurfere Formen gestaltet hatte, diente rur dazu,
die Wucht der Faust ins Ungemessene zu steigern.14

Ganz abgesehen davon, daB hier zum Teil nur noch einmal wiederholt wird, was Junger schon kurz vorher zu sagen hatte, wird auch hier wieder das Pseudoreligiose seiner Aussage deutlich. Jungers Junger sind "Martyrer", des Menschen Triebe werden wieder zur "heiligen" Vernunft. Noch deutlicher wird hier der Aufruf zur Gewalt. Junger verherrlicht am Krieg die Ruckkehr zu den Trieben, den Rtckfall ins Animalische. Nicht der Geist herrscht mehr, sondern allein die Faust. Junger kehrt wieder zu den Ursprungen zuruck Man kann Junger nicht verubeln, daB er meint, steter Fortschritt hätte 
den Menschen nur immer weiter von seinem wahren Selbst entfernt, ihn immer unnaturlicher werden lassen, aber daB er als Losung eine Ruckkehr zur Farst vorschlagt, heiBt am eigentlichen Problem vorbeizugehen. Seine Welt ist eine ursprungliche in einer hochentwickelten Gesellschaft. Im Ausnahmezustand, im Krieg, mag sich dies temporar verwirklichen lassen, aber im normalen Leben ist allein die Vorstellung dessen absurd.

Jungers Denkfehler liegt darin, daB seine Wertvorstellungen sich umgekehrt haben. Fur ihn war der Krieg das Normale, nicht mehr das AuBergewuhnliche. "Der Krieg - ein Normalzustand; Kampfen, TUten, Siegen und Besiegtwerden - die ewige, unausweichliche Bestimmung des Menschen."15

Noch bei Kriegsbeginn war es die Suche nach dem Ungewohnlichen, die den Schuier in die Reihen der Soldaten trieb, aber diese vorstellung unterzieht sich in den vier Jahren einem Wandel, der in den Buchern nur zu deutlich wird. Der Bruch mit der burgerlichen Welt gelingt Junger vollkommen und das, was fruher fur inn das Abenteuer symbolisierte, gilt inm jetzt als das Leben schlechthin. Der Krieg dient ihm zur Erfullung seines Wunsches, dem Leben, so wie er es bis dahin erfahren hatte, ein Ende zu bereiten.

Der Krieg bereitete dem Leben ohne Sinn ein Ende. Das ist das groBe Aufatmen der Jugend jener Zeit, die in Raum des Privaten kein cenuge mehr findet und in ihren aktiven Kraften schon auf absonderlichste Auswege verfallen war, ohne jedoch die Befriedigung des gelungenen AnschluBes an eine elementare Notwendigkeit, an eine verbindliche Aufgabe oder Berufung zu haben. 
Der Krieg als Naturereignis kommt der Revolution gegen die Welt des Privaten, die Welt des Burgers, zu Hilfe, der Revolution, die bislang eher ein Aufstand war, etwa derart, wie ihn der junge Afrikafahrer vollzog, oder wie er noch unklar und sich selbst wenig begreifend in der Jugendbewegung vor dem Krieg Ausdruck gewann. $16^{1}$

Es mutet fast wie eine Flucht an, was sich hier vollzieht. Man war seiner Zeit uberdrussig und der Krieg bot sich als willkommene Ablosung, ja als wirkliche Erlosung an. Entscheidend jedoch ist, daB diese Bewegung nicht wieder zuruckfand in eine zwar veranderte, aber doch reale Welt. Stattdessen lebt man im Irrealen weiter. Bei Kriegsende wird nicht versucht soweit dies moglichist, beide Welten harmonisch $\mathrm{zu}$ verbinden, sondern die MaBstabe des Krieges werden jetzt plotzlich uberall angelegt. Aber was im Krieg seine Berechtigung und seine Gultigkeit hatte, fallt nun vollkommen aus dem Rahmen des Alltaglichen und wiederum entsteht eine Verdrehung der Werte.

Wie der Krieg vom auBergewbhnlichen Ereignis zum Normalzustand wird, so werden jetzt die MaBstube des Krieges als Norm an das ubrige Ieben angelegt. Der Krieg diente dazu, den Typ zu erzeugen, der stark genug ist, dies zu tun. Junger glaubte im Kampfer den wahren Menschen gefunden zu haben, der dazu ausersehen war, das Leben aktiv mitzugestalten. Vor allem war er dazu befuhight, da er dies im Krieg in kleinerem MaBstab bereits getan hatte. Im Krieg hatte eine Auslese der starksten stattgefunden, nun galt es, dieses Leben in das wirliche Ieben hineinzuprojizieren. 
Der Kern seiner Kriegsdeutung aber ist seine Rechtfertigung des Krieges, seine Darstellung des Krieges als notwendige AuBerung des Lebens, in dessen Verlauf sich ein menschlicher Typus herauskristallisierte, der bestimmt ist, die welt nach seinem Willen zu formen.1?

Das sieht Junger als Auftrag des Vaters an die sohne an. Er ignoriert dabei vollstandig veranderte Gegebenheiten und orientiert sich allein am Recht der starke. Was einmal fur gut befunden worden ist, wird sich auch spater wieder bewahren. Dies scheint das Fazit seiner Erkenntnis zu sein. Der Krieg ist die groBe Generalprobe zum Leben. Wurde hier das ziel durch brutale Gewalt erreicht, so fordert Junger auch nach dem Krieg noch die Ruckkehr zu den üsprungen. Nur so, meint er, labt sich das Leben wirklich leben.

Was Jungers Kriegsdarstellung von anderen kriegsbejahenden unterscheidet, ist das rucksichtslose Bekenntnis zur zerstorerischen Aktivitut des Menschen im Krieg. Junger vertritt nicht die Auffassung wie andere. Autoren kriegsbejahender Darstellungen, daB die Leiden und Entbehrungen, die der Krieg bringt, aus bestimmten, mehr oder weniger dubiosen, uberindividuellen Motiven ertragen werden mussen. Er bejaht ihn vielnehr. weil er ein Gesellschaftszustand ist, der inm die Moglichkeit einer anarchischen Lebensfuhrung gibt. Hinter Jungers Kriegsbejahung steht nicht das geringste Trotzdem, sie kennt keine Vorbehalte gegenuber dem Krieg, sondern nur die Genugtuung tber sein Vorhandensein.18

Krieg bedarf fur Junger keiner Rechtfertigung, denn er sieht ihn als Manifestation des Lebens schlechthin und entruckt inn somit jeglicher Kritik. Im Krieg kehrt der Mensch zu seinem wahren Selbst zurtlck. Nur hier konnen sich seine Triebe ungehindert durch Ordnungen und Gesetze wirklich entfalten. 
Somit werden auch die burgerlichen Werte und Vorstellungen hinfullig. Sie machen nicht den eigentlichen Menschen aus, da sie ihm erst im Laufe der Geschichte aufgezwungen worden sind. Im Krieg fallt aller zivilisatorische Fortschritt vom Menschen $a b$, allein die Faust regiert.

Jungers eigentliches Thema ist die Fuhrung des Lebens aus der innersten Kraft. Was dem Fremdenlegionar Junger noch als Ideal vorschwebt, dem offizier ist es Wirklichkeit geworden.

Vielleicht war es doch muglich, dachte ich mir, so zu leben, wie man es an den Tieren und Pflanzen sieht, ohne Hilfe, ohne Geld, ohne Brot, ohne alles, was Menschenhand je schuf und beruhrte - zu leben aus der innersten Kraft.19

Er Ubersieht, daB auch Tiere und Pflanzen bestimmte Gesetze haben an die sie sich halten mussen, um ihr Ujoerleben zu garantieren. Eines der vordringlichsten ist das Gesetz der Anpassung. Gerade das ist es, was Junger hier verletat. Er kann sich nicht anpassen, da er den Unterschied nicht sieht. Krieg ist fur ihn ein Zustand der Permanenz geworden. Er hat sein Leben total im Krieg eingesetzt, und der Lohn, den er dafur empfungt, ist die Tatsache, daB er nun den Krieg als die Zeit seines groBen Einsatzes betrachtet und ihr seine MaBstube entnimmt. Hier findet er sein Weltbild, welches frei von allen geschichtlichen und sozialen tberlieferungen ist. Der Mensch, der nur dem Gesetz des Blutes gehorcht, ist auch nur sich selbst verantwortlich. In sich und aus sich empfangt 
er das Gesetz seines Handelns. Der Krieg dient nur dazu, dies dem Menschen auch bewuBt zu machen.

\section{DER KRIEGER}

Krieg ist fur Junger die Manifestation des Lebens und der Kampfer ist fur ihn der Mensch schlechthin. Nur er verdient sich wirklich diesen Namen. "Was konnte auch heiliger sein als der kampfende Mensch? Ein Gott? Weil wir an seiner Allmacht zerschellen mussen wie an einer geschliffenen Kugel?"20 In erster Iinie ist der Krieger ein Ideal. Er entspricht nicht der Wirklichkeit und der Mensch kann nur immer danach streben, so nahe an das wunschbild heranzukommen wie moglich. Aber je naher er seinem ziel kommt, umso mehr wird er der realen Welt entzogen.

Jungers Werk umfaBt den kampfenden Menschen in seiner Totalitat. Er sieht inn, wie er als junger Freiwilliger an die Front zieht, er beschreibt, wie er im "Stahlbad" zum Kampfer wird, und er spricht schlieBlich von dem Menschen, der den Krieg uberlebt, hat. Im Vorwort zu neunten Auflage seines Buches Der Kampf als inneres Erlebnis (1943) umreiBt Junger den eigentlichen Wert dieses Buches.

Es umreiBt die seelische Haltung eines Menschenschlages, der unmittelbar nach der Uberwindung der grubten Anstrengungen sich bemunte, das Geleistete zu sichten, die Hurte seiner Taten vor sich selbst zu rechtfertigen und den Blick auf neue ziele zu werfen.2l

Hauptaufgabe desjenigen, der den Krieg Uberlebt, ist es also, die Eindrucke und Erlebnisse zu verarbeiten, um anderen 
Situationen gewachsen zu sein. So entwickelt der kumpfende Mensch sich standig weiter, immer auf sein Ideal zu. Ähnlich, wie er selbst einmal gehammert wurde, wird er durch seine Einsichten eine neue Generation hummern helfen. Es entsteht eine Spirale, deren hochstes Ziel das Ideal ist.

Der Beginn dieser Spirale laBt sich bei Junger auf den Freiwilligen festlegen. Junger selbst gehort zu dieser Gruppe.

Wir hatten Horsale, Schulbanke und Werktische verlassen und waren in den kurzen Ausbildungswochen zu einem groBen Korper zusammengeschmolzen. Aufgewachsen in einem Zeitalter der Sicherheit, fuhlten wir alle die Sehnsucht nach dem UngewUhnlichen, nach der groBen Gefahr. Da hatte uns der Krieg gepackt wie ein Rausch. In einem Regen von Blumen waren wir hinausgezogen, in einer trunkenen stimmung von Rosen und Blut. Der Krieg muBte es uns ja bringen, das GroBe, Starke, Feierliche. Er schien uns mannliche Tat, ein frohliches schutzenfest auf blumigen, blutbetauten Wiesen. "Kein schunrer Tod ist auf der WElt..." Ach, nur nicht zu Haus bleiben, nur mitmachen durfen: 22

Da der kumpfende Mensch, so wie ihn Junger versteht, ein Ideal ist, kann es, wenn Uberhaupt, nur von Wenigen erreicht werden. Schon hier setzt eine Auslese ein. Es sind bewuBt die Freiwilligen von denen Junger hier spricht und nicht die groBe Masse der Kriegsteilnehmer insgesamt. Nur aus ihrem Kreis kann der Held geboren werden. Die anderen verrichten im Krieg nur ihre Arbeit, wie sie es bis dahin auch getan haben. Fur sie ist der Krieg kein Fest der Rosen und des Blutes, stumpfsinnig leben sie vor sich hin und werden nach Kriegsende wieder nach Hause zurUckkehren, ohne das Geschehene jemals zu begreifen. 
Noch deutlicher wird diese elitare Auffassung, wenn man sich vergegenwartigt, was die jungen Freiwilligen verlassen. "Horsale, Schulbanke und Werktische". Die Werktisch, stehen nicht von ungefahr erst an letzter Stelle in der Aufzahlung. Ohne $Z$ weifel entstammten die meisten der Freiwilligen einem beguterten Elternhaus, das ihnen Schulbildung oder gar Studium ermoglichen konnte. Aber ebenso ohne $Z$ weifel setzte sich das Gros der Kriegsteilnehmer nicht aus diesen Leuten zusammen. Diese zahlen also in jedem Fall schon zur Elite, der Krieg dient nur dazu, sie schneller an ihr ziel gelangen zu lassen. Betrachtet man den Krieg als den Beginn des Lebens, so sind es die Freiwilligen, die der Oberschicht gleichsam durch Geburt angehuren. Die anderen mussen ihren verdienst erst unter Beweis stellen. Erst dann haben auch sie die Myglichkeit auf die Ebene jener hinaufzusteigen.

Der Freiwillige will den Kampf und begierig wartet er auf den Einsatz an der Front. Er hat sich nicht etwa aus irgendwelcher patriotischer Gefuhlsduselei gemeldet, sondern um an sich selbst in der kriegerischen Auseinandersetzung zu erfahren, was Leben heiBt.

Wie das Kind in der Gesindekuche, der Bauernbursche im Schreckenskabinett, so hockten in ihren Kasernenstuben junge Freiwillige um einen ulteren Jahrgang geschart, aus dessen Stimme noch das Grauen des Schlachtfeldes bebte. Wurden die Gesichter auch fahl, die Augen dunkel, so war doch kaum einer, der nicht noch brennender den Tag des Ausmarsches ersehnte. Jeden trieb es der Gorgo ins Antlitz zu stajrren, mochte auch der Herzschlag daruber verstummen.

Sie wissen, was sie erwartet. Aber das Grauen auf das sie sich 
vorbereiten ist romantisch verbrumt. Es ist der Wunsch nach dem anderen Leben, der sie eint, sie sind noch immer auf der Suche nach dem AuBerordentlichen und hier nun, weitah von aller burgerlichen Zivilisation und ihrer Fesseln entledigt, hoffen sie, es endich zu finden.

Wiederum wird deutlich, daB Junger den Eintritt in den Krieg als Eintritt in das Leben versteht. "Wie das Kind..., der Bauernbursche..." so harren die Freiwilligen der Dinge. Noch ungebildet und unverbildet wie Kinder sind sie. Der Bauernbursche erinnert an den dummen Tor. Sie sind bereit fur das Abenteuer. Was sie bis jetzt erlebt haben, ist unwichtig, es diente allein zur Vorbereitung auf das, was jetzt kommt. So ist es nur folgerichtig, wenn Junger spater ihre ersten Gefechte als Taufe oder als Feuertaufe bezeichnet. Als Freiwillige treten sie in das Leben ein, clas in der Feuertaufe sanktioniert wird. Wenn der Krieg vortber ist, so werden Manner dorthin zuruckkehren, wo Kinder auszogen.

Die Feuertaufel Da war die Iuft so von uberstromender Mannlichkeit geladen daB jeder Atemzug berauschte, daB man hatte weinen mogen, ohne zu wissen warum. Mannerherzen, die das empfinden konnent 24

Der Krieg wird zum rein munnlichen Erlebnis abgestempelt. Hier machen Manner wie Junger ihre Grunderfahrung. Alles andere kann diesem Grunderlebnis gegenuber nur von untergeordneter Bedeutung sein. Soldatentum, wie es Junger sieht, wird zum alleinigen Lebensinhalt. 


\begin{abstract}
"Soldiery", to the neo-nationalist mind, is not a necessity, but a religion; not a rampart of normal life but its main content; not a condition, nor a profession, but the determining prototype of community. 25
\end{abstract}

Die Krone der Schopfung ist der Sturmtruppfuhrer oder doch der Typ, der das Potential am Sturmfuhrer in sich tragt. Er ist das Mannlichkeitsideal und dem einfachen Soldaten weit Uberlegen.

Unter allen erregenden Momenten des Krieges ist keiner so stark wie die Begegnung zweier StoBtruppenfuhrer zwischen den engen Lehmwanden der Kampfsteliung. Da gibt es kein Zurlick und kein Erbarmen. Das weiB jeder, der sie in ihrem Reich gesehen hat, die Fursten des Grabens mitden harten, entschlossenen Gesichtern, tollkuhn, geschmeidig vor- und zuruckspringend, mit scharfen, blutdurstigen Augen, Manner, die ihref Stunde gewachsen waren und die kein Bericht nennt. 26

Der sturmfuhrer geht ganz ins Kriegswesen ein, der Graben wird ihm zur Heimstatt, sein Reich. Wiederum wird deutlich, wie weit Jungers Bruch mit der AuBenwelt geht. Das Regiment wird zur Familie, der Graben zum Reich, der Krieger zum neuen Menschen. Er ignoriert das Nebeneinander verschiedener Lebenselemente. Fur inn hat der krieg, und was er beansprucht, AusschlieBlichkeitscharakter und alles andere ist demgegentber keiner Beachtung und Erwahnung wert.

For Junger, only the shock-troop type is a real soldier. He utterly despises the citizen-soldier. Not even by his death on the field of honor can he compensate for his inferiority. The shock trooper belongs to a "different race", while nothing can make a hero of a civilian.27 
Dies also ist der Lauf der Spirale, von der Masse der Kriegsteilnehmer, Uber die Freiwilligen zum Sturmfuhrer. Dem Sturmfuhrertyp wiederum obliegt es, das Kriegserlebnis wachzuhalten und die neue Generation auf das Leben vorzubereiten. Er wird zum Vorkumpfer fur die neue Rasse. Darin sieht Junger seine eigentliche Aufgabe. Inm geht es nicht darum, fur irgendein Land, irgendeine Regierung Siege auf dem Schlachtfeld zu erringen. DaB Uberhaupt Krieg gefuhrt wird ist das Entscheidende, denn Krieg ist die Geburtsstunde der neuen Rasse.

\section{DIE NEUE RASSE}

In seinem Buch Afrikanische Spiele sagt Junger einmal von einem Italiener, "Proletarier durch Geburt und Rasse, fuhlte er sich am wohlsten in der Abhangigkeit." 28 Dies macht wenigstens zum Teil deutlich, wie Junger den Begriff der Rasse verstanden wissen will. Es ist fur ihnkein antrophologischer Begriff, eher ein Begriff aus der Soziologie.

Rasse ist etwas, das nicht erworben werden kann. Es ist gleichsam angeboren und braucht nur die Moglichkeit, sich zu entfalten.

To them, the attempts of National Socialist racial theorists to measure skulls and compare profiles and cheekbones are a pedantic and belated tributg to $a$ bygone era of antropological race doctrine.

Genauso wie Junger erkennen muB, daB es im Krieg auch auf der Gegenseite Manner gibt, muB er zugestehen, daB auch dort eine 
neue Rasse ihren Ausdruck finden kann. Entscheidend ist, daB man sich im Krieg bewahrt hat. Anspruch darauf, zur neuen Rasse zu gehoren, hat in jedem Fall nur der Freiwillige. Fur die anderen Kriegsteilnehmer ist es praktisch unmoglich, jemals dazu gerechnet zu werden, es sei denn, sie bewahrten sich als Manner auf ganz auBerordentliche Weise. Sonst dienen sie der Elite nur zu Handlangerdiensten. Jene sind weder Manner noch Menschen und konnen genau wie Material verbraucht und verschlissen werden. In Grunde befinden sie sich nur wenig uber der Stufe desjenigen, der, aus welchen Grunden auch immer, Uberhaupt nicht am Krieg teilnimmt. Dem bewegenden Erlebnis des Krieges stehen sie unverstundig gegenuber.

Der Sturmtruppfuhrer auf der anderen Seite erfuhrt das Leben in seiner ursprunglichsten From. Stundig am Rand des Todes jonglierend, sind seine Empfindungen und Sinne hellwach. Da Junger selbst durch Strebsamkeit und Zufall zu dieser Gruppe zahlt, vermag er den Typ umso praziser zu beschreiben.

Es war eine ganz neue Rasse, verkorperte Energie mit hochster Wucht geladen. Geschmeidige, hagere, sehnige Korper, markante Gesichter, Augen in tausend Schrecken unterm Helm versteinert. Sie waren Uberwinder, eingestellt auf den Kampf in seiner grablichsten Form. Ihr Anlauf uber zersplitterte Landschaften bedeutete den letzten Triumph eines phantastischen Grausens. Brachen ihre verwegenen Trupps in zerschlagene Stellungen ein, wo bleiche Gestalten ihnen mit ihren Augen entgegenstarrten, so wurden ungeahnte Energien frei. Jongleure des Todes, Meister des Sprengstoffes und der Flamme, pradchtige Raubtiere, schnellten sie durch die Graben. Im Augenblick der Begegnung waren sie der Inbegriff des Kamphaftesten, was die Welt tragen konnte, die scharfste Versammlung des Korpers, der Intelligenz, des willens und der Sinne. 30 
Im Kampf kehrt der Mensch wieder zu dem ursprtinglichen, dem tierischen Sein zurtick. Alles, was er sich in Jahrtausenden an Kultur und zivilisation erworben hat, fallt von ihm ab und die eigentliche Kraft wird freigesetzt.

Um diesen Ausbruch zu mildern behalt der Mensch seine Intelligenz bei. Er wird nicht zur brutalen Bestie, die durch einen rohen Kraftakt alles nierderschlagt, was sich ihr in den Weg stellt. Ursprungliche Energien werden freigesetzt, aber sie werden doch standig durch Intelligenz und Willen kontrolliert. Der Held der Jungerschen Schriften ist kein brutaler Schlachter, ebensowenig wie der Kampf das bloBe Niedermetzeln des Feindes ist, sondern es ist ein Mensch, der standig Herr aller seiner Fanigkeiten ist und der sie ausgewogen in Betrieb zu setzen weiB.

Hohepunkt des Kampfes ist der Zusammenprall zweier solcher Menschen. Auch hier fragt Junger nicht nach dem Ausgang einer solchen Begegnung. Dies ist zweitrangig. Entscheidend ist, daB diese Begegnung Uberhaupt stattfindet. Sie erscheint gleichsam als ein Naturereignis, bei dem ungeahnte Gewalten freiwerden, vor denen der unschuldige Beobachter sich nur ehrfurchtig verbeugen kann. Es kommt inm die Erkenntnis von der Allgewalt des Kampfes.

Junger jedoch kann es nicht bei dieser Feststellung bewenden lassen. SchlieBlich war er ausgezogen, das Abenteuer zu suchen. Wenn er dies im Kampf findet, so bedeutet das, daB der Kampfer zugleich der Prototyp des Abenteurers ist. 
So wie zum ausgepragten Tanze Rasse erforderlich ist, entspringt auch groBer Mut sehr scharfer Rasse. Wenn breite Linien im Sturme zerbrachen, zersplitterte der Kampf in kleine Haufen. $\mathrm{Zu}$ denen schloB sich alles was Rasse hatte; der zuhe Bauernbursche mit kantigem Schadel, der geschulte Arbeiter mit intelligentem Gesicht, der offizier, dem der Kampf seit Jahrhunderten im Blute steckte, der Fahnenjunker, dessen schmale Hande das Gewehr kaum schwingen konnten. 31

Dies sind die gleichen Leute, die Ernst Junger schon in der Fremdenlegion vorgefunden hatte. Ein scheinbar wild zusammengewurfelter Haufen, der dennoch durch Rasse geeint ist. Wie so oft bei der Erklurung von Bezeichnungen kommt Junger auch hier ins Fabulieren. Er sagt nicht, was im Grunde Rasse ausmacht, sondern wie sie sich auswirkt. Zur Definition des Begriffes genugt inm der "kantige Schadel", das intelligente Gesicht und der Offizier, dem sein Beruf durch seine Herkunft gleichsam in die Wiege gelegt worden j.st. Nur eines wird dabei deutlich, namlich $d a B$ er sich vom biologischen Aspekt der Rasse weitgehend entfernt hat; denn die oben aufgefuhrten Merkmale sind keine Charakteristika des Kaukasen oder sogar des Ariers, noch irgendeiner anderen Rasse. Seiner Rasse haftet etwas Abenteuerliches an.

Thre Umgebung war die mannlichste. Rohe Bretterwănde, durch Balken und grobrindige Stempel gestutzt, mit Gewehren behangen, Bunke und ein klobiger Tisch, eine Flasche mit hineingesteckter Kerze. So mochten Trapper in ihren Blockhausern hausen oder die Kapitane von ihren Piratenschiffen in ihren Kajuten. So mochte in den Tavernen des Vaganten Villon, so im Wilden Schweinskopf zu Eastcheap tolle Urkraft sich vergeudet haben. Da hockten sie im Engen, verwogene Brut, verwittert und zerschlissen, mit Gesichtern wi geschliffene Klingen, voll Sprung, Rasse und Energie. 32 
Junger hatte sich zum Krieg gemeldet, um das Abenteuer zu finden. $\mathrm{zu}$ oft schon war er ausgezogen und unverrichteter Dinge wieder heimgekehrt. Hier nun endlich scheint ihm Erfolg beschieden zu sein. Es ist ein wilder Haufen IMtnner deren Gemeinschaft er jahrelang geteilt hat. Junger konnte sich endich am Ziel seiner wunsche sehen. Aber etwas stort den Leser. Junger schatzt zwar die Gegebenheiten richtig ein, aber er schmuckt sie auf romantisch-abenteuerliche Art aus.

Als Schuljunge hatte er sich $z u$ den Bllchern gefluchtet, um der Realitat zu entkommen. Hier ist er nun in der Realitat, die er sich selbst aufgebaut hat, aber wie armselig stellt sie sich dar. Trostlose Stellungsgraben, deren Insassen durch Jahre des Krieges gekennzeichnet sind. Junger verschweigt, wie viele dieser verwitterten und zerschlissenen Gestalten diesen Stempel durch den Rest ihres Lebens tragen mussen, weil sie an Leib oder Seele ernsthaft Schaden genommen haben. Wahrscheinlich rechnet Junger Gesundheit zu den Banalitaten des Irebens und es liegt weit unter seiner wurde, sich damit abzugeben. Wieder fluchtet er sich in eine Traumwelt. Er kann sich die HaBlichkeit und die Absurditat einer solchen Existenz nicht eingestehen und versucht, sie darum mit den begehrenswertesten Attributen auszuschmucken. Seine Elite sind keine Menschen mehr, es sind nur noch Lebewesen, deren taglicher Kampf ums tberleben sie maBlos erschopft hat, die ihre ganze Kraft nur mehr darauf verwenden konnen den nächsten Morgen noch zu erleben. 
Dieser Zustand ist nicht nur im Krieg zu finden. Es gab ihn auch bei den Arbeitern whrend der industriellen Revolution, es gibt ihn in unzahligen GroBstadten noch heute. Der Unterschied liegt darin, daB jene Menschen eigentumlicherweise nie oder selten als Helden gefeiert wurden. Aber wie so viele vor und nach ihm, macht Junger aus der Not eine Tugend. Etwas anderes kommt ihm dabei zustatten. Er kann sich immer darauf berufen, daB die, die es anders wissen ja nicht dabei gewesen sind, es also auch gar nicht aus eigener Anschauung und folglich richtig beurteilen konnen.

Jungers Rasse unterscheidet sich aber nicht nur durch ihr abenteuerliches Gebahren und ihr verwegenes Aussehen, sondern sie hat auch inre eigene Sprache.

Inre Sprache war kurz, von Schlagwortern beherrscht, zerhackt und zerrissen wie die FeuerstoBe ihrer Maschinengewehre, die Worte gepragt und voll Erdkraft. boerall wo Manner im Ursprunglichen sich finden, entstehen solche Sprachen. 33

Wie so oft, operiert Junger auch hier mit Halbwahrheiten. Selbstverstandlich hat seine Rasse in den Jahren des Grabenkampfes eine eigene Sprache entwickelt. Aber auch dies ist nicht etwas, was seiner Rasse eigentumlich ist, sondern labt sich bei jeder abgeschlossenen Gruppe finden. Kinder und Jugendliche sprechen ihre eigene Sprache. Ein Tagelohner wird anders sprechen als ein GroBgrundbesitzer. oft genug geht dieser Unterschied so weit, daB eine gemeinsame Kommunikationsbasis unmoglich wird. Aber Sprache ist nur Aus- 
druck, nicht Sinn. Zwangslaufig wird jede Gruppe das zum Ausdruck bringen, was ihr am vordergrundigsten erschein sie schafft sich ihre eigene Sprache, gepragt durch die IImgebung in der sie wurzelt. Sprache ist Ausdruck des Menschen, sie wird durch ihn geschaffen, aber nur soweit, wie der Mensch selbst durch seine Umgebung geschaffen wird.

Bedeutsam ist, daB beim. Zusammenkommen der verschiedenen Gruppen kein Austausch der Sprache stattfindet, oder zumindest von Junger nicht erwahnt wird, sondern daB wiederum jede Gruppe, oder hier doch wenigstens die neue Rasse, ihre eigene, neue Sprache formt.

Das Menschenbild in seiner Kriegsdarstellung war begrenzt auf die Wiedergabe des auBeren Verhaltens und des Seelenzustandes des Landsknechts. Von der groBen Bedeutung des Krieges fur den burgerlichen Intellektuellen, die im zusammentreffen mit Angehorigen anderer gesellschaftlicher Klassen and Schichten, im Kennenlernen ihrer Lebensart und Denkweise lag - sie spielt eine bedeutende Rolle in anderen literarischen Darstellungen des Krieges - ist bei Junger nichts spurbar. $34^{4}$

Das, was fur andere Kriegsteilnehmer oft das einzige positive Erlebnis im Krieg war, enthalt fur Junger keinerlei Bedeutung. Krieg heiBt fur inn das Erzeugen einer neuen Rasse und nicht das Zusammenkommen vieler bestehender.

Auch hier bestatigt er selbst die Worte vom Krieg als dem Vater aller Dinge. Die sunne eben jenes Vaters machen die neue Rasse aus.

Wenn ich beobachte, wie sie gertuschlos. Gassen in den Drahtverhau schneiden, Sturmstufen graben, Leuchtuhren vergleichen, nach den Gestirnen die Nordrichtung 
bestimmen, dann Uberkommt mich die Erkenntnis, Das ist der neue Mensch, der Sturmpionier, die Auslese Mitteleuropas, Eine ganz neue Rasse, klug, stark und willensvoll. Was hier im Kampfe als Erscheinung sich offenbart, wird morgen die Achse sein, um die das Leben schneller und schneller schwirrt. 35

Junger wiederholt hier zum Teil auf den Wortlaut genau, was er im Vorwort zum Krieg schlechthin gesagt hat. Deutlich wird dabei, daB Person oder Ausfuhrender und Sache selbst immer mehr ineinander ubergehen und sich schlieblich nicht mehr unterscheiden und trennen lassen.

Wieder ist Jungers Beschreibung der Rasse nur vage, was die rein auBerliche oder erfaBbare Erscheinung angeht. Es labt sich daraus schlieBen, daB Junger weder dem Aussehen, noch dem Intellekt und Geistigen seiner Rasse groBe Bedeutung beimiBt. Was ihr innewoht, und was auch immer wieder hervorgehoben wird, ist ihr besonderes Verhaltnis zum Ursprunglichen und zu den eigentlichen Kraften.

Die Angehorigen dieser neuen Rasse ermangeln der Bildung ebenso wie der Individualitat, der Freiheit ebenso wie der Religion, und auch Ideen, fur die zu kampfen sich lohnte, sind in ihrem Herzen nur sparlich anwesend. Dagegen ist das Element in ihnen zu prachtvollem Wuchs gediehen, im Blutdurst, in der abenteuerlichen Unbekummertheit um den Tod, in der bedenkenlosen
vitalitat und in der kraftigen Nahe zum Schmerz. 36

Mit seiner Verbundenheit zum Elementaren wird der neue Mensch der Sphare der Realitaten entzogen. Nur wer selbst das UrSein erfahren hat, kann uber den Menschen ein Urteil abgeben, ja nur der kann ihn im Grunde eigentlich verstehen. 
Der Burger steht dem neuen Menschen ebenso unverstandig gegenuber wie dem Krieg selbst. Allenfalls bemuht er sich noch, Verstundnis fur das Geschehen aufzubringen, aber das eigentliche Kriegserlebnis vollzieht sich auBerhalb seines Erfahrungsbereichs. Nur die neue Rasse ist vollauf fuhig das innere Erlebnis zu haben. Das ist der wahre Zusammenhang zwischen ihren einzelnen Gliedern. Aus dieser Haltung heraus kann Junger auch den Anspruch ableiten, daB nur bestimmte Dichter das Recht haben uber den Krieg zu schreiben. "Wer darf vom Krieg reden, der nicht in unserem Ringe stand?" 37 Junger macht es im Verlauf seiner Kriegsbllcher nur zu klar, daB der neue Mensch allein die Berechtigung dazu trägt, denn er allein weiB um die ungeheuerlichen vorgange, die sich hier vollziehen.

Der wahre Krieger sieht im Krieg nicht so sehr das Ungewohnliche, als viel mehr das Normale. Wohl kann er sich auf eine perverse Art und Weise an Dingen erfreuen, die jedem anderen einen Schauer des Grauens den Rücken hinunter jagen wdrden. Es ist dies aber nicht so sehr eine Freude an dem Ungewohnlichen, als Freude am Leben schlechthin. Denn Krieg wird ja fur ihn zum Normalzustand und wird schlieBlich als das reinste Leben angesehen.

Auch Jungers Krieg findet wie der anderer Schriftsteller auf einer realen Ebene statt. Aber das ist fur den wahren Helden nicht das, was den Krieg eigentlich ausmacht. Was sonst leicht als den Krieg besonders charakterisierend dargestellt wird, erhalt hier ganz gewohnlichen, beiluufigen Charakter. 
"Du Karl, du hast doch schon Gefechte mitgemacht.
Wie ist dern das eigentlich, wenn man so die Kugeln
pfeifen hort?" - "Das? - Nichts Besonderes - das
klingt am besten, wenn mans in den Schmokern liest.
Ich habe noch nie "ne Kugel pfeifen gehort; die
Kerle haben alle gute Gewehre, da gibts bloB'n Knall. "38

Es ist fur Junger ganz selbstverstandlich, daB Krieg kein Massenerlebnis sein kann, selbst wenn Unzuhlige direkt oder indirekt daran beteiligt sind. Denn Ziel des Krieges ist es, den Menschen zu formen, der fur den weiteren Verlauf der Geschichte verantwortlich ist. Das kannn nie in der Masse geschehen. Immer werden dazu Fuhrer notwendig sein und die neuen Fuhrer werden hier herangebildet.

GewiB waren es nur wenige Erlesene, in denen so gedrangt der Krieg sich ballte, doch wird der Geist einer zeit ja immer nur von Einzelnen getragen. 39

Sicher hat Junger mit dieser Feststellung recht, aber es ist interessant zu verfolgen, warum er gerade seine Elite dazu pradestiniert, diese Aufgabe zu Ubernehmen. Seine Rasse ist eben nicht nur eine spezielle Gruppe, die sich im Krieg herausgebildet hat und die bei Kriegsende wieder in Vergessenheit geraten wird. Sondern sie war zu weit Hoherem erlesen, und Krieg ist nur die entscheidende Entwicklungsstufe. Es ist der Zeitpunkt, an dem der Mensch der Elite seine Bewahrungsprobe ablegen muB. Es ist dies keine Auffassung, die Junger allein eigentumlich ist. Schon oft wurde Krieg als ein Erlebnis betrachtet, das die Spreu vom Weizen sondert. Allein die Beharrlichkeit mit der Junger seine Auf fassung vertritt, macht sie 
so ungewthnlich. Auch dies hat wiederum zur Folge, daB sich die Zahl derer, die sich als Manner qualifizieren, im Verlauf des Krieges stromlinienfurmig verjungt. "Im Laufe von vier Jahren schmolz das Feuer ein immer reineres, ein immer kuhneres Kriegertum heraus."40 Da nach Jungers Meinung hier eine positive Auswahl erfolgt, bleibt, sofern der Krieg nur lange genug dauert, am SchluB nur wirklich der Beste Ubrig. Was Junger so stark als Gesetz des Krieges feiert, ist jedoch nichts weiter, als primitivster Darwinismus.

Bei Junger uberlebt weder der, der durch reine korperkraft der sturkste ist, noch der, der sich durch einen besonders scharfen Intellekt auszeichnet. Sein neuer Mensch greift vielmehr weit in die Ursprunge der Zivilisation zuruck. Nur. wer sich den Urtrieben verbunden sieht, nur wer die Kraft des Elementaren in sich walten laBt, kann Mitglied der neuen Rasse werden.

\section{KAMERADEN}

Weite Teile seines Werkes widmet Ernst Junger der Beschreibung seiner Kameraden. Der Kamerad ist nicht nur jemand, der zufallig in der gleichen stellung mit ihm am Krieg teilnimmt, sondern es ist jemand, der Jungers Idealbild des Menschen am ehesten entspricht. Junger ist sich daruber bewuBt, welch wichtigen Teil diese Gemeinschaft innerhalb eines Krieges einnimmt. Ohne den Kamerad, nur auf sich allein und die Technik der Kriegsmaschinerie angewiesen, wtlrde selbst der Beste unter ihnen nur schwerlich Uberleben. Zwar konnte er das 
Abenteuer physisch vielleicht bestehen, aber seelisch wurde er langsam zugrunde gerichtet. Erst die Gemeinschaft gibt ihm Halt und Starke. Sie wird zum Familienersatz. Einerseits beschttrt sie ihn, andererseits kann das Individumm vollkommen in ihrer Anonymitat untertauchen. Allerdings ahnelt sie weniger der Familie in unserem heutigen Sinne, als einer mittelalterlichen familia. Daher ist es verstundlich, daB Junger auch Mitglieder einbeziehen kann, zu denen er sonst jede Verbindung ablehnen welrde.

Kameradschaft verbindet ihn mit seinem Burschen ebenso wie mit offizieren.

Innerhalb der strengen Zucht des Heeres, die alles umspannte, hat der lebendige Volkszusammenhang zwei Grundformen ausgepragt, die Kameradschaft von Mann zu Mann und die Bindung, Fuhrertum und Gefolgschaft. 41

Beides war zum Uberleben notwendig. Es ist selbstverstundlich, daB die Kameradschaft von Mann zu Mann sich in erster Linie innerhalb der einzelnen sozialen Stande, die das Heer aus dem burgerlichen Dasein ubernommen hatte, fortsetzte. Der offizier fand zu offizier, der einfache soldat zum einfachen Soldaten. Die andere Form der Kameradschaft ging uber diese Grenzen hinweg, der einfache Soldat druckte seine Zugehorigkeit zum offizier damit aus. Sicher mogen sich die Grenzen zeitweise verwischt haben, aber grundsutzlich bestand diese Haltung whrend des ganzen Krieges. Junger selbst beschreibt dieses feudalistisch anmutende Verhaltnis immer wieder, besonders, wenn er auf seinen 
eigenen Burschen zu sprechen kommt.

Er besaB nicht, wie etwa Haller, Sinn fur das Abenteuer, aber er folgte mir im Gefecht wie einer der alten Lehnsleute nach, und er sah sein Amt in der Sorge fur meine Person. Lang nach dem Krieg bat er mich um ein Bild, "damit er seinen Enkeln von seinem Leutnant erzuhlen kunne". Ich verdanke inm einen Einblick in die ruhenden Machte, wie sie das Volk in def Cestalt des Landwehrmannes zum Kampfe stellt. 42

Wieder wird deutlich, daB Junger hier nicht die Gelegenheit ergreift, Dinge kennenzulernen, die ihm normalerweise nicht zuganglich waren. Fur das fruhere Leben seines Burschen hat er keine Verwendung; die soziale Ausein andersetzung findet nicht statt. Ihm genugt es, einen Einblick in die "ruhenden Machte" zu werfen, was auch immer er darunter verstehen mag, und im ubrigen alles beim alten zu belassen.

Seine Kameradschaft dem Burschen gegenuber genugt sich darin, mit einer naturlichen Selbstverstandlichkeit dessen Hilfsleis tungen anzunehmen.

Oft genug, wenn die Verpflegung knapp wurde, fand $i c h$ auf meinem Tisch ein Stuck Butter vor von einem Mann aus der Kompanie, der nicht genannt sein wollte und der doch unschwer zu erraten war. 43

Wahrscheinlich bis in die seele geruhrt nahm Junger diese Liebesbezeugung an, anstatt dem guten Mann seine Butter zu belassen. Es durfte unschwer zu erraten sein, daB es fur seinen Burschen weit schwieriger war, kraftigende Nahrung zu erhalten, als fur den offizier junger. Aber daruber macht er sich keine Gedanken. 
Gewi $B$ ist auch dem Burschen vorzuwerfen, daB er seine untergebene und unterwurfige Haltung auch dann noch beibehalt, wenn dazu kein auBerer 2 wang mehr besteht. Aber es ratte wohl Junger obgelegen, diese Einstellung zu korrigieren und ihr Verhaltnis in normale, zwischenmenschliche Beziehungen zu leiten. Das jedoch hatte bedeutet, daB er von seinen ruhmgeschwangerten Hohen zur Ebene des einfachen Mannes herabsteigen muBte, und eben dazu ist Junger nicht in der Lage. So labt er sich lieber weiter bedienen und stellt seine eigenen Theorien uber das niedersachsische Wesen auf.

Mein Bursche, der treue Knigge, war trotz allem Zureden nicht zu bewegen, sein Nachtlager im warmen Wohnzimmer aufzuschlagen, sondern wollte durchaus in der kalten Kuche schlafen - ein bezeichnender $7 \mathrm{ug}$ fur die unseren
Niedersachsen eigene Zuruckhaltung.

Woher leitet Junger die Berechtigung $a b$, hier mit Begriffen wie "unsere Niedersachsen" zu operieren?

Seine Kameradschaft ist kein gesundes Verhaltnis zwischen zwei Menschen. Es ahnelt vielmehr einem Herr-Knecht-Verhaltnis. Der Bursche ist vollkommen in seiner Gewalt, und kunnte sich aus dem Verhaltnis selbst dann nicht befreien, wenn er es wollte. Es mag sogar sein, daB sich der Bursche des Unnaturlichen seiner eigenen Haltung gar nicht bewuBt ist. Junger jedoch weiB genau, mit was fur einer situation er es zu tun hat, aber es erwachsen ihm daraus keinerlei moralische und ethische 2 weifel, im Gegenteil erhebt er gerade das Unnaturliche zum Selbstverstandichen. 
Hier fand ich auch meinen Burschen - ein neuer Beweis fur Winkes Zuverlassigkeit. Er war, nachdem er mich aus den Augen verloren hatte, am Bahndamm verwundet worden. Bevor er sich ins Lazarett und ron dort auf seinen westfulischen Hof begab, ruhte er nicht eher, als bis er die ihm anvertrauten Sachen in meinem Handen wuBte. Daran erkannte ich ihn; er war weniger mein Bursche als mein alterer Kamerad. 45

Mit einer Selbstaufgabe, die an Stupiditat grenzt, wertet der Bursche noch im Augenblick der Verwundung die materiellen Dinge seines Herrn hoher als seine eigene Gesundheit. Alles was ihm Junger dafur zu bieten hat, ist die zweifelhafte Auszeichnung mehr sein Kamerad als sein Vorgesetzter zu sein. Wann immer Junger von seinem Burschen spricht, wird deutlich, daB inr Verhaltnis recht einseitig ist. An keiner Stelle wird die Butter erwahnt, die sich Junger fur seinen Burschen vom Munde abspart. Das Verhaltnis, das nichts weiter als Ausnutzung des Untergebenen durch den Hohergestellten ist, wird zur Abmilderung als Kameradschaft geschildert. Aus Jungers gesamter Haltung weniger privilegierten Bevolkerungsschichten gegenuber, kann allerdings gar nichts anderes folgern. Dennoch ist es erstaunlich, mit welcher Unverfrorenheit er vermag, diesem Verhaltnis den Mantel der Kameradschaft umzuhangen. Schon der Junger der Fremdenlegion ist sich der Kraft der Kameradschaft bewuBt. Im Kameraden sieht Junger einen Menschen, der inm selbst Gesellschaft und innere Starke verleiht.

Mit einem lebhaften Gefunl der Freude begrubte ich die Aussicht auf Kameradschaft, die sich so unerwartet bot. An der Warme mit der mir das Blut zu Herzen schoB, merkte ich, daB ich, mehr als ich ahnte, nach 
meiner heimlichen Wande fung der Gesellschaft eines Menschen bedurftig war.

War das Verhaltnis zwischen Offizier und Bursche eines, das zwei Ebenen einschloB, der sozial Hoohergestellte gegenuber dem Abhangigen, so ist hier der Begriff der Kameradschaft auf ein Verhaltnis zwischen zwei gleichgestellten Menschen zu beziehen. Dabei braucht es nun durchaus nicht ein Verhaltnis von Offizier zu Offizier zu sein. Entscheidend ist vielmehr, daB der Kamerad ebenso wie Junger zur Gruppe des neuen Menschen zu zahlen ist.

Der Bursche als Kamerad ist Mitglied der familia, aber wenn Junger von dem anderen Kameraden spricht, so wird dieser Begriff plotzlich eingeengt und kommt unserer heutigen Auffassung von Familie viel naher.

Der Schlaf war schwer und beklommen; die in der undurchdringlichen Dunkelheit rings ums das Haus niederfallenden Brisanzgeschosse riefen inmitten der toten Landschaft ein unsagliches Gefuhlt der Einsamkeit und Verlassenheit hervor. Ich schmiegte mich unwillkuf-
lich an einen Mann der neben mir auf der Pritsche lag.

Auch hier nutzt Junger letztlich nur wieder einen anderen Menschen aus, aber zugleich ist es trostlich zu erfahren, daB Junger noch so menschliche Regungen wie Einsamkeit und Verlassenheit hat. Er schmiegt sich an diesen Mann, wie vielleicht ein Kind zur Mutter drangen mag. Der Kamerad gibt ihm ein Gefuhl der Geborgenheit und der Sicherheit. Fruher hatten ihm Elternhaus und Schule diese Sicherheit gegeben. 
Gerade daraus hatte er ausbrechen wollen, weil inm diese welt zu burgerlich erschien. Aber als er dann wirklich den Bruch zu vollziehen versucht, nimmt er die Sicherheit ebenco mit sich wie sein elitures Denken und seine sozialen MaBstube. Der Hintergrund hat sich geandert, aber Junger vermag nicht, sich den Gegebenheiten anzupassen. Er projiziert nur seine frtheren MaBstabe in eine neue Welt hinein.

Im Verband mit seinen Kameraden fuhlt er sich stark genug, den Krieg zu uberleben.

$A b$ und $z u$, beim Schein einer Leuchtkugel, sah ich Stahlhelm an Stahlhelm, Klinge an Klinge blinken und wurde von einem Gefuhl der Unverletzbarkeit erfulft. Wir konnten zermalmt, aber nicht besiegt werden. 48

Junger erkennt, daB er als Einzelner praktisch unbedeutend ist. wurde er getutet, so wure sein Ansehen vielleicht bei ein paar Kameraden, die ihn besonders gut kannten noch einige zeit wachgehalten, ehe auch das allmahlich verschwindet. Geht jedoch ein ganzes Regiment unter, so wird das in die Geschichte eingehen, und in Jahrhunderten vielleicht noch werden die Annalen davon berichten.

Kameradschaft ist fur ihn in erster Linie zuverlussigkeit. Er braucht das Gefuhl sich ganz jemandem anvertrauen zu kunnen.

Wahrend dieser Tage lernte ich die Manner schatzen, mit denen ich noch zwei Kampfjahre verbringen sollte. - - Dabei kam es fur die Mannschaft eigentlich immer nur darauf an, wenige Schritte zu tun, namlich jene kurze Spanne zu Uberwinden, die den Postenstand von den Stolleneingangen trennt. Diese Schritte aber waren whyrenà der Sekunde der hochsten Feuersteigerung zu tun, die den Angriff vorbereitet und die nur gefunls- 
maBig zu erfassen ist. Die dunkle Welle, die in diesen Nachten haufig und ohne daB ein Befehl moglich gewesen ware, durch das wltende Feuer hinter den Brustwehren flutete, blieb mir im Herzen als ein verborgenes Gleichnis menschlicher Zuverlassigkeit. 49

So ungern Junger dies zugeben mag - er ist kein sturmerischer Abenteurer, der die Welt allein erobern mochte. Er bedarf der Gesellschaft und der Hilfe anderer im Krieg genauso wie im Frieden. Seine Umgebung hat sich vertndert, die Intensitat des Lebens ist gestiegen, aber das Problem ist das gleiche geblieben. Dabei ist es fur Junger unwesentlich, von wem inm diese Hilfe zuteil wird, Eltern, Wandervygeln oder Kameraden im Krieg.

Es ist auffallend, daB er sich in vier Kriegsjahren nicht enger an einen anderen Menschen anschloB. Aber nur selten wird Uberhaupt bei einem Kameraden der Name erwahnt. Der einzelne Kamerad ist fur ihn nicht so wichtig wie die Existenz des Typus des Kameraden. Es besteht keine personliche Bindung fur ihn zum Kameraden. Was sie verbindet ist vielmehr das Ziel. Der Kamerad selbst ist auswechselbar und ersetzbar. Wichtig ist nur, daB er Uberhaupt da ist. Der Einzige, der dabei eine Ausnahme darstellt, ist sein Bruder Ernst. Ansonsten interessiert ihn der Mensch im anderen Kameraden herzlich wenig. Wichtig ist nur, daB die Kameraden sich vereinigen konnen, um gefestigter auf ihr ziel hinzuarbeiten. "Wir sind Kameraden wie nur Soldaten es sein kunnen, durch Tat, Blut und Gesinnung zu einem Korper und einem willen verwachsen.50 
Junger vermag nicht zu erkennen, daB dies eine kunstliche Gemeinschaft ist, die ihren einzigen Zusammenhalt aus der Tatsache des Krieges erfuhrt. Eliminiert man den Krieg, so wird auch die Gemeinschaft wie ein lebloses Ding auseinanderfallen.

So hat diese Gemeinschaft im Grunde viel weniger Kraft als diejenigen, denen er ursprunglich zu entrinnen suchte. Elternhaus und Schule waren naturlich gewachsen und hatten sich langsam zu dem entwickelt, was sie sind. Junger wird erkennen mussen, daB seine Gemeinschaft, in der er sich so sicher geglaubt hat, den Krieg selbst kaum Uberleben wird. Die Kameradschaft ist nichts weiter als die Hoffnung auf ein biBchen Sicherheit.

FEIND

Junger hat sich schon fruh im westlichen Ausland einen Namen gemacht. Seine Kriegsberichte wurden 1929 ins Englische Ubersetzt, erreichten auch dort hohe Auflagenzahlen und erfreuten sich groBer Beliebtheit. Alș seine Bucher 1945 in der britischen Besatzungszone in Deutschland verboten waren, wurden sie in London gedruckt und verbreitet. Mit ein Grund fur diese Popularitat mag die Tatsache sein, daB Junger von der herkommlichen Darstellungsweise des Feindes erheblich abweicht.

Seine Kriegswerke zeichnen kein schwarz-weiB Bild mit dem Feind auf der einen, dem deutschen Heer auf der anderen Seite. Das war auch gar nicht Jungers Anliegen. Ihm geht es darum, 
den neuen Menschen und seine Entwicklung aufzuzeigen. Wohl tbt er am Gegner Kritik, aber nur dort und in der Weise, wie er sie auch auf Soldaten des eigenen Heeres anzuwenden bereit ist. GleichermaBen zeigt er die Verbundenheit mit dem Feind an verschiedenen Stellen und erwahnt mehrmals die Gemeinsamkeiten seiner Munner und die des Gegners.

Der wertfreie Blick erfaBt die Gegner in ihrem gemeinsamen, aber unbewuBten, leidenschaftlichen und todbringenden Dienst am Kommenden, das sie durch ihren Kampf verwirklichen helfen. Diese unbewuBte Gemeinsamkeit im Opfer des Kampfes ist die tiefe Bruderlickheit des Lebens, von der Junger zuweilen spricht. 51

Junger sah im Gegner keine hinterhaltige Bestie, die unter allen Umstunden beseitigt werden muBte. Durch die Kriegssituation bedingt, ist er zwar bereit, den Feind umzubringen, aber er erwartet auch von ihm nichts anderes und erkennt dies als ein Gesetz des Krieges an, dessen Logik Uber alle zweifel erhaben ist.

Ich war im Krieg immer bestrebt, den Gegner ohne HaB zu betrachten und ihn als Mann seinem Mute entsprechend zu schatzen. Ich bemuhte mich, ihn im Kampf aufzusuchen, um inn $z u$ toten und erwartete auch von inm nichts anderes. Niemals aber habe ich niedrig von inm gedacht. Wenn mir spater Gefangene in die Hande fielen, fuhlte ich mich fur inre Sicherheit verantwortlich und suchte fur sie zu tun, was in meinen Kraften stand. 52

Sein Verhaltnis zum Gegner ist nicht durch Emotionen beschwert und verzerrt. Rein verstandesmaBig erkennt er ihn als Mann an, der gleich ihm seine Pflicht tut. Es ist deutlich, daB Junger seine Pflicht nicht als einen Dienst am Vaterland erkennt. 
$\mathrm{Zu}$ derart gefuhlsgeschwangerten Uberlegungen wurde er sich nie herablassen. Er betrachtet sie als einen Dienst fur den Krieg, in dessen totaler Perspektive Seiten und Nationalitaten unwichtig sind.

Junger sucht die Auseinandersetzung mit dem Feind. Fur ihn ist der Kampf nicht so sehr eine Frage des Uberlebens, sondern eine Frage nach der Macht des Sturkeren. "Auch hier hatten wir wieder wie Uberall wo wir Englundern begegneten, den erfreulichen Eindruck kuhner Mannlichkeit."53 Alle Kamfenden stehen mitten in der Evolution aus der nur der Starkste siegreich hervortreten kann. Junger braucht die Auseinandersetzung mit dem Gegner, um seine eigene Starke bestatigt zu sehen. Daruberhinaus glaubt er, daB eine stetig wiederkehrende kriegerische Auseinandersetzung den einzelnen volkern nur Gutes bringen kann. Zu leicht, befurchtet er, kunnten sie sonst in stumpfe Tragheit versinken, aus der sie nur schwer wieder zu befreien waren. Nur solange sie sich in auBerster physischer und psychischer Anstrengung verhalten, gelingt es ihnen, ihre Sinne wachzuhalten und zu schurfen.

Was waren wir ohne diese verwegene und rucksichtslose Nachbarschaft, die uns alle funfaig Jahre den Rost von den Klingen fegt? Europa als Flachland, grun und beweidet, soviel gutmutige Tiere darauf als irgend fressen konnen. Solange germanisches und gailisches Blut durch Herzen und Hirne kreist, wird dieser Kelch an uns vorubergehen! 54

So gesehen stellt die eigentliche Auseinandersetzung schon fast einen Anti-Klimax dar. Sie ist zwar notwendige Folge, aber im Grunde sanktioniert sie nur, was sich langst voll- 
zogen hat. Der Feind ist ihm nur Mittel zum Zweck, denn an ihm kann er offentlich seine Uberlegenheit beweissen.

Da Junger ihn braucht, kann er den Feind auch gar nicht hassen. Seine Haltung entspringt nicht einer plotzlich aufkeimenden Menschenliebe, sondern der Erkenntnis, daB er fur ihn ebenso bedeutsam ist, wie die eigenen Kameraden. Daher muten auch seine wiederholten Beteuerungen jeglicher Abwesenheit eines emotionellen Engagements fast naiv an.

Tatskchlich, ich liege in einem Bett, in einem vorzuglichen Bett sogar. Das verstehen sie, die Franzosen. Sind Uberhaupt Lebenskunstler. Eigentlich recht gefallige Leute. Ich hasse sie nicht. 55

Junger ist der Pazifist in den eigenen Reihen mehr zuwider, als der Krieger in den Reihen des Gegners.

DaB man den Gegner achten kann und ihn trotzdem bekmpfen, nicht als Menschen sondern als reines Prinzip, daB man fur eine Idee einstehen kann mit allen Mitteln des Geistes und der Gewalt bis zum Flammenwurf und zum Gasangriff, das werden sie nie verstehen. Daruber kann man sich nur mit Munnern unterhalten. Man totet als denkender Mensch nicht ohne weiteres. Je mehr man sich dem Leben durch Muskel, Herz und Hirn verbunden fuhlt, desto hohere Achtung empfindet man vor ihm. 56

Junger vergiBt hier, daB sterben fur ihn nur leben bis zur auBersten Konsequenz heiBt. Der Tod ist kein abgetrenntes Ereignis, das nach dem Ieben kommt, sondern der Hohepunkt des Lebens Uberhaupt, ist integrierter Bestandteil dessen. Er bekampft auch den Gegner nicht als Prinzip, sondern der Gegner ist ebenso Teil des Prinzips wie er selbst. Der Sieg uber den Gegner ist fur ihn gleichbedeutend mit der eigenen Selbstuber- 
windung.

Junger sucht den Kampf. Wo ihm dieser versagt wird, hat er fur den Feind nicht mehr Verwendung als fur Leute der eigenen Seite, die seinem Ideal des Kriegers nicht entsprechen können oder wollen.

Vor dem Abschnitt des ersten Zuges erschienen bei Einbruch der Dunkelheit zwei englische Essenholer, die sich verlaufen hatten. Sie naherten sich mit groBer Gemutlichkeit, der eine hielt ein rundes EBgefaB, der andere einen langen Kessel voll Tee in der Hand. Beide wurden auf ktrzeste Entfernung niedergeschossen, der eine schlug mit dem oberkorper in den Hohlweg, whrhrend seine Beine auf der Buschung liegenblieben. Gefangene zu machen war in diesem Inferno kaum moglich, und wie hatte man sie durch die Sperrfeuerzone bringen sollen? 5 ?

Obwohl hier versucht wird das ErschieBen der beiden Englander aus der Situation heraus zu rechtfertigen oder doch zumindest zu erklurer, scheint fast so etwas wie Enttuuschung in Jungers stimme zu liegen. Der Tod dieser Manner mutet gleichsam als gerechte Strafe dafur an, daB sie so unkriegerisch auftreten. Ein Jungerscher Kampfer gibt sich nicht mit solchen Banalitaten wie Essenholen ab, er verlauft sich auch nicht, und statt Gemutlichkeit legt er Mut an den Tag. Hier wird der unpersonliche Junger fast emotionell. Solange es um das Prinzip einer Sache geht, ist er von einer erstaunlichen Kalte, aber sowie dieses Prinzip durchkreuzt wird, treten plotzlich Gefuhle auf. Einen Gegner, der im entmenschlichten Kampf seinen Mann steht, weiB er zu schatzen, aber sowie der Gegner menschliche Schwachen zeigt, hat Junger fur ihn keine verwendung mehr. An ihm kann er sich 
nicht mehr selbst beweisen. Obgleich er behauptet, Leben, auch das gegnerische, schatzen gelernt zu haben, zeigt er dafur kein Verstundnis, wenn es seinen Ideen zuwiderluuft.

\section{ETAPPE}

Wir haben festgestellt, daB bei Junger die geistige Verbindung zum Feind unter Umstanden viel enger ist, als die Verbindung zu Mannern der eigenen Truppe. Das Entscheidende ist fur ihn, ob er in seinem Gegenuber den neuen Menschen erkennt.

Jungers Kriegsjahre ahneln oft mehr einer verzweifelten Suche nach dem neuen Menschen als einem Kampf ums Uberleben. So wie er Uberzeugt ist, diesen Menschen auch in den Reihen des Feindes zu finden, so ist er auch uberzeugt, inn gewiBlich nicht in der Heimat oder auf schreibstubenposten zu finden. Krieg is zur zeugung des neuen Menschen unerlaBlich, und Krieg bedeutet bei Junger immer nur die Front. So ist es nicht verwunderlich, wenn er den Ereignissen auBerhalb der Front nur werig Beachtung zukommen laBt und den Menschen dort, wenn er ihn uberhaupt erwahnt, stets nur verachtlich behandelt.

Der Mensch im Kriege ist im tiefsten einsam; das private Leben des einzelnen verschwindet unter dem grauen Tuch, das sie alle einhullt. Alle Bindungen zur Vergangenheit sind abgerissen. Selbst die Nachststehenden, die zu Hause zuruckgeblieben sind, werden dem Soldaten durch sein gewaltiges Erleben fremd, und wenn er im Urlaub auf kurze Zeit zu ihnen zurllckkommt, kann er kaum mehr das alte Verhultnis zu ihnen gewinnen. Mit der Zukunft zu rechnen aber 

lohnt sich nicht, wenn einep jede Stunde die
todliche Kugel treffen kan. 58

Sicher hat sich der Kampfer in einem stundigen Gefuhl der Unsicherheit befunden. Junger jedoch scheint dieses Gefuhl bewuBt zu kultivieren, scheint dartber hinaus stolz darauf zu sein, eben nicht zur groBen Masse der Unbekannten zu gehoren, sondern doch hier immerhin aktiv am wirklichen Leben teilzunehmen. Damit laBt er es aber nicht bewenden, sondern leitet daraus wiederum Ansprtiche $a b$, daB der neue Mensch nur im Kriege, d.h. an der Front, entstehen kann, oder daB nur derjenige, der wie er am Krieg teilgenommen hat, berechtigt ist, uber den Krieg zu schreiben.

Friedrich Bethge laBt in seinem Schauspiel Reims einen gewissen Hauptmann Junger auftreten, der als einer der kthnsten Offiziere der Heeresgruppe gilt. Dieser Hauptmann wirkt als Verteidiger in einem Verfahren uber angebliche Desertation mit. Bethge laBt ihn dabei sagen,

Der Herr Vorsitzende zeiht den Angeklagten der Feigheit. Ich meine: Uber die Front vermag nur die Front zu urteilen. Stabe, Herr Oberst, sind fur die Front schon Etappe. Auf funf lieter Entfernung nehmen sich Granateinschluge anders aus als durchs Scherenfernrohr. . . Front und Stybe reden in verschiedener zunge. 59

Auf genau dem gleichen Standpunkt steht auch der Leutnant Junger. Hier wird jedoch auch die Gefuhrlichkeit seiner Auffassung vom Anders-Sein des Frontsoldaten besonders deutlich. Hier geht es um Rechtsprechung, und der verteidiger gibt dem 
Vorsitzenden nur zu deutlich zu verstehen, daB ein Angeklagter nur von einem ihm Ebenturtigen abgeurteilt werden kann. Es geht nicht mehr darum, den Krieg auf diese oder jene Weise darzustellen, sondern es geht um Wahrheitsfindung. Ernst Junger kannte dieses Schauspiel und war sich seiner Rolle darin bewuBt. Er selbst sollte erst viel spater Gelgenheit dazu haben, dieses von ihm selbst aufgestellte Gesetz in Anspruch nehmen zu mussen, als es numlich um den Entnazifizierungsproze $B$ ging, und er sich standhaft weigerte, daran tejizunehrnen.

In einem anderen stuck, diesmal von einem Franzosen, sagt ein junger kriegsteilnehmer uber den Krieg:

$\mathrm{Ja}$, nur ist das, was man sich vorstellt, immer entweder weniger schrecklich oder noch schlimmer als die Wirklichkeit, jedenfalls anders. Sich eing Sache vorstellen heiBt diese Sache verfulschen.

Wiederum wird behauptet, daB nur einer, der eine Sache selbst erlebt hat, wirklichkeitsgetreu daruber zu berichten weiB.

Diese Einstellung war zur zeit des Erscheinens der Jungerschen Kriegsromane weit verbreitet und keineswegs auf Junger allein beschrankt. Junger jedoch hat diese These in seinem Werk noch erhartet. Damit kann er erfolgreich jeglicher Kritik von auBen die Spitze brechen. Der Kreis der Kriegskritiker kann auf einen ganz kleinen Teil der Bevolkerung eingeschrankt werden. Nach Jungers Auffassung ist uberhaupt nur der neue Mensch befahigt uber den Krieg zu 
berichten.

Junger sucht eine neue Rasse. Dazu ist auch eine neue Umgebung nutig, die an der Front gegeben ist. Je weiter der Mensch sich jedoch von der Front entfernt, umso mehr werden die Einflusse der frtheren Welt erkennbar. Diese Entwicklung geht von der Front uber den Stab, zur Etappe bis schlieBlich zur Heimat. In der Heimat sind die Grundzuge der Friedenswelt noch am starksten erhalten geblieben. Daraus labt sich die negative Haltung Jungers gegenuber allem, was sich von der Front entfernt vollzieht, ableiten. Da er den Anspruch erhebt, nur der, der am Krieg teilnimmt, sei berechtigt auch uber ihn zu schreiben, muB er diesen Satz auch umgekehrt bestehen lassen, numlich, daB er selbst nicht uber die Heimat schreiben kann. Junger schreibt auch nicht uber die Heimat, aber er macht es sehr deutlich, daB er nichts daruber sagt, weil es fur ihn im Grunde nichts zu sagen gibt.

\section{DER KAMPF}

Hohepunkt des Krieges ist fur den neuen Menschen die tatliche Auseinandersetzung. Fast scheint es, als ob er ihretwillen Uberhaupt nur Krieg fuhrt. Im Kampf wird letztlich entschieden, wer zur neuen Rasse gehort. Daher sehnt der Kampfer die Auseinandersetzung auch immer wieder herbei. Der Kampf ist nicht nur eine willkommene Abwechslung in der Monotonie des Grabendaseins, sondern er ist zur stundigen Selbstbestatigung ebenso notwendig. 
Die kurzen Streifzuge, bei denen man das Herz fest in die Hand nehmen muBte, waren ein gutes Hittel, den Mut zu stahlen und die Eintonigkeit des Grabendaseins zu unterbrechen: Der Soldat darf sich vor allem nicht langweilen.6i

Jede kleinste Abwechslung war Junger willkommen.

Obgleich diese kurzen streifzuge bei weitem nicht an die Elementarmacht der groBen Auseinandersetzung heranreichen, dienen sie doch dazu, den Soldaten standig zu uben. Er muB sich permanent bewuBt sein, in welcher situation er sich befindet. AuBerdem helfen sie, sein monotones Dasein zu unterbrechen. Denn mit der Langeweile konnte auch das Nachdenken einsetzen. Aber Jungers Soldat ist kein denkender soldat, sondern er erledigt seine Aufgabe rein instinktmuBig. Nachdenken und Langeweile signalisieren fur Junger einen Punkt der hochsten Gefahr, bei dem die Existenz seines Typs uberhaupt in Frage gestellt wird.

Zugleich macht die Stellung dem Soldaten seine ganze armselige Existenz bewuBt. Kann er seinen Mut oder sein Heldentum nicht mehr im Kampf unter Beweis stellen, so unterscheidet sich sein Leben oft kaum noch von dem Zuhause. Auch hier gibt es eintunige Arbeiten, die erledigt werden mussen, auch hier gibt es eine soziale Struktur an die er sich halten muB und die er nicht durchbrechen kann, es sei denn im Kampf.

Nach kurzem Aufenthalt beim Regiment hatten wir grundlich die Illusionen verloren, mit denen wir ausgezogen waren. Statt der erhofften Gefahren hatten wir Schmutz, Arbeit und schlaflose Nachte vorgefunden, 
deren Bezwingung ein uns wenig liegendes Heldentum erforderte. Schlimmer noch war die Langeweile, die fur gen Soldaten entnervender als die Nuhe des Todes ist. 62

Der Jungersche Held sucht nach einem Ausweg aus dem Gewohnlichen. Den meint er nur im Kampfe zu finden, denn nach seiner Auffassung unterscheidet sich der Stellungskrieg wenig von seinem fruheren Dasein. In der Sicherheit der Stellung glaubt er eben die Sicherheit anzutreffen, der er zu entrinnen suchte.

Der Kampf wird dem Soldaten wichtiger als alles andere. So nutzt er die zeit zwischen den Kampfen damit aus, sich wiederum auf die nachste Auseinandersetzung vorzubereiten. Dabei verfolgt er zweierlei ziele. Das eine ist ein rein physisches. Die stellung muB in ordnung gealten werden, denn sie kann jederzeit ziel eines Angriffs werden. Eine schlecht instand gehaltene Stellung wurde die Gefahr des Unterlegens um ein Vielfaches erhohen. Zum anderen laBt der Offfizier seine Manschaft Spiele und andere Turnubungen veranstalten, damit der Gemeingeist, der sich im Kampf leicht und wie von selbst einstellt, wachgehalten wird. Auf diesem Zusammengehorigkeitsgefuhl der Munner beruht nach Junger die eigentliche Sicherheit der Stellung. Der Einzelne muB sich der Gemeinschaft verbunden fuhlen, um selbst uberleben zu kunnen und das ziel aller, den Kampf, zu erreichen.

Der Kampf bedeutet fur Junger das eigentliche Leben. Hier reduziert die Natur inre Machte auf das Ursprungliche und 
Elementare.

Im Kampf, im Sterben, in den Stahlgewittern des Grabenkrieges, so lehrte Junger, taucht der Kampfer in die Elementargewalt ein. Er findet zum wahren Sein zurtlck, zu den quellen des Lebens.63

Alles, was der Mensch sich in Jahrhunderten und Jahrtausenden angeeignet hat, wird plotzlich unwichtig. Urkrafte, die er langst verga3, werden wieder freigesetzt. Sie sind es auch, die ihm beim Kampfe und Überleben helfen und Beistand leisten. Im Kampf findet das eigentliche innere Erlebnis statt und der neue Mensch erhalt im Stahlbad seine letzte Weihe. Der Kampf wird in der Entwicklung des Menschen notwendig. Es kann nicht mehr um eine Auseinandersetzung zwischen volkern und Ideologien gehen, denn der neue Mensch braucht den Kampf um seiner selbst willen.

Es kann sich allerdings die Frage aufdrangen, ob die verabsolutierung des Kampfes nicht einen anderen, paradoxen Hintersinn verbirgt, dem wirklichen Kampfe, welcher die Entscheidung im gehaltvollen Fur und Wider erzwingt und damit die Gegner uberhaupt erst zu Gegnern macht, auszuweichen. Denn im Nichts der Gehalte, im "Kampf an sich" wird man vom Gegner nicht getrennt, sondern mit ihm vereint, einfach weil nichts da ist, was trennen kunnte, weil die Gegner eines solchen "nichtigen Kampfes" sich wechselseitig bestutigen, ja einander zur Voraussetzung ihrer Existenz

So erklurt sich die Freude am Kampf. Es ist nicht nur die Freude daruber, daB die Eintonigkeit des Stellungskampfes vortber ist, Kampf ist nicht nur eine andere Form der Kriegsfuhrung, sondern es ist die Freude auf das, was letztlich dem 
Menschen den Zugang zur Elite ermuglicht. Durch den Kampf erst wird die Sache geheiligt.

Der Kampf ist immer noch etwas Heiliges, ein Gottesurteil Uber zwei Ideen. Es liegt in uns, unsere Sache scharfer und scharfer zu vertreten, und so ist Kampf unsere letzte vernunft und nur Erkampftes wahrer Besitz. Keine Frucht wird uns reifen, die nicht in eisernen Sturmen hielt und auch das Beste und Schonste will erst erkampft werden. 6.5

Wie:immer, wenn Junger mit logischen Argumenten nicht weiter kommt, nicht mehr uberzeugen kann, bringt er Emotionelles, Mystisches, Unerklariches ins Spiel. Hier wird Kampf zum "Gottesurteil". Auf diese Weise gelingt es ihm allmahlich, alle Schichten der Bevolkerung anzusprechen. Der religiuse Mensch, der eine Sache durch oberstes Gesetz geheiligt sieht, der Intellektuelle, dem verdeutlicht wird, daB es um Kampf schlechthin geht, der einfache Mensch, dem erzahlt wird, im Kampf wurde er sich aller negativen Zivilisationseinflusse entledigen konnen, und ganz zu seinen Ursprungen, dem Tier im Menschen, zuruckkehren kunnen, sie alle werden von Junger angesprochen. lian fragt sich, ob Junger vieles von dem, was er propagiert bis zur letzten Konsequenz durchgedacht hat. Was heiBt "eine Sache scharfer und scharfer vertreten" anderes als den Aufruf zur langsamen Iiquidation jedes Andersdenkenden? Junger ist $\mathrm{zu}$ keinen Kompromissen bereit. Aber wieder hat er eine IUsung bereit, selbst fur diejenigen, die dem Kampf weniger glucklich entkommen als er. Wir erinnern uns an seine 
Ausfuhrungen vom Krieg als dem Vater aller Dinge. Darauf kommt er jetzt zuruck, wenn er sagt,

Der Kampf ist nicht nur eine Vernichtung, sondern auch die mannlichste Form der Zeugung, und so kumpft nicht einmal der umsonst, welcher fur Irrtumer ficht.

Obwohl es fast den Anschein hat, als wollte Junger sich selbst hier zugleich absichern und Mut zusprechen, ist entscheidender, daB er den Begriff der mannlichen Zeugung wieder aufnimmt. Fur die Frau gibt es in seinem Weltbild, in dem der Kampf solch eine groBe Rolle spielt, keinen Platz. Zwar ist sie rein physisch zur Fortpflanzung der Rasse notwendig, aber das Geistig-Spirituelle ist ausschlieBlich Mannersache. Hierin bestatigt Junger auch, daB der Kampf der eigentliche Kern des Krieges ist. Ohne ihn, kann der neue Mensch nicht entstehen. Zwar ist der Krieg selbst wichtig, aber im Grunde ist der Kampf der Nukleus seiner ganzen Theorie. Damit garantiert er sich selbst den Fortbestand der Rasse.

Der Mensch braucht den Krieg zur Vorbereitung zum Kampf, zur Vorbereitung auf die Gemeinschaft, zur Vorbereitung auf die naturlichen Krafte. Aber dies alles gilt nichts, solange er sich nicht im Karnpf beweisen kann. Aus dieser Auffassung heraus erscheint ihm der Mensch in der Heimat oder der Soldat der Etappe als "Untermensch". So wie der Kampf die Achse des Krieges ist, ist der Zusammen- 
prall im Kampf der Hohepunkt und das Zentrum des Krieges zugleich. Ohne den morderischen Zusammenprall mit dem Gegner wird jeder Kampf zu einem StoB ins Leere.

Ich hatte an einer groBen Kampfhandlung teilgenommen, ohne einen Gegner zu Gesicht bekommen zu haben. Erst viel spater erlebte ich den Zusammenprall, den Gipfelpunkt des Kamfes im Erscheinen der Sturmwellen auf freiem Felde, das fur enscheidende, morderische Augenblicke gje chaotische Leere des Schlachtfeldes
unterbricht. 67

Beim Zusammenprall der Gegner kunnen alle technischen Hilfsgerate weitgehend ausgeschaltet werden. Der Krieg wird entmechanisiert, es wird wieder ein Kampf von Mann zu Mann, bei dem der Einzelne zahlt und sich unter Beweis zu stellen hat. Hohepunkt war fur Junger selbst der Zusammenprall im Graben.

Da hetzten in kumpfenden Rudeln die Auserlesenen von Nationen, furchtlose Sturmer, durch den Dammer, dressiert, auf Pfiff und kurzen Ruf sich in den Tod zu sturzen. Begegneten sich zwei Trupps von solchen Kumpfern in den schmalen Gängen der flammenden Wuste, so prallte die Verkorperung des rucksichtslosesten Willens zweier volker zusammen. Das war der Hohepunkt des Krieges, ein Hohepunkt, der alles Grausige, das zuvor die Nerven zerissen hatte, Ubergipfelte. Eine luhmende Sekunde der Stille, in der sich die Augen trafen, ging voran. Dann trieb ein Schrei hoch, steil, wild, blutrot, der sich in die Gehirne brannte als gluhender, unvergeBlicher Stempel. Dieser Schrei riB Schleier von dunklen, ungeahnten Welten des Gefuhls, er zwang jeden, der ihn horte, vorwarts zu schnellen, um zu toten oder geto tet zu werden. Zitternde Leuchtabfalle hingen uber dem Wurgen, dessen Geist kein Bericht fassen kann und das keinen Zuschauer hatte auBer den in dunkeln winkeln verblutenden, deren aufgerissenen Augen diese wustheit das letzte Bild war, das sie mit hinubertrugen in das groBe Schweigen. 68 
Bei dieser Art des Kampfes ist die Versohnung der Gegner nach der morderischen Schlacht ebenso selbstverstandlich, wie der Kampf erforderlich und :unschenswert war. Es geht ja nicht darum, den Gegner zu toten, obwohl dies zwangslaufig geschehen muB, sondern darum, sich selbst und den anderen $\mathrm{zu}$ beweisen, wer der Sturkste ist. Der Mensch hat als Mensch nur eine untergeordnete Funktion.

Wer so zu des Kampfes Wurzeln grabt und echtes Kumpfertum verehrt, verehre es uberall, auch beim Gegner. Daher sollte Versohnung nach dem Kampf zuerst die Munner der Front umschlieBen. 69

Echtes Kumpfertum, das also ist das Entscheidende hier und nicht Humanitat. So ist diese Geste der Versohnung auch nicht als menschliche Geste zu verstehen. Vielmehr ist sie eine ritterliche Annerkennung dafur, daB der andere sich dem Kampf gestellt hat und so die letzte Probe des neuen Menschen Uberhaupt erst ermoglicht hat. Doppelt stark ist daher auch Jungers verachtung denen gegenuber, die sich dem Kampf entziehen. Dabei macht es keinen Unterschied, ob dies auf der eigenen oder der feindlichen seite geschieht. Wer sich dem Kampf nicht stellt, setzt nicht nur die Kameraden umso groberer Gefahr aus, sondern er versagt auch dem Jungerschen Krieger die MUglichkeit, sein Kampfertum unter Beweis zu stellen.

Da unser Hauflein sehr klein war, versuchte ich, es durch die zahlreichen fuhrungslos umherirrenden Leute zu versturken. Die meisten folgten willig unseren Zurufen, froh, sich anschlieBen zu konnen, whrend andere weitereil- 
ten, nachdem sie èinen Augenblick gestutzt und gesehen hatten, daB es bei uns nichts zu holen gab. In solchen Lagen hurt jede Rucksicht auf. Ich lieB auf sie anschlagen. 70

Felglinge und Druckeberger sind fur Junger Freiwild, das er nach eigenem Belieben meint abschieBen zu kunnen, da sie ihm die MUglichkeit sein Kumpfertum zu beweisen versagen.

Immer wieder verbindet Junger bei der Beschreibung des Krieges reines Ästhetentum mit Brutalitat. Besonders kraB wirkt dieser Gegensatz bei der Beschreibung der Kampfe. Ännlich wie er spater den Bombenhagel auf Paris durch ein Glas Burgunder betrachten wird, sieht und beschreibt er die kumpfe des ersten Weltkrieges.

Der Handgranatenwechsel erinnert an das Florettfechten; man muB dabei Sprunge machen wie beim Ballett. Er ist der todlichste der Zweikampfe, der nur dadurch, daB einer der beiden Gegner in die Luft fliegt, beendet wird. Auch daB beide fallen kann varkommen. 71

Die Tatsache, daB hier ein Kampf auf Leben und Tod gefochten wird, scheint fast nur beiluufig. Wichtiger ist das usthetische Moment des Kampfes. Es ist nicht von ungefuhr, daB Junger bei der Beschreibung des Kampfes auf den Vergleich mit dem Sport oder dem Spiel ausweicht.

Im Wesenszug des Spiels, dem gleichermaBen der Mut des Hasardeurs als auch die festen kegeln einer usthetischen Form innewoinnen, erweist sich die ninilistische Abgrundigkeit von Jungers Heroismus.?2

Sein Kampf, der genau wie das Spiel leicht und unbeschwert 
erscheint, unterliegt dennoch festen Regeln an die sich nach Jungers Auffassung jeder Teilnehmer halten muB. Der Einsatz ist zu hoch, als $d a B$ er willkurlich gefuhrt werden kann. Im Kampf sowohl wie im Sport oder Spiel ist Spannung, die aus der Unsicherheit der Chance entsteht. Selbst wenn sich alle an die Regeln halten, gibt es doch immer Momente, die sich nicht bis ins Detail vorausberechnen lassen. Hier liegt die Chance des Besseren. Der Kampf ist keine Auseinandersetzung zwischen zwei ungleichen Gegnern. Die beiden Kontrahenten sind sich ebenburtig. Allein das Unberechenbare, Gluck, Zufall, Schicksal lassen einen von ihnen als Sieger aus dem Kampf hervorgehen. Und nur der Sieger wird zur neuen Rasse gehoren.

In diesem Kampfe muB der Schwachere am Boden bleiben, whrend der Sieger, die Waffe fester in der Faust, uber den Erschlagenen hinwegtritt, tiefer ins Leben, tiefer in den Kampf. So ist der Aufschrei, den solcher Anprall mit dem des Feindes vermischt, ein Schrei, der sich Herzen entringt, vor denen die Grenzen der Ewigkeit schimmern. 73

Dies endlich ist der wahre Grund fur den Kampf: nur der Kumpfende kann an die Grenzen der Ewigkeit vorstoBen, und nur der Überlebenden kann als Mitglied der neuen Rasse begruBt werden.

Im Krieg geht es also um den edlen Wettkampf, der nicht dazu dienen soll, andere Nationen zu unterdrucken, sondern die Besten jedes Volkes hervorzubringen und $\mathrm{zu}$ vereinen. 
TOD

Bei Jungers Einstellung zum Kampf ist es verstundlich, daB er sich nicht mehr an den althergebrachten Werten orientieren kann. Er muB alte Werte neu gestalten und neue Werte finden. Dies wird besonders deutlich an seiner Haltung zum Tod. Sein Tod ist nicht etwas Bedauerliches. Er ist nichts Beklagenswertes. Sein Tod ist, sofern er ruhmlich war, Vollendung. Beim Anblick seines ersten Toten noch erfaBt Junger ein abgrund tiefes Grauen.

Dann strich es die Kolonne entlang mit Fledermausschwingen, daB Lachen und Zuruf im liunde erstarben. Am Weg zur Seite lag einer holzern und steif mit spitzem, wachsgelbem Gesicht, aus dem die Augen so glusern ins Leere starrten. Der erste Tote, ein unvergeBlicher Augenblick, der das Herzblut zu stockenden Eiskristallen zerfror. Da baumte sich in jedem das Grauen auf als blasser, scheuender Gaul vor nachtlichem Abgrund.74

Aber schon hier wird das asthetisierende Element, das sich spater immer mehr durchsetzen wird, uberdeutlich. Der erste Tote wird zum unvergeBlichen Augenblick, fast als befande Junger sich auf einer vergnugungsreise, und beschriebe uns die Sch ${ }^{2} h e i t$ der Landschaft. Es ist nicht so sehr die Grausamkeit und die Unmenschlichkeit die hier angesprochen wird, als vielmehr die Ungeheuerlichkeit und die UnfaBbarkeit des Geschehenen. Zugleich mischt sich dabei so etwas wie die Unglaubigkeit daruber, daB das Ereignis sich tatsachlich vollzogen hat. Man hat die erste Auseinandersetzung herbeigesehnt und nun endlicherlebt, und hier wird Junger mit 
den Folgen dieses Gefechts konfrontiert.

An den Tod wird nur eine Bedingung gestellt: er muB ruhmlich sein, dann kann er jederzeit kommen. Ohne aweifel gehort der Heldentod fur Junger in jedem Falle dazu.

Der Tod fullt umso leichter, als er nicht so sehr als Lebensende, sondern vielmehr als Hohepunkt des Lebens betrachtet wird.

Der Krieg hatte dem Bilde dieser Iandschaft, ohne seine Lieblichkeit zu zerstoren, heroische und schwermutige Iichter aufgesetzt; der bluhende sonsflub wirkte betuubender und strahlender als

Es fyllt leichter, inmitten einer solchen Natur in die Schlacht zu gehen als aus eirem toten und kalten Winterland heraus. Hier drangt sich auch dem einfachen Gemut die Ahnung auf, daB sein Tod kein Ende ist.75

Junger symbolisiert an der Natur wie er den Tod versteht. Es ist kein dusteres Ende, etwas das gefurchtet verden muB, sondern der Tod ist Teil einer fortlaufenden Entwicklung, Folge nur eines naturlichen Ereignisses. Gleichgultig wo er dem Menschen begegnet, er ist kein zu betrauernder SchluBpunkt des Lebens, sondern kann nur mit diesem zusammen verstanden werden. Nur er gibt dem Leben seinen eigentlichen Sinn und nur im heroischen Tod kann das Leben sich wirklich erfullen.

Besonders im Krieg sollte Sterben Freude sein. Junger trauert den Zeiten nach, wo groBe Kumpfe und heroisches Kriegertum sich in der Zahl der Toten ausdruckten. Im Stellungskampf dagegen wird das Gewaltige des Todes vom Alltag zerschliffen. Umso willkommener sind daher die Tage an denen 
dem Krieger Gelegenheit geboten wird, sein Mannestum ganz unter Beweis zu stellen. 76

Der Tod erst bringt die Vollendung des Lebens. Noch ganz am Ende seines Buches Der Kampf als inneres Erlebnis spricht Junger von dem Verdienst des Todes. Voll tberzeugung nennt er ihn das "huchste vollbringen".

Er ist Bekenntnis, Tat, Erfullung, Glaube, Liebe, Hoffnung und Ziel; er ist auf dieser unvollkommenen Welt ein Vollkommenes und die Vollendung schlechthin. Dabei ist die Sache nichts und die berzeugung alles. Mag einer sterben, in einen zweifellosen Irrtum verbohrt; er hat sein Grobtes geleistet. ??

Diese Aussage wirkt wie ein hilfloser Versuch den Schmerz uber den verlorenen Krieg zu mildern, den Schmerz auch daruber, wie viele Leben hier unnutz vergeudet wurden. Wie immer, wenn Junger eine Sache nicht rational erkluren kann, nimmt er auch hier beim Religiosen zuflucht. 78 Er muB den Massen, die jubelnd in den Krieg gezogen sind etwas anderes anbieten, als nur die Niederlage an der Front und Revolution und Unsicherheit zu Hause. Was er ihnen anbietet, ist die Vorgaukelung des neuen Menschen. Aber da dies die Toten nicht wieder zu neuem Leben erwecken kann, bezieht er den Tod mit in das Leben hinein.

Bis zum Tod ist unser Leben noch unvollkommen, erst der Tod gibt ihm die vollendung. Jungers ekstatischer Held sucht nicht allein den Tod, sondern er sucht den spektakularen Tod, den Tod des auBerordentlichen Menschen. Je nther der Mensch an den Tod herankommt, : umso lebenswerter wird das Leben. Nur 
in unmittelbarer Todesnthe kann es sich wirklich entfalten. So ist Jungers Einstellung in gleicher Weise eine Todessehnsucht und eine Ablehnung des Todes. Eine Sehnsucht deshalb, weil das Leben umso wunschenwerter erscheint, je naher es an den Tod heranruckt. Ablehnen muBte er ihn deswegen, weil er diesem reicherfullten Leben ein Ende bereitet und jede Steigerung unmoglich macht.

Die Nihilisten spielen allesamt mit dem Selbstmord, und wenn sie auch nicht mehr auf ein jenseitiges Paradies hoffen, so wollen sie sich doch wenigsten aus dem empfundenen Nichts in die Empfindungslosigkeit hinuberretten. Das ist nicht Jungers Sache, den vielmehr die Todesnthe - mit einer rauschhaften Daseinsdichte beschenkt.?9

Ich meine, daB Nebel Jungers Einstellung zum Tode richtig erfaBt hat. Im Kriegszustand wird die Idee des Selbstmordes von selbst ad absurdum gefuhrt. Die Aggressionen kunnen sich anderweitig entladen, sie sind nicht mehr primar gegen das eigene Ich gerichtet, und somit bestehen, jedenfalls zum Teil, die Voraussetzungen, die zum selbstmord fuhren, nicht mehr.

Der Kriegertod nun nimmt die Eigenschaft des Opfers an. - Es handelt sich nicht mehr um Feldzuge, also um Aktionen, sondern um die Metzelei als Dauerzust and; . um Knochenmuhlen, die sich Tag und Nacht unverdrossen drehen. Die Dauer aber, diese groBe probe des lienschen, labt jeden Glanz erbleichen. Junger fragt nach dem Sinn, der hoch genug ist, um ein solches Leiden, ein solche Schlachterei zu rechtfertigen. ... Auch die Toten stacheln dies Fragen an. Um ihretwillen kann Junger sich nicht damit abfinden, den Krieg fur einen unsinnigen, zufalligen, der Dummheit oder Gemeinheit weniger Tater entsprungenen ProzeB zu halten. Den Toten muB Ehre erwiesen werden, und deshalb muB man annehmen, daB aych die Akteure unter dem Griff des Weltgeistes handeln.80 
Gerhard Nebel ruckt sich selbst und seinen Autoren hier in gefahrliche Nachbarschaft. Er macht sich zum Fusprecher einer Auge-.um-Auge-, Zahn-um-Zahn-Ideologie. Wenn Jt:nger sich nicht damit abfinden kann, den krieg fur einen unsinnigen, dummen ProzeB zu halten, so liegt eben darin sein entscheidender Fehler. Wiederum entzieht er sich der Realitut. Er muB verschonigen, was er so nicht anerkennen kann. Damit jedoch setzt er eine Bewegung in FluB, die er selbst bald nicht mehr bundigen kunnte. Solange die Kriegstoten nach Ehre und Rechtfertigung rufen und solange Menschen wie Ernst Junger und Gerhard Nebel diesem Ruf Folge leisten, kann das Ergebnis nur immer wieder neue Kriege und mehr Kriegstote heiBen.

Der Mensch im Krieg hat sich der Realitat entzogen. Nur so kann er die stundige Gegenwart des Todes Uberhaupt ertragen. Er befindet sich gleichsam in einem Rauschzustand, der umso intensivierter erfahren wird, je weiter der Mensch sich vom HerkUmmlichen, vom Gewohnten entfernt.

Die todbringende Macht des Krieges packt den jungen Menschen wie ein ungeheurer Rausch. Gerade wenn das Trommelfeuer den einzelnen bis zur Erschopfung und Gleichgultigkeit stumpf gemacht hat, oder wenn die todliche Langeweile und Ausweglosigkeit des Stellungskrieges an den Nerven reiBt, dann ist die Tat im Rausch des Angriffs oder des Abenteuers die Erlosung. 81

Nur dadurch, daB er sich immer weiter von der Wirklichkeit entfernt, meint Junger, dem wirklichen Leben naher zu kommen. 
Dabei scheut sich Junger keineswegs, Bilder des Todes zu beschreiben, die die grausige Wirklichkeit dahinter nur zu deutlich ahnen lassen.

Was half es, daB sie die nachsten mit Sand und Kalk bestreuten oder eine Zeltbahn Uber sie warfen, um dem steten Anblick der schwarzen gedunsenen Gesichter zu entgehen. Es waren zu viele; Uberall stieB der Spaten auf etwas verschuttetes. Alle Geheimnisse des Grabens lagen offen in einer ScheuBlichkeit, vor der die tollsten Traume verblichen. Haare fielen in Buschen von Schadeln wie fahles Laub von herbstlichen Bumen. Manche zergingen in grunliches Fischfleisch, das nachts durch zerissene Uniformen glanzte. Trat man auf sie, so hinterlieB der FuB phosphorische Spuren. Andere wurden zu kalkigen, langsam zerblatternden Mumien gedurrt. Anderen $f l o B$ das Fleisch als rotbraune Gelatine von den Knochen. In schwllen Nachten erwachten geschwollene Kadaver zu gespenstischem Leben, wenn gespannte Gase zischend und sprudelnd den Wunden entwichen. Am furchtbarsten jedoch war das brodelnde GewUhl, das denen entfitromte, die nur noch aus unzahligen wurmern bestanden. 82

So schreibt nur jemand, der den Tod abstrahiert hat und meint, ihn auch rationalisieren zu konnen. Dies sind keine Menschen mehr, deren schauerliches Ende hier kuhl beschrieben wird. Fur Junger sind sie nur noch Werkzeuge einer Idee. Sein pervertierter Asthetizismus hat hier seine grobte und schunste Blute hervorgebracht. Mit einer Gefuhlskalte, die an Gefuhlsroheit grenzt, findet seine Beschreibung der Leichenfelder hier ihren Ausdruck. Zugleich zerstort er hier auch seine eigene Theorie vom Tod als Teil nur des Lebens. Der Tod ist der SchluBpunkt, das physische Ende nur allzu deutlich. Wer jedoch die Sinnlosigkeit dieses Wahnsinns sieht und dennoch an den Krieg als die mannlichste Form der 
Zeugung und als ein Stahlbad glaubt, der wird moglicherweise auch funfundzwanzig Jahre sputer vor Konzentrationslagern keine menschlichen Grauen empfinden konnen, besonders, wenn es auch dann um eine Idee als Dienst an etwas Huherem gehen sollte. Was Junger hier beschreibt sind keine Menschen mehr. Es sind nicht einmal mehr schwachste Abbilder ihrer selbst. Aber es waren einmal Menschen und das beliebt Ernst Junger so geflissentlich zu Ubersehen. Es waren Lebewesen, denen der von Junger so glorifizierte Krieg die Moglichkeit nahm, einen menschlichen und menschenwurdigen Tod $\mathrm{zu}$ sterben.

\section{DAS TIER IM MENSCHEN}

Um eine solche Geisteshaltung dem Menschen und dem Leben gegenuber zu verwirklichen, mussen Krufte freigesetzt werden, die der zivilisierte Mensch seit Jahrtausenden unterdruckt hat. Die Elementarmacht des Krieges fordert vom Menschen, daB er wieder zu seiner primitivsten Urform zuruckkehrt, daB er wieder zur Stufe des Tieres hinabsinkt und allein seinen Trieben lebt. Es genugt nicht, daB er sein Kriegswerkzeug bis zur Perfektion weiterentwickelt und es vollkommen beherscht. Im Angesicht der Gefahr muB er jederzeit bereit sein aus sich selbst heraus $z u$ handeln. Wo Sekunden und Bruchteile von Sekunden uber Leben entscheiden konnen, muB er sich instinktiv zu verteidigen wissen.

Ob ein zug voruberrasselte, ein Buch zu Boden fiel, ein nuchtlicher Schrei erscholl - immer stockte der Herzschlag fur einen Augenblick. Unter dem Gefuhl 
einer groBen und unbekannten Gefahr. 83

Gerausche und Vorkommnisse, die sonst kaum der Beachtung wert erschienen, nehmen plotzlich ungeheuere AusmaBe an. Der Krieger ist standig damit beschaftigt, auch die Dinge an der Peripherie wahrzunehmen. Jeden Augenblick kann er angegriffen werden, jeden Augenblick aber auch muB er bereit sein, selbst anzugreifen. So liegt hier eine doppelte Aufgabe vor ihm. Es genugt nicht, daB sein Gehirn das Ungewöhnliche zur Kenntnis nimmt. Es muB sich auch blitzschnell darauf einstellen konnen und darauf reagieren.

Aber selbst dies kann noch zu lange dauern, und so feilt der Krieger an diesem ProzeB so lange, bis er das Gehirn auBer Funktion gesetzt hat. Seine Aktionen und Reaktionen sind nicht mehr willkurlich, sondern rein instinktiv. Ohne jede uberlegung greift seine Hand beim Angriff zur Waffe. Die Gefahr wird nicht eigentlich mehr verstandesmaBig erkannt, sondern nur noch "erfuhlt".

Whrend dieser Tage lernte ich die Mianner schatzen, mit denen ich noch zwei Kampfjahre verbringen sollte. Es handelte sich hier um ein Unternehmen des Englunders, das in den Heeresberichten kaum Erwahnung fand und das uns an einem Abschnitt keschaftigen sollte, der fur den GroBangriff nicht vorgesehen war. Dabei kam es fur die Mannschaft eigentlich immer nur darauf an, wenige Schritte zu tun, numlich jene kurze spanne zu Uberwinden, die den Postenstand von den Stolleneingangen trennt. Diese Schritte aber waren whrend der Sekunde der huchsten Feuersteigerung zu tun, die den Angriff vorbereitet und die nur gefunlsmaBig zu erfassen ist. 84 
Nur durch das instinktive Erkennen der Gefahr gelingt es dem Soldaten Uberhaupt am Leben zu bleiben. Versuchte er die Gefahr rational zu erfassen, so ware sein Untergang unwiderruflich besiegelt.

Junger beschrankt sich jedoch nicht darauf, dem Menschen tierische Eigenschaften zu unterstellen. Ofters vergleicht er bestimmte Menschen auch direkt mit Tieren.

Es wurde lebhaft geschossen, aber auch gezielt. Ich sah einen stammigen Gefreiten der achten Kompanie mit groBer Ruhe sein Gewehr auf einen zersplitterten Baumstumpf legen; mit jedem SchuB fiel ein Angreifer. Die anderen stutzten und begannen im Feuer wie die Hasen hin- und herzuspriggen, wahrend Staubwolkchen zwischen ihnen aufwirbelten. 85

Hier wird noch ein anderer Aspekt des Jungerschen Vergleichs deutlich. Uberleben und gewinnen wird nur der Sturkste, Der Gefreite symbolisiert den Juger oder das starkere Tier. Trotz aller sozialen und biologischen Fortschritte, die der Mensch meint im Laufe seiner Geschichte errungen zu haben, unterliegt er dennoch dem uralten Naturgesetz, wonach nur der Starkste Uberlebt.

So sehr Junger auch die tierischen Eigenschaften lobt, so mB er dennoch zugestehen, daB auch im Kampf nur derjenige Sieger werden kann, der sowohl. Tierisches als Menschliches verbindet und gleichermaBen $z u$ beherrschen weiB. Das Tierische mag zum Uberleben genugen, aber um siegreich zu sein, bedarf der Mensch seiner anerzogenen Eigenschaften. Gerade in der Verbindung der beiden liegt seine starke und 
seine Uberlegenheit. Jungers Kampf ist der ewige $\mathrm{Zwei-}$ kampf der Natur, der nach dem Gesetz der Starke entschieden wird. Aber diese Sturke kann nicht mehr aus den Trieben, aus dem Instinkt allein hervorgebracht werden.

Es ist sehr aufschluBreich zu sehen, wie sich hier in den fruhesten Reflexionen Jungers die Schilderung eines allen verstandesmaBigen Sublimierungen vorgeschalteten Rauschzustandes in sozialdarwinistische Terminologie Ubersetzt: der Kampf ums Dasein ein Urverhaltnis, der Mensch - ein dem Ursprunglichen entfremdetes Tier, das Unterliegen des Schwacheren eine Naturnotwendigkeit. 86

Es gelingt Junger nicht, zu spezifizieren, was dieses Tierische im Menschen ist. Fur ihn bedeutet es das InstinktmaBige, das Irrationale, das Triebriafte. Es liegt dem Menschen, auch dem Zivilisationsmenschen noch, einfach im Blut und seine kraft braucht nur geweckt $z u$ werden. Es ist der Mensch in seinem Urzustand. Das Tierische ist ihm angeboren, wohingegen ihm das Rationale anerzogen worden ist. Letzteres muBte er sich erst in seiner Entwicklung erwerben, das Erste war von Anbeginn seiner Geschichte Teil seiner selbst.

Stets war das Gewehr im Bereich des Armes, sprang plotzlich Feuer auf oder schallten wirre Rufe in die Tiefe der Stollen, so war nach ihm der erste Griff, der noch vom Schlafe Trunkenen. Dieser Griff aus der Tiefe des Schlafes heraus zur Waffe war etwas, das im Blute lag, eine AuBerung des primitiven Menschen, dieselbe Bewegung, mit der der Eiszeitmensch sein Steinbeil gepackt hatte.

Das pragte dem Grabenkumpfer den Stempel des Tierischen auf, das Ungewisse, das elementar Verhangnisvolle, die wie zur Urzeit von standiger Drohung 
geladene Umgebung. 8 ?

Das Animalische ist das Naturlich-Kraftvolle, wohingegen die Thatigkeit des Verstandes als etwas Gekunsteltes, etwas Durftiges erscheint. So stark ist diese elementare Kraft, daB sie auch nach Jahrtausenden der Uberfremdung und des Brachliegens noch wirksam werden kann. Vieles mag der Mensch sich in seiner Geschichte angeeignet haben, aber in den Dingen die er zum Leben braucht, gleicht der heutige Mensch dem Urzeitmenschen bis aufs Letzte. Noch immer besteht sein Leben aus Nahrungsaufnahme, noch immer ist er in einer stundigen Verteidigungssituation. Frther wie heute gilt es, seine Umwelt stets von neuem zu verteidigen und im Krieg tritt diese situation nur uberdeutlich hervor.

Fur Junger ist der moderne Mensch nur eine Fortsetzung des Eiszeitmenschen in einer verunderten Umwelt. Ebenso baut dieser auf dem Tier auf.

ob im Augenblick der Begegnung die Krallen gespreizt und die zahne entblozt, ob roh gekantete Beile geschwungen, holzerne Bogen gespannt werden oder ob sehr feine Technik die Vernichtung zu hochster Kunst erhebt, stets kommt der Punkt, wo aus.dem WeiBen im Auge des Feindes der Rausch des roten Blutes flammt. Immer lust der keuchende Ansprung, der letzte, verzweifel te Gang dieselbe Summe der Gefuhle aus, ob nun die Faust die geschnitzte Keule oder die sprengstoffgefulite Handgranate schwingt. Und immer auf den Gefilden, wo die Menschheit ihre sache zur blutigen Entscheidung stellt, mag es der schmale PaB zwischen zwei kleinen Bergvolkern, mag es der weit geschwungene Bogen moderner Schlachten sein, kann alles Grausige, alle Hzufung raffiniertester schrecken nicht so den Menschen mit Grauen durchtranken wie die sekundenlange Erscheinung seines Ebenbildes, das vor 
ihm auftaucht, alle Feuer der Vorzeit im verzerrten Gesicht. Denn alle Technik ist Maschine, ist Zufall, das GeschoB blind und willenlos; den Menschen aber treibt der Wille zu toten durch das Gewitter aus Sprengstoff, Eisen und Stahl, und wenn zwei Menschen im Taumel des Kampfes aufeinanderprallen, so treffen sich zwei Wesen, von denen nur eins bestehen kann. Denn diese zwei Wesen haben sich zueinander in ein Urverhaltnis gesetzt, in den Kampf ums Dasein in seiner nacktesten Form. In diesem Kampfe muB der Schwachere am Boden bleiben, wahrend der Sieger, die Waffe fester in der Faust, uber den Erschlagenen hinwegtritt, tiefer ins Leben, tiefer in den Kampf. So ist der Aufschrei, den solcher Anprall mit dem des Feindes vermischt, ein Schrei, der sich Herzen entringt, vor denen die Grenzen der Ewigkeit schimmern. Es ist ein Schrei, im Flusse der Kultur langst vergessen, ein Schrei aus Erkennen, Grauen und Blutdurst. 88

Verbunden werden alle drei, moderner Mensch, Urmensch und Tier, durch das Blut. Damit entzieht Junger seine Hypothese wiederum jeglicher Realitat. Blut in diesem sinne ist nicht etwas, was sich definieren laBt. Es ist ein gefuhlsbeladener Begriff. Somit wird es Junger ein Leichtes, jeden, der mit ihm nicht ubereinstimmt, aus dem Kreis der Erlesenen auszuschlieBen. Die Verbindung durch das Blut zum Tier kann nicht erlernt, sie kann nicht einmal erklurt werden. Fest steht nur, daB der Starkere dieses Gefunl in sich tragt.

Wieder befindet sich Junger hier in geftuhrlicher Nahe zum Gedankengut des Nationalsozialismus. Nur wenige Jahre spater sollte mit dem Blut- und Bodenmythos reichlich Unsinn getrieben werden. Hier wie dort sind die Ursachen die gleichen. Wo immer es gegeben oder erforderlich scheint, werden die Dinge der Realitat entzogen, sie werden in Kaugummibegriffe umgewan- 
delt, so daB ihre Anwendung letztlich bei allem moglich erscheint. "Der Mythos des Blutes und der Erde feiert hier Triumphe, mehr als ein Jahrzehnt noch, bevor die NS-Ideologie inn zur staatsreligion erhob." 89

BLUT

Das Blut und die Wucht der Faust werden also zur allestreibenden Macht. Da beides jedoch nicht mehr rational erklart werden kann, wird es entfremdet. Besonders eindrucksvoll meint Junger die Macht des Blutes zu gestalten, wenn er immer wieder vom Blutrausch spricht. Der Begriff des Blutes gleicht dem Zustand des Rausches. Der Mensch wird der Verantwortung fur sein Handeln enthoben. Nur wer selbst einen Rausch erlebt hat, kann sich von dieser unfaBbaren Macht eine vorstellung machen. Alle anderen sind automatisch davon ausgeschloBen. Sie theoretisieren und abstrahieren nur. Wer von dem Rausch des Blutes ergriffen wird, kennt nur noch ein ziel, den Gegner zu toten. "Sich auf den Gegner sturzen, ihn packen, wie es das Blut verlangt, ohne Waffe, im Taumel, mit wildem Griff der Faust." 90

Nur im Rausch kann der Krieger Erlosung finden, denn dort meint er, alles Falsche und Unnaturliche von sich abgestreift zu haben. Im Rausch fuhlt er sich den Ursprungen am nuchsten. Seine wahre Natur, die er sonst standig unterdrucken muB, kommt hier plotzlich explosionsartig an die oberflache. Hier kann er seinen Gefuhlen ungehinderten Lauf lassen. Er 
versinkt wieder vollkommen in seine Raubtiernatur und ist allein von dem Gedanken beseelt, zu toten. Und erst nachdem sein Auftrag erfullt, Blut geflossen ist, kehrt er wieder zu jich selbst zuruck.

Da ist der Ring von Gefuhlen, der Kampf, der in der Brust des Kumpfers tobt, wenn er die Flammenwusten der riesigen Schlachten durchirrt: Das Grauen, die Angst, die Ahnung der Vernichtung und das Lechzen, sich im Kampfe vollig zu entfesseln. Hat er, eine durch das Ungeheuere rasende kleine Welt in sich, die bis zum Platzen gestaute Wildheit in juher Explosion, dem klaren Gedachtnis fur immer verlorenen Augenblicken entladen, ist Blut geflossen, sei es eigener Wunde entstromend oder das des anderen, so sinken die Nebel vor seinen Augen. Er starrt um sich, ein Nachtwandler, aus druckenden Truumen erwacht. Der ungeheuerliche Traum, den die Tierheit in ihm getroumt in Erinnerung an Zeiten, wo sich der Mensch in stets bedrohten Horden durch wlste Steppen kumpfte, verraucht und laBt ihn zuruck, entsetzt, geblendet von dem Ungeahnten in der eigenen Brust, erschopft durch riesenhafte Verschwendung von willen und brutaler Kraft.91

Noch flieBt das Blut des Urmenschen in seinen Adern, noch tragt er die unbezahmbare Wildheit seiner vater im Blut, aber er braucht schon den Zustand des Rausches, um dies noch recht aktivieren zu kønnen.

Urkraft und Zivilisation wissen von einander nicht, wo das eine herrscht, kann das andere nicht sein. Dennoch sind sie untrennbar miteinander verbunden: Das Blut halt sie zusammen. Erst gemeinsam machen sie den wahren Menschen aus.

\footnotetext{
"Blut" - in diesem Wort versucht Junger begrifflich zu fassen, was er an tierhaften, chthonischen Kraften im Menschen wirksam sehen will. Blut und Verstand sind zwei Reiche. . . Junger erblickt in der vom Krieg erzwungenen Reduzierung des menschlichen Lebens auf seine naturlich-triebhaften AuBerungen
} 
ein lang unterdrucktes Hervortreten des Animalischen im Menschen, das unvermittelt und in Zeiten des Friedens nur verdeckt neben dem Geistig-Rationalen existiert. Das Naturhaft-Animalische symbolisiert er im Begriff des Blutes als das Kraftvolle und Gesunde. 92

Es ist auffallend, daB bei Junger die Beschreibung des entfesselten Blutes und eine Art Rauschzustand immer Hand in Hand gehen. Dies deutet einerseits darauf hin, daB Junger diesen Begriff nicht konkretisieren kann, nicht konkretisieren will. Zum anderen jedoch stellt sich die Frage, ob dies Uberhaupt moglich ist. Wir haben festgestellt, daB Blut eine irrationale Kraft ist, die nur dort, in der Irrationalitat ihre Sturke hat. Den Begriff zu rationalisieren, hieBe zugleich ihn seiner ihm eigenen Wirklichkeit zu entreiBen und ihn mit eben den Worten zu erklaren, die dem zivilisationsmenschen zur verfugung stehen. Damit jedoch wurde der Blutrausch herabgewtlrdigt zur bloBen Bestialitut. Die beiden Menschen befanden sich dann nicht mehr auf der gleichen Ebene, sondern der eine ware dem anderen weit unterlegen. Der Mensch des Blutrausches wurde zum Untermenschen.

Wirklich wird der Mensch nur, wenn er transzendierend damonische oder gottliche Wesen beruhrt, und so ist denn auch die Begegnung mit der ghthonischen Macht des Blutes genuine Transzendenz.93

Hier liegt die Losung dessen, was Junger meint, wenn er sagt, leben heiBt toten. In diesem Rausch des Blutes ist der Krieger nur darauf aus, Blut flieBen zu sehen. Dieser Trieb jedoch kann nicht mit unseren heutigen MaBstaben und Begriffen 
erklurt oder. gar verstandlich gemacht werden. Dennoch ist er eine Grundvoraussetzung zum eigentlichen Leben. Im Blutrausch erscheint der Tod dem Soldaten nicht mehr als Grenze,als Einschnitt. Im Gegenteil, je groBer die Triebkraft des Rausches wird, umso nuher begibt sich der Mensch in den Bannkreis des Todes, ohne dem jedoch Achtung zu schenken. Der Tod selber verliert immer mehr an Wichtigkeit und Bedeutung. Entscheidend ist vielmehr, daB der Mensch gleichsam uber sich selbst und uber die zeit hinauswachst. Je naher er selbst an den Tod kommt, umso starker wird zwangslaufig auch die ungeheuere Urkraft der Triebe. Dies halt solange an, bis eine Explosion stattfindet, welche das physische Erlebnis des BlutflieBens ist. Da Junger jedoch voraussetzt, daB der Gegner die gleiche Auffassung vom Leben hat wie er selbst, ist es unwichtig, wessen Blut hier flieBt. Toten kann hier nicht von einer Seite gesehen werden. Der Begriff vom woten schlieBt die Vorstellung des getutet werdens in sich ein. 


\section{KAPITEL III}

\section{DER DICHTER ALS BAROMETER}

Liest man die frthen Kriegsbucher Ernst Jungers, so kann man sich des Eindrucks nicht erwehren, daB Junger mit ihnen zu einem der Hegbereiter des Nationalsozialismus gehort. Er hat zwar deutlich gemacht, daB es ihm nicht um Sieg oder Niederlage einer Nation oder eines Iandes ging, aber er hat den Krieg selbst auf eine Weise verherrlicht, die dem Nationalsozialismus geradezu Vorschub fur seine Ideologie leisten muBte. Jungers Anspruche an den Krieg sind nicht auf einen bestimmten Krieg bezogen, sondern sie gelten dem Krieg ganz allgemein. Seine Kriegswerke sind eine Apotheose des Krieges schlechthin, und es dauerte fast ein hal bes Jahrhundert, bis Junger erkannte, daB der Krieg seiner Vorstellung weder dem konkreten Beispiel des ersten Weltkrieges entsprach, noch fur irgendjemanden von Vorteil war, am wenigsten dem Krieger selbst.

Wie lange sollte es nach dem Ersten Weltkrieg dauern, bis wir erkannten, das dort nicht zwischen volkern und um Ideen gerungen wurde, sondern daB etwas anderes eintrat, das die Fronten ubergriff und verwischte - ein Schicksal, das allen aufgeburdet war. Daher wirde auch nicht dieser oder jener Krieg verloren, sondern der Krieg schlechthin, der Krieg des Kriegers - das ist ein Kapitel der Vernichtung der standischen Welt.1

Damit, so scheint es, bricht Junger endgultig den stab uber seiner mystifizierten Vorstellung des Krieges. Dies heiBt 
nicht, daB sich sein Bild des Krieges gewandelt hat, sondern vielmehr, daB der Krieg selbst etwas anderes geworden ist.

Dennoch hat Junger wenig dazu beigetragen, seine Haltung uber den Krieg dann klarzustellen, wenn es vonnoten war. Obwohl er wuBte, daB die Verbreitung seiner Bucher von den Nationalsozialisten unterstutzt wurde, unternahm er wenig, um sich deutlich von der nationalsozialistischen Kriegsauffassung abzusondern und seine Haltung uber den Krieg deutlich zu machen. Stattdessen zog er sich in eine Art innere Emigration zurtick.

There is not the slightest need to doubt the sincerity or heroism of Ernst Junger; but at the same time one must deplore and condemn the disastrous consequences of his militarism, and above all the exploitation of his views by the Nazis. 2

Man kann Jungers Kriegsdeutung teilen oder man kann sie ablehnen. Allein aus der Tatsache heraus, daB er den Krieg auf seine Art sieht, ist inm kein Vorwurf zu machen. Wohl aber muB man sich fragen, warum er die Veryffentlichung seiner schriften auch dann noch zulieB, als er sich daruber bewuBt gewesen sein muBte, daB sie von verantwortlicher stelle ganz anders interpretiert wurden, als er es sich vorgestellt hatte und daB ihre verbreitung nur noch Mittel zum 2 weck war.

Der Pragger von Begriffen ist nicht und niemals fur die Art und Weise der Verwendung dieser Begriffe oder ihre Interpretation durch andere verantwortlich, mit denen er wenig oder gar nichts gemein hat. Er ist jedoch verantwortlich fur die Gedankenwelt, aus der er solche Begriffe schopft. Diese Gedankenwelt grenzt aber nicht er $a b$, sondern jener, auf welchen die Begriffe sich auswirken. Dabei gerat er in oft 
unwillkommene Gesellschaft, aber es ist seine Gesellschaft. Das ist sein Dilemma und auf der Ebene der Ideen auch seine Schuld.3

Die Frage, ob der Dichter fur die Wirkung seiner Werke verantwortlich gemacht werden kann, wurde den Rahmen dieser Arbeit sprengen. AuBerdem ist zweifelhaft, ob sie sich allgemein oder im Bezug auf eben diesen Autor therhaupt endgultig beantworten lieBe. Dennoch muB hervorgehoben werden, daB auch die dichterische Freiheit, sowohl in der Form, als auch im Inhalt, ihre Grenzen hat. "Es gibt keine licentia poetica welche die verantwortung aufhobe fur die Wirkungen, die von einem Schrifttum ausgehen mussen, mogen sie auch ungewollt sein."4 Ernst Junger Uberschritt diese Grenze der dichterischen Freiheit nicht, als er seine Werke schrieb, sondern als er ihre verbreitung auch dann noch zulieB, als diese selbst in den Dienst einer ganz anderen Sache gestellt worden waren. Warum er dies tat wird ungewiB bleiben, und es lassen sich dartber nur vermutungen und Hypothesen aufstellen.

Fest steht allein, daB seine Werke uber den Krieg einen gewaltigen EinfluB hatten. Der Grund darur lag sowohl im Zeitpunkt der Veroffentlichungen, als auch in der eigenwilligen Behandlung des Themas und nicht zuletzt in der Person des Autors selber.

Die Zeitpunkte seiner jeweiligen Wirkung fielen mit einer bemerkenswerten Genauigkeit auf die Momente 
kritischen BewuBtseinszustandes in der deutschen Geschichte des 20. Jahrhunderts. 1920 - damals, als der Reichswehrleutnant im Selbstverlag sein Kriegstagebuch In Stahlgewittern herausbrachte, war er einer der ersten, der das Weltkriegserlebnis des Grabenkampfers in umfassender Form literarisch gestaltete. Der Kampf als inneres Erlebnis (1922) nahm bereits die zeitdiagnostische Vertiefung der Begegnung mit dem Krieg vor. Jungers pragende Erfahrung - die Materialschlacht an der Westfront - war auch die vieler Angehorigen jener Kriegsgeneration, die sich anschickte, gestaltend in Deutschlands Zukunft einzugreifen. Ein Avantgardist des eisernen Zeitalters, ein Sprecher aktivistischer Jugend, ein ReprHsentant der Generation, die an die Wacht kommen wurde - so verstand ihn eine stetig wachsende Schar mitgerissener Leser. 5

Wir haben festgestellt, daB die Frage, inwieweit Junger fur den EinfluB seiner Bucher zur verantwortung gezogen werden kann, sich hier nicht beantworten laBt. Hier kann nur aufgezeigt werden, was die Schriften fur den Autoren selber bewirkten. Vor ihrem Erscheinen war Junger weithin unbekannt und hatte sich allein auf militarischem Gebiet Verdienst erworben. Diesen beiden Werken hatte er es zu verdanken, daB sein Name einer viel breiteren Offentlichkeit zuganglich wurde. Daruber hinaus ermoglichten sie ihm eine groBere finanzielle Unabhangigkeit. Aus dem Krieger mit dichterischen Ambitionen war ein Schriftsteller geworden, der im Krieg seine grundlegenden Erfahrungen gesammelt hatte und hier versucht, diese in einem Beitrag zum Geistesleben in Deutschland zu verarbeiten. 
FUSSNOTEN

Kapitel I

1: Gerhard Loose, Ernst Junger: Gestalt und Werk (Frankfurt: vittorio Klostermann, 1957), s. 60.

. 2 ibid., s. 60 .

3 Ernst Junger, "Afrikanische Spiele," in Werke: Erzahlende Schriften I: Erzahlungen (Stuttgart, Ernst Klett verlag, n॰d.) 9. S. 15 .

4

ibid., S. 15 .

5 ibid., s. 25 .

6 Hubert Becher, Ernst Junger: Wensch und Werk (Warendorf, J. Schnell, 1949), S. 15 .

7 Junger, Werke 2, s. 135.

8 ibid., s. 132.

9 Jurgen Rausch, Ernst Jungers Optik (Stuttgart: Deutsche Verlagsanstalt, 1951), S. 11 .

10 Ernst Junger, Der Kampf als inneres Erlebnis (Berlin: E. S. Mittler und Sohn, 1943), S. XIV.

11 Armin Nohler, Die konservative Revolution in Deutschland 1918 - 1932: GrundriB ihrer Weltanschauungen (Stuttgart: Friedrich Vorwerk, 1950), s. 47 .

12 Eugen Gottlob Winkler, Gestalten und Probleme (Leipzig, Karl Rauch, 1937), S. 110.

13 Hans-Peter Schwarz, Der konservative Anarchist: Politik und Zeitkritik Ernst Jungers (Freiburg im Breisgau: Verlag Rombach, 1962), s. 60 .

14 ibid., s. 60 .

15 Gerhard Nebel, Ernst Junger: Abenteuer des Geistes (Wuppertal: Warees Verlag, 1949), S. 52 . 
8 November 1947 , s. 576.

17 Loose, Ernst Junger, s. 24.

18 Karl 0. Paetel, Ernst Junger in Selbstzeugnissen und Bilddokumenten (Reinbek bei Jamburg, Rowohlt, 1962), S. 81 .

19 ibid., S. 81.

20 Helmut Kaiser, Mythos, Rausch und Reaktion: Der Weg Gottfried Benns und Ernst Jungers (BerIin: Aurbau-Verlag, 1962), S. 189.

21 Armin Mohler, Die Schleife: Dokumente zum Weg von Ernst Junger (zurich: Verlag die Arche, 1955), S. $10 \%$.

22 Hans-Joachim Bernhard, "Die apologetische Darstellung des imperialistischen Krieges im Werk Ernst Jungers," Weimarer Beitrage (1963), S. 351.

23 Karl Lowith, Von Hegel bis Nietzsche (Zurich: Europa Verlag, 1941), S. 354 .

24 F. A. V., "More German War Books," Manchester Guardian, 26 June 1929 , S. 7 .

25 s. S., "In Praise of the War," Everyman, 30 May 1929, S. 12.

26 ibid., s. 12.

27 ibid., s. 12.

28 Stephen Spender, European Witness (London, Hamish Hamilton, 1946), S. 199-200.

29 Kaiser, s. 253.

30 ibid., s. 254.

31 schwarz, s. 36.

32 Kaiser, s. 44-45.

33 ibid., s. 45.

34 Bernhard, s. 349.

35 ibid., s. 324 .

36 J. P. Stern, Ernst Junger (New Haven: Yale University Press, 1953), S. 51-52. 
37 ibid., s. 52 .

38 S. D. Stirk, The Prussian Spirit: A Survey of German Literature and politics $1914-1940$ (London, Faber and Faber, 1941), S. 93 .

39 Ernst Junger, "Der Kampf als inneres Erlebnis," Werke: Betrachtungen zur Zeit (Stuttgart, Ernst Klett Verlag, n. d. ) 5. S. 26 .

40

ibid., s. 18.

41 Bernhard, S. 329.

42 Winkler, s. 117.

43 Kaiser, S. 252.

44 ibid., s. 252.

45 stern, s. 26.

46 ibid., s. 30 .

Kapitel II

1 Ernst Junger, "In Stahlgewittern," Werke 1 Tagebucher: Der erste Weltkrieg (Suttgart: Ernst Klett Verlag, n. d.) 1, S. 10 .

2 Junger, Werke 5, s. 12.

3 Junger, Werke 1, s. 11.

4 ibid., s. 14 .

5 Becher, S. 14-15.

6 Spender, S. 199.

7 Junger, Werke 2, s. 16.

8 Bernhard, S. 335.

9 Junger, Werke 5, s. 43.

10 ibid., s. 13.

11 ibid., s. 13. 
12 Bernhard, S. 325.

13 Junger, Werke 5, s. 13-14.

14 ibid., s. 14-15.

15 Schwarz, S. 60 .

16 Wulf Dieter Muller, Ernst Junger: Ein Leben im Umbruch der Zeit (Berlinı Junker und Dunnhaupt, 1934), S. 38 .

17 Bernhard, S. 347-348.

18 ibid., s. $333-334$.

19 Junger, Werke 2, s. 85-86.

20 Junger, Werke 5, S. 51-52.

21 Junger, Der Kampf als inneres Erlebnis, S. XIII.

22 Junger, Werke 1, S. 11.

23 Junger, Werke 5, s. 21-22.

24 ibid., s. 22.

25 Aurel Kolnai, The War against the West (London: Victor Gollancz Itd, 1938), s. 84 .

26 Junger, Werke 1, S. 235.

27 Hans Ernest Fried, The Guilt of the German Army (New York: The MacMillan Company, 1942), s. 333-334.

28 Junger, Werke 2, s. 121.

29 Fried, S. 334.

30 Junger, Werke 5, s. 40.

31 ibid., s. 55.

32 ibid., s. 61 .

33 ibid., s. 61 .

34 Bernhard, s. 332.

35 Junger, Werke 5, s. 76.

36 Nebel, Ernst Junger: Abenteuer des Geistes, S. 121. 
37 Junger, Werke 5, s. 25.

38 Junger, Werke 2, s. 156.

39 Junger, Werke 5, s. 1:0-41.

40 Junger, Werke 1, S. 155.

41 Hermann Pongs, "Krieg als Volksschicksal im deutschen Schrifttum," Dichtung und Volkstum: Neue Folge des Euphorion: Zeitschrift fur Literaturgeschichte, ed. Julius Petersen und Hermann Pongs (Stuttgart: J. B. lietzlersche Verlagsbuchhandlung, 1934), S. 42 .

42 Junger, Werke 1, S. $274-275$.

43 ibid., s. 274 .

44 ibid., S. 144.

45 ibid., s. 274 .

46 Junger, Werke 2, s. 50.

47 Junger, werke 1, s. 176.

48 ibid., S. 111.

49 ibid., s. 95-96.

50 Junger, Werke 2, s. 103.

51 Rausch, S. 18-19.

52 Junger, Werke 1, s. 66.

53 . ibid., s. 139.

54 Junger, Werke 5, s. 65.

55 ibid., s. 65.

56 ibid., s. 91-92.

57 Junger, Werke 1, s. 113.

58 Hermann Feilner, "Deutsche und englische Kriegsepik," Literatur, 39, No. 12 (September 1937), S. 712.

59 Friedrich Bethge, Reims (Berlin, Verlag Reimar Hobbing, 1934), S. 59-60. 
60 Gabriel Marcel, "Ein Gerechter, Stuck in einem Akt," Wandlung und Wiederkehr: Festschrift zum 70. Geburtstag Ernst Jungers, ed. Heinz Ludwig Arnold (Aachen: Georgi, n. d.), S• 53 .

61 Junger, Werke 1 , S. 100 .

62 ibid., s. 19.

63 Schwarz, S. 68.

64 Christian von Krokow, Die Entscheidung: Eine Untersuchung aber Ernst Junger, Carl Schmitt, Martin Heidegger (Stuttgart, Ferd. Enke, 1958), s. 46.

65 Junger, Werke 5, s. 52.

66 ibid., s. 53-54.

67 Junger, Werke 1, s. 40.

68 Junger, Werke 5, s. 36-37.

69 ibid., s. 52 .

70 Junger, Werke 1, S. 184 .

71 ibid., s. 233.

72 Rolf Geisler, Dekadenz und Heroismus: Zeitroman und volkisch-nationalsozialistische Literaturkritik (Stuttgart: Deutsche Verlags-Anstalt, 1964). S. 127 .

73 Junger, Werke 5, s. 19.

74 ibid., s. 22.

75 Junger, Werke 1, S. 157.

76 Junger, Werke 5, S. 33 .

77 ibid., s. 105.

78 1. Korinther 13, 13 "Nun aber bleibt Glaube, Hoffnung, Liebe, diese drei; aber die Liebe ist die grobte unter ihnenn"

79 Nebel, Ernst Junger: Abenteuer des Geistes, S. 99.

80 ibid., s. 100-101.

81 Hans-Rudolf Muller-Schwefe, Ernst Junger (WuppertalBarmen: Emil Muller Verlag, 1951), s. 14. 
82 Junger, Werke 5, s. 24-25.

83 Junger, Werke 1, S. 14.

84 ibid., s. 95-96.

85 ibid., s. 186.

86 schwarz, s. 67.

87 Junger, Werke 5, s. 32.

88 ibid., s. 18-19.

S. 22 .

89 Franz Baumer, Ernst Junger (Berlin, Colloquium, 1967),

90 Junger, Werke 5, S. 20.

91 ibid., s. 20.

92 Bernhard, s. 327 .

93 Nebel, Ernst Junger: Abenteuer des Geistes, S. 71-72.

Kapitel III

1 Ernst Junger, Ad Hoc (Stuttgart: Ernst Klett Verlag, 1970), S. 20 .

2 stirk, s: 95 .

3 Peter de Mendelsohn, Der Geist in der Despotie: Versuche uber die moralischen Muglichkeiten des Inteli ektuellen in der totalitaren Gesellschaft (Berlin: verlag Herbig, 1953) $, \frac{\mathrm{s}}{\mathrm{S}}, \frac{\mathrm{d}}{182}$.

4 Alfred von Martin, Der heroische Nihilismus und seine Uberwindung: Ernst Jungers Weg durch die Krise (Krefeld: Scherpe, 1948), s. 11 .

5 Schwarz, S. 12 . 


\section{AUSGEWÄHLTE BIBLIOGRAPHIE}

\section{Primar-Literatur}

Junger, Ernst. Ad Hoc. Stuttgart: Ernst Klett Verlag, 1970

Junger, Ernst. Annaherungen: Drogen und Rausch. Stuttgart, Ernst Klett Verlag, 1970 .

Junger, Ernst. Der Kampf als inneres Erlebnis. 9. Aufl. Berlin: E. S. Hittler und Sohn, 1943.

Junger, Ernst. In Stahlgewittern: Ein Kriegstagebuch. 16. Aufl. Berlin: E. S. Mittler und Sohn, 1926.

Junger, Ernst. "Afrikanische Spiele." Werke: Erzahlende Schriften I: Erzahlungen. Stuttgartı Ernst Klett Verlag, $\frac{\text { n. d. }}{\overline{I X}, ~}$ $\overline{I X}, \overline{9-185 .}$

Junger, Ernst. "In Stahlgewittern." Werke: Tagebucher: Der erste

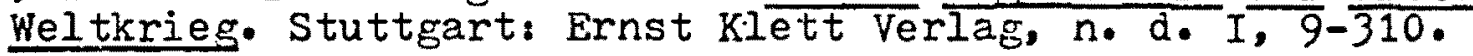

Junger, Ernst. "Der Kampf als inneres Erlebnis." Werke: Betrachtungen zur Zeit. Stuttgart, Ernst Klett Verlag, n. d. V, 11-108.

II. Sekundar-Literatur

Anon. "The Crucible of War." The Times Literary Supplement, 8 November 1947 , S. 576.

Anon. "Germany at War." The Saturday Review of Literature, 14 December 1929, S. 556 .

Anon. "The War." Saturday Review, 27 July 1929, S. 104-105.

Arnold. Heinz Ludwig, ed. Wandlung und Wiederkehri Festschrift zum 20. Geturtstag Ernst Jungers. Aachen: Georgi, n. d.

Auer, Annemarie. "Nachtragliches zu einem Jubelfest, Ernst Junger und die formierte Gesellschaft." Weimarer Beiträge, 1966, S. 581-605.

Baumer, Franz. Ernst Junger. Berlin, Colloquium, 1967.

Becher, Hubert. Ernst Junger: Mensch und Werk. Warendorf: J. Schnell, 1949. 
Bense, Max. Ptolomaer und Mauretanier oder die theologische Emigration der deutschen Li teratur. Koln und Berlin: Verlag Gustav Kiepenheuer, 1950.

Bernhard, Hans-Joachim. "Dic apologetische Darstellung des imperialistischen Krieges im Werk Ernst Jungers." Weimarer Beitrage, 1963, s. 321-55.

Bethge, Friedrich. Reims. Berlin, Verlag Reimar Hobbing, 1934.

Boehm, Max Hildebert. Der Burger im Kreuzfeuer. G甘ttingen, Vandenhoeck und Ruprecht, 1933.

Brock, Erich. Ernst Junger und die Problematik der Gegenwart. Basel: Benno schwabe, n.

Brock, Erich. Das Weltbild Ernst Jungers: Darstellung und Deutung. Zurich, Max Niehaus, n. d.

Cooley, Hohn K. "The Adventures of Ernst Junger." Books Abroad, $32(1958), 365-68$.

Duwe, Wilhelm. Deutsche Dichtung des 20. Jahrhunderts: Vom Naturali smus zum Surrealismus. Zurich: 0rell Fussli

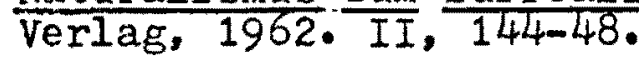

F. A. V. "More German War Books." Manchester Guardian, 26 June 1929, S. 7 .

Feilner, Hermann. "Deutsche und englische Kriegsepik." Literatur, 39, No. 12 (September 1937), 711-14.

Fried, Hans Ernest. The Guilt of the German Army. New York, The MacMillan Company, 1942 .

Geisler, Rolf. Dekadenz und Heroismus: Zeitroman und vylkischnationalsozialistische literaturkritik. Stuttgart. Deutsche Verlags-Anstalt, 1964.

Hafkesbrink, Hanna. Unknown Germany: An inner Chronicle of the First World War based on letters and diaries. New Haven: Yale University Press, 1948.

Hielscher, Friedrich. Funfzig Jahre unter Deutschen. Hamburg! Rowohlt, 1954.

Hoffman, Frederick J. "The Moment of Violence, Ernst Junger and the Iiterary Problem of Fact." Essays in Criticism, 10, No. 4 (1960), 405-21.

Jancke, Oskar. Kunst und Reichtum deutscher Prosa: Von Lessing bis thomas Mann. Nunchen: Verlag Piper, 1954. 
Junger, Friedrich Georg. "Erinnerungen an die Eltern." Freundschaftliche Begegnungen: Festschrift fur Ernst Junger zum 60. Geburtstag. Ed. Armin Mohler. Frankfurt Vittorio KIostermann, 1955, S. 207-232.

Junger, Friedrich Georg. Grune Zweige: Ein Erinnerungsbuch. Munchen: Hanser, 1951.

Kahle, Wilhelm. Geschichte der deutschen Dichtung. 3. Aufl. Munsterı Regensberg, 1958.

Kahler, Erich. Man the Measure: A new Approach to History. New York, George Braziller, Inc., 1956.

Kaiser, Helmut. Mythos, Rausch und Reaktion: Der Weg Gottfried Benns und Ernst Jungers. Eerlin: Aufbau-Verlag, 1962 .

Kantorowicz, Alfred. "German Nationalist Iiterature." The New Republic, 6 December 1943. CIX, 814-16.

Klose, Werner. "Soldatentod, Interpretation dreier Texte von Flex, Junger und Polgar." Wirkendes Wort, 8 (1957-58), $33-40$.

Kolnai, Aurel. The War against the West. London, Victor Gollancz Ltd, 1938.

Kranz, Gisbert. Ernst Jungers symbolische Weltschau. Dusseldorf: Pudagogischer Verlag Schwann, 1968.

Krokow, Christian von. Die Entscheidung: Eine Untersuchung uber Ernst Junger, Carl Schmitt, liartin Heidegger. Stuttgart: Ferd. Enke, 1958.

Lange, Victor. Modern German Literature: 1870-1940. Ithaca, New York: CornelI University Press, 1945.

Loewy, Ernst. Literatur unterm Hakenkreuz: Das Dritte Reich und seine Dichtung: Eine Dokumentation. Frankfurt am Main und Hamburg: Fischer, 1969.

Loose, Gerhard. Ernst Junger: Gestalt und Werk. Frankfurt: vittorio Klostermann, 1957.

Loose, Gerhard. "Nationalismus und Weltstaat im Werke Ernst Jungers." Proceedings of the IVth Congress of the InterComparative Literature Association: Fribourg 1964. Ed. Francois Jost. The Hagues houton, 1966. I, 398-403.

Loose, Gerhard. "Die Rei setagebucher Ernst Jungers." Freundschaftliche Begegnungen: Festschrift fur Ernst Junger zum 60. Geburtstag. Ed. Armin Wohler. Frankfurt: vittorio 
Klostermann, 1955, S. 75-94.

Lowith, Karl. Von Hegel bis Nietzsche. Zurich، Europa-Verlag, 1941.

Mandel, Siegfreid. "The German Novel: In the Wake of organized Madness." Contemporary European Novelists. Ed. Siegfried Mandel. Carbondale and Edwardsville: Southern Illinois University Press, 1968, S. 69-125.

Marcel, Gabriel. "Ein Gerechter: Stuck in einem Akt." Wandlung und Wiederkehr: Festschrift zum 20. Geburtstag Ernst Jungers. Ed. Heinz Ludwig Arnold. Aachen: Georgi, n. d., S. $37-74$.

Martin, Alfred von. Der heroische Nihilismus und seine Uberwindung: Ernst Jungers Weg durch die Krise. Krefeld: Scherpe, 1948.

Martini, Fritz. Deutsche Iiteraturgeschichte: Von den Anfungen bis zur Gegenwart. 9. Aufl. Stuttgart: Kroner, 1958 .

Mendelsohn, Peter de. Der Geist in der Despotie: Versuche uber die moralischen Moglichkeiten des Intellektuellen in der totalitaren Gesellschaft. Berlin: Verlag Herbig, 1953 .

Mohler, Armin, ed. Freundschaftliche Begegnungen: Festschrift fur Ernst Junger zum 60. Geburtstag. Frankfurt: vittorio Klostermann, 1955.

Mohler, Armin. Die konservative Revolution in Deutschland 19181932: Grundri 3 ihrer Weltanschauungen. Stuttgart: Friedrich Vorwerk, 1950.

Mohler, Armin. Die Schleife: Dokumente zum Weg von Ernst Junger. Zurich, verlag die Arche, 1955.

Muller, Wulf Dieter. Ernst Junger: Ein Leben im Umbruch der Zeit. Berlin: Junker und Dunnhaupt, 1934 .

Muller-Schwefe, Hans-Rudolf. Ernst Junger. Wuppertal-Barmen: Emil Mttler Verlag, 1951.

Nebel, Gerhard. Ernst Junger: Abenteuer des Geistes. Wuppertal: Marees Verlag, 1949.

Nebel, Gerhard. Ernst Junger und das Schicksal des Menschen. Wuppertal, harees-Verlag, n. d.

Niekisch, Ernst. Die dritte imperiale Figur. Berlin: WiderstandsVerlag, $193 \overline{5}$ 
Paetel, Karl 0. Ernst Junger: Eine Bibliographie. Stuttgart: Lutz und Mejer, 1953.

Paetel, Karl 0. Ernst Junger: Die Wandlung eines deutschen Dichters und Patrioter. New York City: Verlag Friedrich Krause, 1946.

Paetel, Karl 0. Ernst Junger in Selbstzeugnissen und Bilddokumenten. Reinbek bei Hamburgi Rowohlt, 1962.

Peppard, Murray B. "Ernst Junger: Norse Myths and Nihilism." Monatshefte, 56, No. 1 (January 1954), 1-10.

Peters, H. F. "Ernst Junger's Concern with E. A. Poe." Comparative Literature, 10, No. 2 (1958), 144-49.

Pongs, Hermann. "Krieg als Volksschicksal im deutschen Schrifttum." Dichtung und Volkstum: Neue Folge des Euphorion: Zeitschrift fur Iiteraturgeschichte. Ed. Julius Fetersen und Hermann Pongs. Stuttgart: J. B. Hetzlersche Verlagsbuchhandlung, 1934. XXXV, 40-86, 182-219.

Rausch, Jurgen. Ernst Jungers Optik. Stuttgart: Deutsche Verlagsanstalt, 1951 .

Reimann, Hans. Literazzia: Ein Streifzug durchs Dickicht der Bucher. Wunchen: Verlag Pohl, 1952.

Rothe, Wolfgang. Schriftsteller und totalitare Welt. Bern und Munchen: Francke Verlag, 1966.

S. S. "In Praise of the War." Everyman, 30 May 1929, S. 12.

Salomon, Ernst von. Der Fragebogen. Hamburg: Rohwolt Verlag, 1951.

Samuel, Richard and R. Hinton Thomas. Expressionism in German Life, Literature and the Theatre 1910-1924. Cambridge: W. Heffer and Sons Ltd., 1939.

Schwarz, Hans-Peter. Der konservative Anarchist: Politik und Zeitkritik Ernst Jungers. Freiburg im Breisgau: Verlag Romback, 1962.

Shaw, Michael. "Ernst Jungers Vorstellung von einer Intelligenz der Materie." Zeitschrift fur deutsche Philologie, IXXXIII, 219-27.

Shirer, William L. Midcentury Journey: The Western World through its Years of Conflict. New York: Farrar, Straus and Young, n. $\mathrm{d}$. 
Sieburg, Friedrich. Unsere schonsten Jahre: Ein Leben mit Paris. Tubingen: Verlag Rainer Wunderlich, 1950.

Spender, Stephen. European Witness. London, Hamish Hamilton, 1946.

Stern, J. P. Ernst Junger. New Haven Yale University Press, 1953.

Stirk, S. D. The Prussian Spirit: A Survey of German Literature and Politics 1914-1940. London, Faber and Faber, 1941.

Waidson, H. M. The Modern German Novel: A mid-twentieth century. Survey. London, Oxford University Press, 1959.

Winkler, Eugen Gottlob. Gestalten und Probleme. Leipzig: Karl Rauch, 1937 .

Woodland, T. W. "Ernst Jungers War Diaries." German Life and Letters, 13 (1960), 298-302. 